DEPARTMENT.

of

COMMERCE

hompons?

MISCELLANEOUS

PUBLICATIONS

OF THE

NATIONAL

BUREAU

OF

STANDARDS

NOS. $212-219$ 







\title{
Report of the
}

\section{9th NATIONAL CONFERENGE ON}

WEIGHTS AND MEASURES 1954

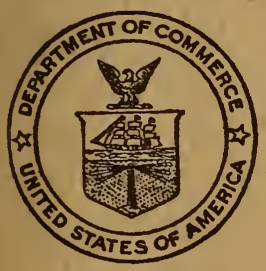

\author{
U. S. DEPARTMENT OF COMMERCE \\ NATIONAL BUREAU OF STANDARDS \\ Miscellaneous PUblication 212
}




\section{SELECTED WEIGHTS AND MEASURES PUBLICATIONS OF THE NATIONAL BUREAU OF STANDARDS}

NBS HANDBOOK 37 Testing of Weighing Equipment

NBS HANDBOOK 44 Specifications, Tolerances, and Regulations for Commercial Weighing and Measuring Devices

NBS HANDBOoK 45 Testing of Measuring Equipment

NBS Crrcolar. 501 Federal and State Weights and Measures Laws

NBS Circular 540 Weights and Measures Case Reference Book

AVAILABLE REPORTS OF THE NATIONAL CONFERENCE ON WEIGHTS AND MEASURES

$\begin{array}{lll}1946 & \text { Miscellaneods Publication } 186 & 40 \phi \\ 1947 & \text { Miscellaneods PUblication } 189 & 40 \phi \\ 1949 & \text { Miscellaneods PUblication } 195 & 35 \phi \\ 1950 & \text { Miscellaneous PUblication } 199 & 50 \phi \\ 1951 & \text { Miscellaneous PUblication 202 } & 50 \phi \\ 1952 & \text { Miscellaneods PUblication 206 } & 40 \phi \\ 1953 & \text { Miscellaneous Publication 209 } & 40 \phi\end{array}$

Index to the Reports of the National Conference on Weights and Measures from the First to the Thirty-sixth, 1905 to 1951, Miscellaneous Publication 203 $20 \varnothing$

ORDER ALL PUBLICATIONS, WITH REMITTANCE, FROM THE SUPERINTENDENT OF DOCUMENTS, GOVERNMENT PRINTING OFFICE, WASHINGTON 25, D. C. 


\section{Report of the}

\section{9th National Conference on}

\section{Weights and Measures 1954}

Attended by Representatives from Various States

Sponsored by the National Bureau of Standards

Washington, D. C., May 17, 18, 19, 20, 21, 1954

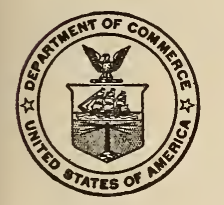

United States Department of Commerce - Sinclair Weeks, Secretary

National Bureau of Standards $\bullet$ A. V. Astin, Director

Issued October 21, 1954 



\section{CONTENTS}

Page

IV

VII

92

Committee Meetings

Persons Attending Conference

FIRST SESSION-MORNING OF TUESDAY, MAY 18, 1954

Invocation, by R. W. Searles, Deputy County Sealer, Medina, Ohio - . - Address by Hon. Walter Williams, Under Secretary of Commerce.

Address by A. V. Astin, Director, National Bureau of Standards, and President, National Conference on Weights and Measures........... Memorial Service for Departed Members, by R. W. Searles Appointment of Committees..... Roll Call of States

SECOND SESSION-AFTERNOON OF TUESDAY, MAY 18, 1954

Roll Call of State and Regional Weights and Measures Associations ...-.

Weights and Measures Advisory Committee, Report of the Special Committee of Vice Presidents of the Conference, Presented by J. A. Boyle, Chairman

Report from National Scale Men's Association, by C. C. Morgan, SecretaryTreasurer, and City Sealer of Weights and Measures, Gary, Indiana...

Looking Ahead in the Scale Industry, by G. C. Worthley, President, National Association of Scale Manufacturers, and Manager, Scale Division, Fairbanks, Morse \& Company, Chicago, Illinois.

State Cooperation in a National Program, by R. J. Neale, Weights and Measures Inspector, Agricultural Marketing Service, U. S. Department

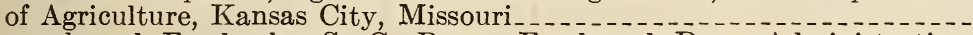

Prepackaged Foods, by S. C. Rowe, Food and Drug Administration, U. S. Department of Health, Education, and Welfare

Remarks of J. T. Kennedy, Chief, Weights, Measures, and Markets, District of Columbia

Check-Weighing Scales, by C. A. Baker, Director, Bureau of Weights and Measures, State of New York

Canned Poultry, by I. M. Levy, City Sealer of Weights and Measures, Chicago, Illinois

THIRD SESSION-MORNING OF WEDNESDAY, MAY 19, 1954

Evolution of Gasoline Pumps, by William Keay, Manager, Sales Service, Gilbert \& Barker Manufacturing Company, West Springfield, Massachusetts.

Report of Committee on Weights and Measures Education, Presented by C. M. Fuller, Chairman _...

Services of the National Bureau of Standards, by A. T. McPherson, Associate Director

Electromagnetic Flowmeter, by C. P. Griffith, Vice President, Bowser, Inc., Fort Wayne, Indiana

Surface Gaging Farm Milk Tanks, by W. M. Shanhouse, General Manager,

S. S. Hunter, Inc., Syosset, New York
Farm Milk Tank Testing, by F. M. Greene, Chief, Division of Weights and Measures, State of Connecticut_...

FOURTH SESSION-MORNING OF THURSDAY, MAY 20, 1954

Report of Committee on Legislation, Presented by M. A. Nelson, Chair-

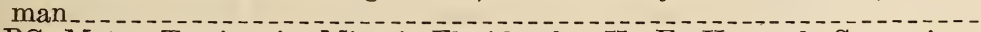

LPG Meter Testing in Miami, Florida, by H. E. Howard, Supervisor, Division of Weights and Measures, Miami, Florida...... 
Report of Committee on Trading by Weight, Presented by J. F. True, Chairman $\ldots$ H. R. 8357-To Amend U. S. Standard Container Act of 1928

Progress Report on LPG Meter Testing, by L. L. Kennedy, Chairman, Weights and Measures Committee, American Petroleum Institute, Elizabeth, New Jersey

Special Test for Vehicle Tank Meters, by J. A. Parron, Assistant Sealer of Weights and Measures, Norfolk, Virginia._. Report of Special Flour Committee, Presented by J. P. McBride, Chairman.

Remarks of C. D. Baucom, North Carolina....

FIFTH SESSION-AFTERNOON OF THURSDAY, MAY 20, 1954

H. R. 8357-To Amend U. S. Standard Container Act of 1928

Report of Committee on Nominations, Presented by J. T. Kennedy, Chair-

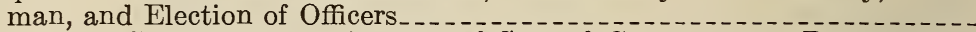

Report of Committee on Methods of Sale of Commodities, Presented by Acting Chairman, J. E. Brenton, at the request of J. G. Rogers, Chairman

Fabric-Measuring Devices, by F. M. Raymund, Assistant County Sealer of Weights and Measures, Los Angeles, California Weights and Measures Approval Seals, by M. W. Jensen, Assistant Chief, Office of Weights and Measures, National Bureau of Standards_......-

Remarks of M. Jacob, Director, Service De La Metrologie, Ministere Des Affaires Economiques, Bruxelles, Belgium _..........

Remarks of H. E. Howard, City of Miami, Florida

Remarks of David Heller, National Association of Scale Manufacturers.--

SIXTH SESSION-MORNING OF FRIDAY, MAY 21, 1954

Report of the Outgoing Executive Committee, Presented by G. F. Austin, Axle Loads, by D. R. Tate, Chief, Mass and Scale Section, Mechanics Division, National Bureau of Standards
Report of Committee on Specifications and Tolerances, Presented by R. E. Meek, Chairman.

H. R. 8357-To Amend U. S. Standard Container Act of 1928

Report of Committee on Resolutions, Presented by W. A. Kerlin, Chairman

Report of the Treasurer of the Conference, J. P. McBride...

Meeting of the Executive Committee...

\section{OFFICERS AND COMMITTEES}

\section{OFFICERS}

(As elected by the Thirty-eighth National Conference to serve during the Thirty-ninth National Conference)

President: A. V. Astin, Director, National Bureau of Standards.

Vice Presidents :

G. F. AUstin, Jr., Deputy Sealer of Weights and Measures, Detroit, Michigan.

J. A. Borle, Deputy Sealer, Bureau of Weights and Measures, Department of Agriculture, State of Maine.

F. M. Greene, Chief, Division of Weights and Measures, Food and Drug Commission, State of Connecticut.

J. Rox Jones, Commissioner, Department of Agriculture, State of South Carolina.

J. W. REESE, * Supervisor, Division of Weights and Measures, Department of Agriculture, State of Iowa.

A. C. SAMENFInK, Sealer of Weights and Measures, Rochester, New York. Secretary: W. S. Busser, Chief, Office of Weights and Measures, National Bureau of Standards.

Treasurer: J. P. McBridE, Director of Standards, State of Massachusetts.

*Mr. Reese was unable to be present. 
(As elected by the Thirty-ninth National Conference for the ensuing year)

President: A. V. Astin, Director, National Bureau of Standards.

Vice Presidents:

W. L. DANIELS, Director of Licenses and Standards, Seattle, Washington.

G. L. JoHnson, Director, Division of Weights and Measures, Department of Agriculture, State of Kentucky.

J. Roy Jones, Commissioner, Department of Agriculture, State of South Carolina.

C. A. LYoN, Director, Division of Markets and Standards, Department of Agriculture, State of New Hampshire.

A. O. OsLund, Superintendent, Department of Weights and Measures, Union City, New Jersey.

J. W. REESE, Supervisor, Division of Weights and Measures, Department of Agriculture, State of Iowa.

Secretary: W. S. BusseY, Chief, Office of Weights and Measures, National Bureau of Standards.

Treasurer: G. F. AUSTiN, JR., Deputy Sealer of Weights and Measures, Detroit, Michigan.

Chaplain: R. W. SEarles, Deputy Sealer of Weights and Measures, Medina County, Ohio.

\section{EXECUTIVE COMMITTEE}

(As elected by the Thirty-ninth National Conference)
A. V. Astin
W. L. DANIELS
G. L. JoHNSON
J. ROY JONES
C. A. LYON
A. O. Oslund $\}$ Ex officio.
J. W. REESE
W. S. BUSSEY
G. F. AUstin, Jr.
R. W. Searles
C. D. BAUCOM, of North Carolina.
T. C. BECK, of Oklahoma.
J. M. DiETz, of Union County, New Jersey.
M. M. EMERICK, of Illinois.
E. R. Fisher, of Rhode Island.
J. T. HARPER, of Terre Haute, Indiana.
H. C. HulshofF, of Niagara County, New York.
ELVIN LeEMAN, of Wyoming.
W. F. Masinda, of Tolland County, Connecticut.
A. J. MAYER, of Louisiana.
C. C. MUNDY, of Richmond, Virginia.
M. O. NICKoN, of Dearborn, Michigan.
W. E. G. RHerN, of Cincinnati, Ohio.
W. B. STEELE, of Oregon.
A. M. Thomas, of Montgomery County, Maryland.

\section{STANDING COMMITTEES}

(As constituted at the conclusion of the Thirty-ninth National Conference, the personnel and organization of each of the standing committees of the Conference are as listed. As reported, the membership of each committee reflects the appointments made by the President of the Conference, changes that have occurred from expiration of term or other cause, and the elections by the several committees of chairmen, and in one case secretary, for the ensuing year. The remaining term of office for each committee member, in years, is shown by the figure in parentheses following each entry.)

\section{COMMITTEE ON SPECIFICATIONS AND TOLERANCES}

R. E. MEEK, of Indiana, Chairman. (3)

W. S. BusSEY, National Bureau of Standards, Secretary.

RoBERT Williams, of Nassau County, New York. (2)

R. D. Thompson, of Virginia.

J. E. BRENToN, of California. 
COMMITTEE ON METHODS OF SALE OF COMMODITIES

J. G. RogERs, of New Jersey, Chairman.

R. J. ZIERTEN, of Racine, Wisconsin. (2)

G. H. Leithauser, of Baltimore, Md. (3)

E. C. Westwood, of Salt Lake City, Utah.

F. M. Greene, of Connecticut. (5)

\section{COMMITTEE ON LEGISLATION}

M. A. Nelson, of Michigan, Chairman.

D. M. Turnbule, of Seattle, Washington. (1)

R. M. BodenweIser, of Mercer County, New Jersey.

Nalls Berryman, of Florida.

J. A. Boyle, of Maine.

\section{COMMITTEE ON WEIGHTS AND MEASURES EDUCATION}

C. M. Fuller, of Los Angeles County, California, Chairman.

H. E. CrawFord, of Jacksonville, Florida.

J. F. Blickley, of Pennsylvania.

C. A. LYoN, of New Hampshire.

J. E. MAHONEY, of Maryland.

\section{COMMITTEE ON TRADING BY WEIGHT}

G. L. Johnson, of Kentucky, Chairman.

J. W. REESE, of Iowa. (2)

A. J. MAYER, of Louisiana.

T. C. BECK, of Oklahoma.

H. N. DuFF, of Colorado.

\section{SPECIAL COMMITTEE}

COMMITTEE ON FLOUR WEIGHTS 1

J. P. McBride, of Massachusetts, Chairman.

M. A. Nelson, of Michigan.

V. D. CAMPBELL, of Ohio.

O. W. Galloway, Pillsbury Mills, Inc., Minneapolis, Minnesota.

O. A. Oudal, General Mills, Inc., Minneapolis, Minnesota.

R. V. Harris, Harris Milling Company, Owosso, Michigan.

W. S. Bussey, National Bureau of Standards, Consultant to the Committee.

S. C. Rowe, Food and Drug Administration, Consultant to the Committee.

\section{COMMITTEES ACTING ONLY DURING THE THIRTY-NINTH NATIONAL CONFERENCE}

Committee on Nominations: J. T. KenNedy of the District of Columbia, Chairman; J. A. Bernard of Saint Louis, Missouri, V. D. Campbell of Ohio, H. E. Crawford of Jacksonville, Florida, J. T. Leonard of Paterson, New Jersey, I. M. LEVY of Chicago, Illinois, J. F. TRUE of Kansas.

Committee on Resolutions: W. A. KerLin of Alameda County, California, Chairman; W. A. Baerwolf of Pontiac, Michigan, L. C. Carpenter of Missouri, H. C. Hulshoff of Niagara County, New York, William Waterman of Wisconsin, F. E. McKinney of Hartford County, Connecticut, P. E. Nrstrom of Maryland.

Ladies' Committee: Mrs. C. M. Fuller and Mrs. R. D. Thompson, Co-Chairmen ; Mrs. J. M. Dietz, Mrs. R. E. Meek, Mrs. W. S. Bussex, Mrs. M. W. Jensen.

\section{IN CHARGE OF REGISTRATIONS}

Mrs. R. E. Taylor, Mrs. F. C. Bell, Mrs. K. M. Schwarz

\section{OFFICIAL REPOR'TER}

Mrs. F. T. Achenbach.

1 This Committee was appointed by the Conference President following the adjournment of the 38th National Conference, as a result of the adoption of a motion to this effect, reported on pages 39 and 40 of the 38 th Conference Report. 
By action of the Executive Committee, in session following the 38th National Conference on Weights and Measures, the Monday preceding the first formal session was designated an official day of the 39th and future National Conferences. That day, according to Executive Committee recommendation, was set aside for meetings, both open and executive, of the Conference committees. Announcements to this effect were carried in all invitations, all pre-Conference publicity, and in the tentative and printed programs.

Many delegates took full advantage of the committee meetings, which were well attended and informative to all.

The Conference committees that met on Monday, May 17, included the Executive Committee, Committee on Legislation, Committee on Methods of Sale of Commodities, Committee on Specifications and Tolerances, Committee on Trading by Weight, Committee on Weights and Measures Education, and Special Flour Committee. 



\section{REPORT OF THE THIRTY-NINTH NATIONAL CONFERENCE ON WEIGHTS AND MEASURES}

\section{First Session-Morning of Tuesday, May 18, 1954}

(A. V. Astin, President, and A. C. Samenfink, Vice President, Presiding)

The invocation was delivered by the Conference Chaplain, R. W. Searles, Deputy County Sealer of Weights and Measures, Medina County, Ohio.

\section{ADDRESS BY HON. WALTER WILLIAMS, UNDER SECRETARY OF COMMERCE}

It is my very great pleasure to extend to you on behalf of the Department of Commerce a welcome to Washington for your 39th National Conference on Weights and Measures. Since a primary purpose of the Department is to foster, promote and develop the commerce of the United States, we are naturally very much interested in the work and objectives of the Conference.

All commerce involves the interchange of goods or services, and before such interchange can be effected, there must be agreement between the buyer and the seller as to how much of a particular item is to be sold or purchased and how much is to be paid for it. The determination of this "how much" usually involves weighing or measuring. It is essential that, if commerce is to progress in an orderly manner, there must be complete understanding as to the methods and techniques of measurement and this in turn promotes good will, confidence and fair play. Thus the activities which are of concern to your Conference provide an essential foundation for the sound development of commerce.

Our Nation's industry and commerce have grown tremendously in recent years and, at the same time, have become increasingly complex. This makes it ineffective to employ arbitrary or isolated individual methods in the development of acceptable standard weighing and measuring procedures. The alternative is to attempt to solve these problems by group effort bringing together many different people trom all parts of our Nation with a wide variety of interests and skills.

Your own Conference has been particularly successful in achieving unity of action leading to the establishment of standards and methods related to the technical problems of commercial transactions. I am pleased to report that the Department of Commerce is applying variations of this procedure on a much wider basis. The recently established office of Business and Defense Services Administration provides a mechanism for bringing together government officials and representatives of private business interests to accomplish through unified group action procedures which will stimulate business and commerce 
and lead to the continual improvement of the economic foundations of our nation.

Furthermore, your Conference has set a fine example in another area involving division of responsibility between the Federal Government and State and local governments. This is a problem to which your present administration has given very serious attention, and it is our policy that the State governments should assume maximum possible responsibilities consistent with a sound national program, and that the Federal Government should provide, primarily, guidance and assistance.

As you know, the Constitution of the United States gives the Congress authority to fix the standards for weights and measures. The Federal Government, however, does not exercise authority to enforce weights and measures provisions but properly leaves this responsibility to the States. The Federal Government does, however, provide leadership in establishing the reference standards for weights and measures and in the development of the reliable and uniform procedures for the day-to-day measuring problems in ordinary commercial transactions. The development of such standardized procedures on a broad and effective basis is made possible primarily through the activities of your Conference. That this approach has been successful is evidenced by the ease and orderliness with which the wide-flung commerce of this nation is carried out.

The American people today enjoy a standard of living far beyond that of any other nation in the world. To an appreciable extent this is due to our orderly system for weighing and measuring the articles of commerce. But it is also due to our well developed ability to exploit the products of science and technology for the good of all the people.

The stability of our economic system, its ability to flourish and grow, and also our ability to remain strong against potential aggressors in this era of international stress depend increasingly upon the new products of science and technology. Our President has recognized this and, in a recent statement, he said: "Science has a vital role in our nation's security and growth. During the past half-century, it has brought about a vast transformation in industry, in agriculture, in medicine, in transportation, and in communications. Military science has been revclutionized by technological development. The impact of science is increasingly felt in every field of public policy including foreign affairs. All this has been brought about through a combination of vision, initiative, business enterprise, a strong educational system, and the dedicated enthusiasm of the scientific community." A little later in the same talk, the President also said: "I believe strongly that this nation must extend its support of research in basic sciences."

Closely related to these statements is the administration's interest in increasing the support to the National Bureau of Standards. The work of this organization is becoming increasingly important as our economy becomes more technological in nature. New products and new processes always involve new measuring and standardization problems as people in your business well know. Furthermore, the work of the Bureau in determining fundamental properties of materials provides important design information which private industry finds most useful in the development of new products and techniques.

We are very proud of our technological achievements in this country and of the support we have been providing to basic science. But 
we cannot be complacent in believing that what we have done is enough. There are groups in the world today who would seek to destroy our economy and prosperity and even our nation. Our ability to resist this threat rests primarily upon our ability to maintain technological supremacy and a sound industrial economy. At the same time, our potential enemy seeks to destroy us by outmatching our technology.

Let us examine how this race is coming on. Your Government is attempting to provide support for a variety of scientific and engineering activities. But in order to carry out these activities, we must have increased numbers of trained men to do the work. This country has, for a long time, faced a serious shortage of scientists and engineers, but over the last several years our colleges have been turning out decreasing numbers of these engineers, dropping from a high of about 52,000 in 1950 to a low of about 19,000 this year. During the same period Russia has been turning out an increasing number of new engineers each year and this year it is estimated that their new crop of engineers will be more than twice as large as ours. This is a very serious situation and one which, if not rectified, could place us in a very disadvantageous position within a few short years.

I do not know what the best remedy is for this situation but most certainly, if it is to be rectified, there must be an increased awareness on the part of the people of this nation of our great dependence on science and technology and a conviction that if we are to remain free, prosperous and strong, our economy will require increasing numbers of new scientists and engineers. Your Conference is as aware as any group in this nation of our dependence on technology. Therefore, you are in an excellent position to convince your friends and neighbors of this dependence. I hope that with increased awareness of this problem on the part of all the people in the country we will be able to evolve some procedure for the continued growth of our scientific and technological competence.

\section{PRESIDENT'S ADDRESS}

\section{By A. V. Astin, Director, National Bureau of Standards}

It is my preference on this occasion, in reporting to you as President of this Conference, to tell you something about the status of the National Bureau of Standards. As a public technological institution, this is your organization and this is the appropriate time to tell you something about its status.

The members of this Conference are, I believe, particularly interested in the National Bureau of Standards, since your group is one by which the results of our basic work on standards gets translated into efforts which influence all the citizens of the nation on a day-to-day basis.

In this connection I would like to read for you a short quotation from a recent article about the Bureau which appeared in the April issue of Nation's Business, a U. S. Chamber of Commerce Publication. It states: "Although the Bureau issues no regulations or orders, it probably exercises more direct influence on the daily life of every citizen than any Government agency, including the Tax Collector. This is partly because the Bureau, for a modest fee, makes tests on the 
instruments by which all measuring devices from carpenters' rules to Geiger counters are calibrated." This, in turn, relates directly to the activities of the members of this Conference in your work of transferring these measurements to the daily commercial transactions throughout the nation.

The work of the Bureau in which members of the Conference are most interested is a continuation of an activity dating back many years before the National Bureau of Standards was organized. The Bureau was established in 1901 when the name of the old Office of Weights and Measures was changed to National Bureau of Standards and the functions greatly enlarged. The Office of Standard Weights and Measures operated in the Treasury Department for about forty years, although work of this character had been carried on in the Treasury Department for approximately a decade before that period. Organized Federal work in weights and measures has thus been carried on in the United States for well over a hundred years. This is the activity of the Bureau that is of greatest concern to the members of this Conference.

Among the activities that have taken place in or about the Bureau during the past year, probably the single most important event was the work and report of the committee known as the Kelly Committee. This group was established by the Secretary of Commerce a little over a year ago to evaluate the functions and operations of the Bureau in relation to present national needs. For constituting the membership of this committee, the Secretary called for nominees from the leading scientific and technological organizations in the country, namely, the professional societies of science and engineering. The National Academy of Sciences nominated the Chairman, Dr. Mervin J. Kelly, who is also president of the Bell Telephone Laboratory. There were also on the committee representatives of the physicists, chemists, and mathematicians, as well as various engineering groups such as electrical, radio, civil, mechanical, mining, and metallurgical. This committee spent a number of months studying various operations at the Bureau and rendered the report to the Secretary last October.

I would like to read to you some of the comments from this report, because we consider the survey a very thorough one, and the results of this survey, I think, are of importance to all of us, to all members of the Conference, to the National Bureau of Standards, and to the country as a whole.

One of the basic conclusions setting the framework for the general importance of the Bureau-and in this framework the Committee made most of its investigations-is as follows :

The functions authorized for the Bureau of Standards are of great importance to national welfare. As our society becomes increasingly industrialized, these functions assume even greater importance and the work of the Bureau in meeting the obligations of its assigned functions becomes more highly scientific, broader in scope and more complex in organization.

In a society whose welfare is so dependent on applied science and technology as is our own, it is most important that the Government carry out those functions in support of science and technology that are uniquely in its province in the most effective manner possible and that a sufficiently high level of effort be maintained to insure an adequate coverage of the area of responsibility. It has placed broad and important functions in this area with the Bureau. 
The general findings of the committee were summarized under ten headings. I would like to read all ten of these, because I think each is important :

1. The Bureau of Standards is of vital importance to national strength.

2. It is an organization with a splendid record and tradition, internationally recognized and respected.

3. It is, in general, staffed with professional men of competence, integrity and loyalty to the Bureau's functions and objectives.

4. With the increasing range and depth of technology, the need for the services of the Bureau of Standards becomes even more important and its functions more complex. The accurate determination of physical constants, the properties of materials, standards and standards practices and testing and evaluation procedures are all essential services for our industrial society.

5. Since the close of the war the technology of the nation has shot rapidy forward. The Bureau's basic programs expanded until 1950 but at a rate beneath that justified by the needs. Since 1950 the decrease in basic programs must be considered as tragic. The ground lost since 1950 should be regained in the next two fiscal years and the programs then expanded as detailed studies by the Director and his advisory committees find necessary.

6. Scientific and technical services to other agencies of Government are important responsibilities of the Bureau. In general, the Bureau has discharged these responsibilities well.

7. The Department of Defense and the Atomic Energy Commission have made broad and significant use of the Bureau. Their use of the Bureau in areas other than development of weapons is of value to the Bureau in its basic programs and should be encouraged.

8. The volume of weaponry development work has become large in comparison with all other activities of the Bureau. Its relative size and its effects on the other Bureau programs make its transfer from the Bureau desirable.

9. Other agencies of Government do not make as large use of the services of the Bureau as might well be expected. The Committee believes that an increase in the use of the Bureau by other agencies of Government should be encouraged.

10. If the recommendations of the Committee are followed, the Bureau should be in a position to perform its authorized functions in balance at the minimum level for the nation's needs within a four-year period.

It is our major concern now to attempt to implement these recommendations, and, in carrying these out, we have had the wholehearted support of the office of the Secretary of Commerce.

Probably one of the most important of the recommendations is the one for increased appropriations to the Bureau. Toward this end we have had the strong endorsement of the Administration to provide for our program increased fiscal support. This matter is now under consideration by the Congress.

Another recommendation in the Kelly Report was that we transfer from the Bureau the major weapons programs which had been started during the last war and which were continuing up until this past year. With the increasing dependence of our defense program on weapon technology, these programs had expanded rather appreciably and we had reached the stage last summer where over half of the Bureau's program, expressed dollarwise, was in this field of weapons work. This was considered undesirable by the Kelly Committee, also by the secretary of Commerce and the Secretary of Defense.

Therefore, these activities were transferred to the Department of Defense and two new laboratories were established to handle these activities. One now is known as the Diamond Ordnance Fuse Laboratory, which occupies part of our grounds here in Washington. The second involved the transfer of a new laboratory which had just been 
activated in Corona, California. This is now known as the Naval Ordnance Laboratory, Corona. Thus this recommendation on the transfer of these laboratories to the Department has been implemented and two strong new laboratories have been set up within the framework of the Defense Department.

A third Kelly Report recommendation is being implemented in the setting up of a series of Advisory Committees. We consider the National Bureau of Standards as a service organization to the nation's scientists, engineers, and technologists. If our program is to be efficient and alive, it is important that it should be adapted to meet the needs of these individuals. In order to assist us in doing this, the Kelly Report recommended a number of Advisory Committees consisting of people named by the nation's scientific organizations. There are nine scientific societies and organizations represented on the committees, and in addition we are setting up two to cover activities in the field of testing and specifications. One of the new Advisory Committees will include representatives from the American Society for Testing Materials and the American Standards Association, and the other will include representatives from the nation's weights and measures officials.

Requests from a number of local and regional weights and measures organizations were made to the Secretary of Commerce following the issuance of the Kelly Report asking that their groups have representation on the Bureau's Advisory Committees. We considered that this Conference provided a useful framework or mechanism around which such Advisory Committees could be established. However, it is important in all of these Advisory Committees that the members on them be named by the groups outside of government and not by the Department of Commerce or by the National Bureau of Standards. In order to accomplish this, I requested the six vice presidents of this organization to meet and develop a set of recommendations for forming such a committee in order that this requirement be met. The vice presidents met two days ago, and their report as to how the Weights and Measures Advisory Committee is to be nominated will be given later during this Conference.

Another recommendation of the report involved increasing the strength of the Bureau at the Associate Director level. Some of the recommendations had to do with internal organization; another suggested a new staff member. The latter recommendation has been complied with, and I am happy to report that during the past year Dr. Robert D. Huntoon, formerly of the Corona Laboratory, has joined the staff as Associate Director for Physics.

The Kelly Report also mentioned specifically the Bureau's Office of Weights and Measures. Since this reference is of direct interest to the members of this Conference, I would like to read to you, as the last item on my summary of the Kelly Report, the recommendations concerning our Office of Weights and Measures:

A. This Office carries out that section of the Organic Act at NBS which provides for "cooperation with the States in securing uniformity in weights and measures laws and methods of inspection."

B. The work is well conceived and the staff is competent.

C. The Office enjoys the support of State and local officials and allied business and industry throughout the United States. 
D. There is a continuing and growing demand for the kinds of assistance which this office is uniquely qualified to furnish.

E. Compliance with this legitimate demand will require increased appropriations.

I would next like to take a few minutes to discuss a few of the technological achievements at the Bureau. Since it is by no means possible to enumerate all or even very many of them, what I plan to discuss will be suggestive rather than inclusive.

One of the achievements involved a project carried out for the Navy's Bureau of Aeronautics and concerned the development of a method of mechanizing the production of electronic equipment. Electronic devices permeate our lives in many ways. They are important in our defense program in aircraft, in fire control, in guided missiles, in proximity fuses, and in virtually all military communications. In our domestic economy electric devices are at the heart of our communications system and at the heart of our entertainment industry-radio, television, and motion pictures. Electronic devices are making possible better and more efficient methods of producing a variety of goods. Thus we see that electronic devices are extremely important, kut curiously enough they have been built by rather old-fashioned hand methods. If we are to increase our potential for building electronic devices quickly, cheaply, and in large quantities, it is essential that we have some method for mechanizing this production.

In studying this problem, our people concluded that if there was to be progress in this field we would have to revolutionize our concept of how electronic devices should be put together. This was accomplished, we believe, in the invention of a modular system of building electronic equipment whereby the basic building block is a small ceramic wafer. This wafer is made integral with many of the conventional electronic components such as resistors, capacitors, and wiring elements. Next, the standard building block can be adapted for machine handling assembly. Following this approach, we put together an operating production line that has successfully built some military devices automatically by machine methods. It is our belief that this product will lead to substantial savings in the cost of building electronic devices, but even more important is the possibility that these devices can be developed more quickly and reliably. This is important to a nation that has to be geared for ready mobilization.

Another area at the Bureau where we have made rather significant achievements is in the field of low temperature investigations. Here we have set up equipment by which the temperature scale, for which we have primary responsibility, can be determined to a few thousandths of a degree of absolute zero, and in this range below one degree from absolute zero many very interesting phenomena take place. Matter behaves in an entirely different way than it does at ordinary temperatures, and from these unusual behavior characteristics we can learn much new information about the fundamental structure of matter. Already we have made a number of important discuveries. One of these involves the alignment of atomic nuclei for the first time in this country. This makes possible a very powerful tool for studying the fundamental characteristics of nuclei. In turn, better techniques for studying atomic nuclei are important to an increased understanding of the problem of atomic and nuclear energy. 
In the standards field we have made a number of contributions during the past year. We were fortunate in getting funds to build a new radioactivity laboratory. It is essential that in the handling of radioactive devices we have facilities where these operations can be carried out without danger of contaminating other laboratory areas, and for this purpose we obtained an isolated and efficiently planned building. This was put into operation during the past year.

Also we have made progress on an international basis in getting agreement on standard measurement techniques for a variety of the radioactive isotopes which are becoming available from atomic piles.

Further, in the standards field you will probably be interested to know that we have made two important recommendations to the International Committee of Weights and Measures which is meeting this coming fall in Paris with the general Conference of Weights and Measures. The latter is an organization, a conference, that meets once every six years to consider international measurement standards problems. One of the proposals concerns a new definition of our standard of length. I think I have referred to this in previous years. To the international group we are proposing that the international meter, represented as the distance between two lines on a meter bar, be replaced by a wavelength standard where the length of light wave that is emitted by some atom such as an isotope of mercury would provide the reference standard for length measurements.

Another proposal to the International Committee concerns the redefinition of one of our temperature scales. Currently the scale is defined in terms of the interval between the ice point and the steam point. It is our proposal to take the ice point as the basic reference and then assign an arbitrary number to that point and abandon the steam point. The reasons for this are quite technological, but the present technique leads to a number of difficulties, particularly in investigating phenomena in the very low temperature regions.

Our radio propagation laboratory at Boulder, Colorado, is now being activated. This is a new building, efficiently equipped to carry out radio research and development programs. The building was finished about a month ago and we are in the process of moving into it. We hope to have a formal dedication service for this new laboratory sometime near the end of summer.

Leaving the technical field, I would like to make a few brief references to the staff. First, the Bureau was honored in having two of its members elected to the National Academy of Sciences last month. These are Dr. Wallace R. Brode, Associate Director for Chemistry, and Dr. William Meggers, our spectroscopy expert, and the man who has pioneered in developing this new wavelength standard for length measurement.

Another item of personal interest concerns your former president and Director of the Bureau, the present Director Emeritus, Dr. Lyman J. Briggs. Dr. Briggs celebrated his eightieth birthday about two weeks ago, and many of his friends gathered to pay their respects. The American Association for the Advancement of Science devoted its May issue of the Scientific Monthly to papers by associates and colleagues of Dr. Briggs.

I would like next to turn more directly to the activities of interest to this group, namely our Office of Weights and Measures and some 
related calibration work. We established a new section in the Bureau during the past year, called the Mass and Scale Section. This was done in order to strengthen our work in mass measurements and scale development and related calibrations. Mr. Douglas R. Tate was named Chief of this new Section, in which are included Mr. Macurdy's work on mass measurements and Mr. Russell's work on scales. These are two activities which are familiar, I am sure, to members of this Confererice.

We have continued in the preparation of specifications and tolerances for standards of mass. It is probable that these will be available for distribution in a tentative form before we meet next year. We anticipate a revised specification to make possible the use of numerous materials such as stainless steel in our reference standards. This will be a step forward in our constant efforts to establish completely realistic yet adequate procedures for mass measurements. Mr. Russell's work on scale development has been pointed toward the development of a 1,000-lb. precision balance which is for two distinct purposes: It will fill the Bureau's need for an instrument of this type, and we plan also that it will provide the State officials with a model of precise equipment for their own work. We believe that the balance will be constructed and ready for the first test this summer. If our tests prove the balance to be adequate for your purposes, we will have detailed drawings and manufacturers' specifications made available to those who are interested.

Our investigation of methods of weighing axle loads of motor vehicles has been started. A preliminary experiment to determine the constancy of the axle weights of normal transport-type trucks was conducted this spring. One important result from our studies is the determination that the so-called weight of a single axle is an exceedingly variable quantity. Of course the total weight of the truck does remain constant, but it is very definite that the weights of individual axles of the truck can go through rather wide variations by minor load shifts. This provides an important limitation on any axle-weighing procedure. We hope that some of the problems can be solved and that during the coming year we will make further progress on this important problem.

The Bureau's program for calibration of railway track scales was carried out fairly successfully, although our funds for this work har to be reduced during the current year. Our scale testing unit No. 2 traveled down the Pacific Coast to Los Angeles, then across to Texas, where quite a number of scales were tested. The important southwest region is still without the master scale which would provide controls for the railroads serving this area. Our eastern States were restricted almost entirely to the use of scale test unit No. 1. We need to add another engineer to this program. Funds currently a vailable did not permit it. We hope, however, that we can get back to two full-time engineers on this railway track scale program during the coming year.

During the past year we have, as in the past, attempted to fulfill the many requests for assistance from weights and measures officials, industry, business, and others. We have provided participation in the State and regional meetings and schools of instruction, and have endeavored to handle as expeditiously as we can all requests received for counsel. 
We also have set up a service which we think will help the States keep their standards certifications up to date and have placed in effect a reminder system wherein the State officer is advised in advance of the time his statute requires the resubmission of the standards of mass, capacity, and length. This has resulted in a minor overloading of facilities in a few of our laboratories, but we believe maintenance of the legal validity of your reference standards is well worth special effort on our part.

We have initiated another project which was requested by this Conference in a resolution passed last year. This is the first of a series of training motion picture films on weights and measures subjects. We have started one on the mass weighing problem, and expect that the film will be ready for release sometime this year. As an aid in helping us to get this film ready, we have called back one of your alumni and your life member, Mr. Ralph W. Smith. His services on this project have been invaluable. We hope that this first film on mass weighing will be one of a series which should be of considerable assistance to weights and measures officials.

We are also hoping that we can add to Mr. Bussey's staff in the future so that we can do a more adequate job in providing assistance to the weights and measures administrative officials throughout the country.

Generally, it has been the pleasure of the President of this Conference to announce outstanding progress in the weights and measures work in the various States, and I am very pleased at this time to tell you that advancements during the past year have been so numerous that it would be impossible to list them at this time. Many localities have secured new equipment, especially for testing large-capacity scales, wholesale liquid-measuring devices, and vehicle tanks. I was privileged to witness the opening of a new facility in North Carolina this past spring, and I would consider that this is a very fine example to other States and a very important advance in the general weights and measures activity. In other instances, laws have been amended and approved and additions have been made to operating personnel. I would suggest that each of you read very carefully your copy of the State Reports and thus review the outstanding progress in the different areas of the country.

Although any progress is a rather indefinite thing and difficult to define, I am sure you will agree that we have been progressing in weights and measures supervision throughout the United States. Your attendance here today is very striking evidence of your interest in this important function of government. We realize that at best we can only offer to you from the National Bureau of Standards some assistance in the solution of your technical problems. We appreciate your willingness to accept our recommendations and we solicit from you continued inquiries and requests and suggestions for our program. Here, of course, we hope that the Advisory Committee which is to be set up following recommendations of your vice presidents will be very valuable toward achieving this objective.

The structure of the organization of this Conference is such that all of its activities and many of its most important functions must be carried out by the officers and committees assigned specific responsibilities. Thus, to a very large extent, the success of this Conference 
depends on just a few of its members. We are very fortunate in that the officers and committeemen have been diligent during the past year and have guided our progress. I am sure that the newly elected officers and newly appointed committee members will carry on in this traditional manner. They will continue to serve the Conference with unselfish diligence and distinction. This, I am sure, will insure the continued progress in this important field of gorernment service.

(R. W. Searles, Chaplain, conducted an appropriate memorial service for departed members. Mr. Searles made special mention of the passing of Mr. Charles C. Neale, who first attended the National Conference on Weights and Measures in the 5ear 1912 and who literally spent a lifetime in weights and measures work.)

Mr. Searles: Just before I left for the East, I received word of the death of a very dear friend-and a friend of all members of the National Conference. Charles C. Neale passed away at his home in Saratoga, California, Sunday, May 9. He had served in some capacity in the weights and measures field nearly all of his working life. As the first Commissioner of Weights and Measures for the State of Minnesota, he established the Department there on a firm foundation. After leaving State service, he was associated successively with several equipment manufacturers. He traveled widely in the course of his long and active career, and wherever he went he made friends-friends who learned to love him through the years.

\section{APPOINTMENT OF COMMITTEES}

The President made the following committee appointments :

COMMitTEES TO SERVE DURING THE 39TH NATIONAL CONFERENCE

Committee on Nominations: J. T. Kennedy, District of Columbia, Chairman; J. A. Bernard, St. Louis, Mo.; V. D. Campbell, Ohio; H. E. Crawford, Jacksonville, Fla.; J. T. Leonard, Paterson, N. J.; I. M. Levy, Chicago, Ill.; J. F. True, Kansas.

Committee on Resolutions: W. A. Kerlin, Alameda County, Calif., Chairman; W. A. Baerwolf, Pontiac, Mich.; L. C. Carpenter, Missouri; H. C. Hulshoff, Niagara County, N. Y.; F. E. MeKimney, Hartford County, Conn.; P. E. Nystrom, Maryland; William Waterman, Wisconsin.

\section{STANDING COMMITTEES}

Committee on Legislation: J. A. Boyle, Maine, 5-year term, to succeed V.D. Campbell, Ohio, whose term expired.

Committee on Methods of Sale of Commodities: R. J. Zierten, Racine Wis., 2-year term, to fill vacancy created by the resignation of J. E. Brenton; F. M. Greene, Connecticut, 5-year term, to succeed C. D. Baucom, North Carolina, whose term expired.

Committee on Specifications and Tolerances: J. E. Brenton, California, 5-year term, to succeed L. E. Witt, Milwaukee, Wis., whose term expired.

Committee on Trading by Weight: H. N. Duff, Colorado, 5-year term, to succeed J. F. True, Kansas, whase term expired.

Committee on Weights and Measures Education: J. E. Mahoney, Maryland, for a 5-year term, to succeed G. E. Carpenter, Vermont (retired), whose term expired. 


\title{
ROLL CALL OF STATES
}

The Secretary called the roll of States. Delegates from 39 States and the District of Columbia responded, as did official visitors from Belgium and Brazil and a manufacturer's representative from England. Delegates and their ladies were introduced individually.

(The Conference was recessed until 2 p.m.)

\section{Second Session-Afternoon of Tuesday, May 18, 1954}

\author{
(J. Roy Jones, Vice President, presiding)
}

\section{ROLL CALL OF STATE AND REGIONAL WEIGHTS AND MEASURES ASSOCIATIONS}

The Secretary called the role of State and Regional Associations of Weights and Measures Officials. Representatives of all 20 Associations on record responded.

(Written reports from many States and Associations were supplied the Secretary in advance of the Conference. These were duplicated and distributed at the Conference.)

\section{WEIGHTS AND MEASURES ADVISORY COMMITTEE}

\section{REPORT OF THE SPECIAL COMMITTEE OF VICE PRESIDENTS OF THE CONFERENCE, PRESENTED BY J. A. BOYLE, CHAIRMAN}

Under date of March 29, 1954, Dr. A. V. Astin, Director of the National Bureau of Standards and President of the National Conference on Weights and Measures wrote each of the current rice presidents of this Conference. His letter read, in part, as follows:

At the suggestion of several associations representing both weights and measures officials and manufacturers, the Secretary of Commerce has authorized the creation of a Weight and Measures Adrisory Committee to the National Bureau of Standards. This committee will serre in a capacity similar to those that are being nominated by major scientific and engineering societies of the United States. We refer you to page 18 of the enclosed Report to the Secretary of Commerce by the Ad Hoc Committee for the Evaluation of the Present Functions and Operations of the National Bureau of Standards.

The members of the adrisory committees are being nominated by the organizations represented and not by the National Bureau of Standards. Since the principal organization of weights and measures officials is the National Conference on Weights and Measures, it is thought that the Weights and Measures Advisory Committee should be nominated by and representative of the National Conference. In this particular case, we beliere that a Committee of the Vice Presidents of the National Conference offers the best means for nominating this Advisory Committee.

In order that you may proceed to function as a nominating committee, I, as President of the National Conference, designate Mr. James A. Boyle, of Maine, Chairman of the Committee of Vice Presidents.

I would suggest that Mr. Boyle call a meeting of the Vice Presidents prior to the 39th National Conference. ****

I would recommend that the Advisory Committee be composed of six members. In order that the members may regularly serve rotating terms of three years, the initial nominations should include two members each for one, two, and three years.

For your information, I will quote briefly from the report to the Secretary of Commerce, of the Committee for the Evaluation of the Present Functions and Operations of the National Bureau of Stand- 
ards. This is the so-called "Kelly Committee Report" that was referred to in Dr. Astin's letter :

In the formation of the programs of the basic area of the Bureau, balanced attentiou should be given to the new areas of science and technology where standards activities will be required. To aid the Director in forming the new programs and in the consideration of balance on programs in being, the Committee believes that a more intimate tie with the science and technology of the country is desirable. It therefore recommends that the Director of the Bureau *** form small advisory groups for the different scientific and technical areas of the Bureau.

The Special Committee of Vice Presidents met, as suggested, Sunday afternoon, May 16, to discharge its assignment. There were present, in addition to myself, Messrs. George F. Austin, Jr., Frank MI. Greene, J. Roy Jones, and Anthony C. Samenfink.

After discussion and deliberation the Committee agreed unanimously upon recommendations to be made to this National Conference, for its formal action, regarding nominations for appointment to the Weights and Measures Advisory Committee to the National Bureau of Standards. The Committee agreed further to recommend a procedure with respect to nominations for replacements on the Advisory Committee as terms expire, or as for any other reasons vacancies in the membership occur or are anticipated.

We first recommend that such nominations be proposed to the National Conference each year by the vice presidents then in office, sitting as a special committee for this purpose. Such future proposals should ordinarily be made for nominations for three-year terms. In some cases the nominations will necessarily be for shorter terms, to take care of replacements for members who have not served the full terms for which they were appointed.

The Committee appreciates the great importance to weights and measures administration throughout the United States, of the selection of a Weights and Measures Advisory Committee to the National Bureau of Standards. It is the opinion of the Committee that this entire program, as well as the nominations themselves, should be formally approved by the National Conference. Also, it seems to the Committee that the procedure should be established before nominations are made.

Accordingly the Committee has prepared two resolutions to place its recommendations before you. At this point I offer for your consideration the first of these resolutions and move its adoption:

Whereas, the Secretary of Commerce has authorized the creation of a Weights and Measures Adrisory Committee to the National Bureau of Standards, to serve for the purposes and in the manner set forth in the Report to the Secretary of Commerce by the Ad Hoc Committee for the Eraluation of the Present Functions and Operations of the National Bureau of Standards; and

Whereas, the Director of the National Bureau of Standards has requested that the National Conference on Weights and Measures nominate six persons, representatice of the National Conference, for appointment as members of such Weights and Measures Advisory Committee; and

Whereas, the Director of the National Bureau of Standards, as President of the National Conference on Weights and Measures, has designated the Vice Presidents of this National Conference, under the chairmanship of James A. Boyle, as a Committee to propose, for nomination br this National Conference, six persons for appointment as members of such Weights and Measures Adrisory Committee; Therefore be it

Resolved, That this the Thirty-Ninth National Conference on Weights and Measures does approre the arrangements made by its President, as recited 
above, and will receive from the special Committee of Vice Presidents its proposals for nominations for appointment, for specific terms, to the Weights and Measures Advisory Committee to the National Bureau of Standards; and be it further

Resolved, That proposals for nominations for replacement on the Weights and Measures Advisory Committee to the National Bureau of Standards shall be made annually to the National Conference on Weights and Measures by the vice presidents of the Conference then in office, sitting as a special committee for that purpose, under the chairmanship of a member selected by the committee, such proposals to include appropriate terms for each nominee according to the circumstances of the vacancies on the Advisory Committee either existing or anticipated; and be it further

Resolved, That it is the recommendation of this National Conference on Weights and Measures that the Advisory Committee should consist of six members; that the membership should be rotating on the normal basis of individual three-year terms with two replacements each year and that members should normally serve for three-year terms or until their replacements are appointed.

(The resolution was adopted by the Conference.)

Your Committee of Vice Presidents now proposes for your consideration its recommendations for nominees for membership on the Weights and Measures Advisory Committee. We propose the nomination of two weights and measures officials, one State and one local; two representatives of equipment manufacturers and two representatives from other groups among those affected by weights and measures supervision. The Committee feels that this distribution of membership is reasonable and proper, that it is representative of the National Conference, and that it may well form a pattern to be followed in the future.

You will understand that the National Conference does not elect or appoint the members of the Advisory Committee. Appointments to membership on the Advisory Committee are made by the Director of the National Bureau of Standards. The function of the National Conference in this relation is to nominate for membership on the Advisory Committee. The function of the Special Committee of Vice Presidents is to propose to the Conference the names of persons recommended by it for nomination.

Accordingly, your Committee now makes its proposal to you in the form of a resolution. I present this resolution and move its adoption:

Whereas, the special Committee of Vice Presidents of the National Conference on Weights and Measures has been authorized to propose the names of persons as nominees of the National Conference for appointment as members, for specified terms, of the Weights and Measures Advisory Committee to the National Bureau of Standards; and

Whereas, the said special committee now proposes for such nomination the following persons, to wit:

Mr. W. M. Harks, Vice President,

Bowser, Inc.,

33 North LaSalle Street,

Chicago, Illinois.

(1 year)

Mr. A. V. Hokanson, Vice President.

National Association of Retail Grocers,

200 Franklin Street,

Porter, Indiana.

(1 year)

Mr. C. M. Fuller,

County Sealer of Weights and Measures,

3200 North Main Street,

Los Angeles, California.

(2 years) 
Mr. Burns H. Dreese,

Vice President and General Manager,

The Hobart Manufacturing Company,

Troy, Ohio.

(2 years)

Mr. John P. McBride, Director of Standards,

Department of Labor and Industries,

194 State House,

Boston, Massachusetts.

(3 years)

Mr. Harry J. Kennedy,

Vice President of Marketing,

Continental Oil Company,

Sterling Building,

Houston, Texas.

(3 years)

Therefore, be it

Resolved, That this Thirty-Ninth National Conference on Weights and Measures does approve the proposals of its Committee of Vice Presidents and does nominate the persons named in this resolution for appointment to membership, for the terms stated, on the Weights and Measures Advisory Committee to the National Bureau of Standards.

(The resolution was adopted by the Conference.)

\section{REPORT FROM NATIONAL SCALE MEN'S ASSOCIATION}

By C. C. Morgan, Secretary-T'reasurer, and City Sealer of Weights and Measures, Gary, Indiana.

I am sure that this audience requires no special briefing on the importance of scales and the vital part they play in our daily economy.

The objectives of the National Scale Men's Association are:

A. To promote a better understanding of the scale industry by society in general.

B. To help create higher standards of commercial integrity and increase social understanding.

C. To cooperate with and aid weights and measures officials in obtaining laws and possible civil service status.

D. To promote a plan of education in the Association by exchanging ideas, keeping informed on new developments, encouraging a broader knowledge of the functions of all concerned in using scale equipment, and seeking ways and means of benefiting society by the promotion of more accurate weights.

E. To formulate recommendations covering specifications, tolerances, and regulations for submission to the National Conference on Weights and Measures.

Many of you here today are members of the National Scale Men's Association and are familiar with our progress during the past year; but for the benefit of those not so informed, I will report briefly on the activities of our Association during the past year.

We have increased our membership substantially, due mostly to the efforts of our past President, Mr. William Scheurer. We have organized three new divisions known as the Mississippi Valley Division, the Intermountain Division, and the Greater New York Division. We have reactivated one of the old divisions, making a total of ten active divisions. We have revived the use of the lapel button like the one I am wearing. We have sponsored the publication of an indexed set of technical papers entitled "Pivots and Bearings" which is available through the Association. 
The activities just mentioned will be continued by the present officers. We held our 35th Conference in Chicago last March at the Edgewater Beach Hotel and had a record registration from all over the United States and Canada. The presentation of outstanding papers and displays of various manufacturers' devices attracted much interest.

We also have revised the by-laws, to the end that more money will be diverted to the division, so that more activities can be sponsored locally, thus promoting more constructive meetings, collecting dues, issuing the membership cards, and several other changes for the advancement of N. S. M. A.

New York City has been selected as the Association's 1955 Conference City, and I hereby extend an invitation to everyone to attend.

I could enumerate additional activities, but this will serve to acquaint you with the fact that N. S. M. A. has made great progress under the leadership of recent officers. You may expect a continuation of this trend under the able leadership of our new President, Mr. Rollin E. Meek, whose qualifications are well known to members of this Conference and to weights and measures officials throughout the country.

Our monthly news bulletin will continue to appear in the Scale Journal. This is providing a convenient means for anyone interested in keeping informed on N. S. M. A. activities. I extend a cordial invitation to everyone interested in scales and accurate weight determinations to become affiliated with the N. S. M. A. and aid in the work we are doing.

We feel that the time has come when cooperation among the various agencies and associations directly concerned with weighing devices and weights and measures supervision could improve greatly their usefulness by a cooperative effort, and, to that end, I have been authorized by the President to pledge you our wholehearted support in any progressive ideas in weights and measures.

\section{LOOKING AHEAD IN THE SCALE INDUSTRY}

By G. C. Worthley, President, National Association of Scale Manufacturers, and Manager, Scale Division, Fairbanks, Morse \& Company, Chicago, Illinois.

I am not so presumptuous as to believe that I am able to foresee everything that may come about in the next several years, as the products of the scale industry are so diversified that it would require a prophet to do so. However, it is a matter of general knowledge that the scale industry is now in a period of transition. This has been brought about by the need for better material-handling methods; in fact, this need is the prime requisite of all producing and marketing organizations today.

It is also a matter of record that there are at least 107 manufacturers of weighing machines of all types. Scales may be placed in four categories: Retail, personal weighing, parcel post and mailing, and industrial scales. I have been associated only with the industrial class; therefore, my remarks will be confined to industrial scales and what is transpiring in that branch of the industry.

The trend in all industries is to automation in production. The required raw materials have always been and still are either in the ground 
or above the ground. So, basically, the cost of any product starts with capturing the raw material, plus the labor hours for processing it into the final product. The fewer labor hours expended, the lower the cost; consequently, industry is searching for ways and means to reduce labor hours. This has led to the development of more and more new machines and methods to speed material handling.

The industrial scale is most certainly an indispensable tool. It seems only a short time back that industry would generally accept the standard product of the manufacturer, but automation has changed this, and now industry demands that the manufacturer tailor the scale to meet special requirements. This is making it compulsory for the manufacturer either to modify his present product or to bring out new weighing machines.

To meet this condition, the industry must expend considerable sums of money for research, development, tooling, plant modernization, and training personnel to sell and service the special-application scales that will be required. I predict that the scale catalog of the future will be an encyclopedia of weighing methods.

The mechanical scale (lever principle) has proved itself over the years. It is still, and will be for years to come, the type most generally used, as no one questions its ability to weigh accurately and well within the commercial tolerances in National Bureau of Standards Handbook 44. However, the weighing requirements of industry became so complex that they could not always be accomplished with the mechanical scale. This led to the necessity of exploring other principles-hydraulics, pneumatics, and electronics. The requirements of World War II actually expanded the use of and the development of electronics for numerous applications, including the advent of the load cell electronic scale.

Scales using the hydraulic and pneumatic principles are available, but the apparent trend is to the electronic principle. Electronic scales have made it possible to accomplish weighing operations that heretofore were impossible. Time will not permit me to describe many of their unusual applications. This would be a subject in itself.

The electronic scale has had much publicity, and many claims have been made for its performance. Only the future will determine if its accuracy and durability will equal the mechanical scale. They both have their place in the weighing field; to determine which to offer to best meet the requirement, a full evaluation should be made of both from the standpoint of their cost, required accuracy, and necessary maintenance. I can make that statement with complete frankness, as iny company produces both mechanical and electronic scales.

Statements have been made that the electronic scale will provide for greater accuracy than is possible to obtain with a mechanical scale. I accept that statement with reservations. At least two manufacturers who produce only electronic scales informed me that such is not the case and that they would not make this claim for their product. The electronic scale in some ranges of capacities and minimum increments will meet the tolerances and requirements of Handbook 44, but in many other ranges of capacities and minimum increments, it will not.

It is the opinion of some in the industry that the tolerances and minimum graduations as now specified in $\mathrm{H} 44$ should be liberalized. 
It is my considered opinion that the present tolerances and minimum increments should continue to apply to any weighing device used in commerce, irrespective of its functional principle.

The National Conferences, sponsored by the National Bureau of Standards, have provided a common ground for weights and measures officials and manufacturers to interchange ideas. That is typically American, for groups of people with a common purpose to get together to work out their objectives. Your Committee on Specifications and Tolerances has been most cooperative. They have considered carefully suggestions of the manufacturers before recommending to the Conference changes or new regulations for adoption in Handbook 44 .

With your permission, I wish to lay before you two recommendations from the National Association of Scale Manufacturers for your consideration.

First, reconsideration of type approval by the twelve States and four cities which have these regulations. I do not know the origin of type approval. Possibly it was necessary in years back, but is it necessary today? Does it provide for better scales in those jurisdictions that have type approval than in the thirty-six States and hundreds of cities which do not require type approval? That is worthy of your consideration. It is a hardship and a costly procedure for the manufacturers to go through to obtain type approval, and this causes a reluctance on their part to improve their product.

To procure type approval, the manufacturer must submit his small scales to the department of weights and measures, and, for his large scales that cannot be set up in the department's laboratory, he must submit specifications and design details. It may be possible for the department's technician to determine from the specifications and design details of a mechanical scale if, in his opinion, it qualifies for type approval, but it will never be possible to follow this procedure for type approving electronic scales.

I understand that some jurisdictions have found it necessary to allow the manufacturer of the electronic scale to sell and install it and then the department examines and tests, and the results of their findings determine whether or not they will approve type. With more and more new types of electronic scales coming into use, this procedure will create an extra burden and expense on the department. This is something they should also consider. It is possible that some administrators of weights and measures have inherited type approval, but personally do not favor it. They carry it on because their State laws (not regulations) require it. Is it realistic for them to continue with type approval if they are not fully in accord with it? That is a fair question for them to consider.

No business is without change, and certainly weights and measures is a big business of enforcing laws against misrepresentation. All business should examine itself frequently to determine if it is in step with the changing trend of the times. Then should not the big business of weights and measures do the same to determine if type approval is still necessary for the enforcement of their laws? We think this is deserving of your consideration.

Our second request for your consideration is-Why the necessity of three different regulations to control scale service mechanics? 
We believe this was brought about by the fact that scale production in the last 15 years, measured dollarwise, has increased almost fivefold. To install and service this tremendous increase was a problem, especially during the war when manpower was scare. Manufacturers trained many men for this work, only to lose them to the services. The work potential was greater than the available facilities of the manufacturer.

This condition led to unqualified individuals, with little or no experience, starting to service and repair scales in the field and to charge exorbitant prices. When the scales were then tested by weights and measures officials, many were found inaccurate. The itinerant had left the job, his address was unknown, and he could not be found and compelled to re-do his work. This left the owner holding the bag.

It is quite understandable that weights and measures administrators decided to do something to correct this condition. Several States adopted different methods of controlling scale servicemen, either by bonding, by licensing, or by registration. It is unnecessary to explain in detail the three different methods of control, as they are known to weights and measures officials.

Only a small minority of States have adopted control regulations over servicemen. To the other States who may decide in the future that some method of control is necessary in their jurisdictions, the National Association of Scale Manufacturers recommends the registration plan. The manufacturers operate on a nation-wide level; consequently, we have servicemen operating under the three different plans. It is our experience that the registration plan is the most practical and accomplishes the objective. We also suggest that those States who in the future may consider it necessary to place servicemen under control, carefully evaluate the three different methods. If they will, then their findings should result in favor of the registration plan.

In conclusion, I want to thank this Conference for the opportunity of submitting the scale manufacturers' suggestions. We believe they are worthy of your consideration.

The manufacturers know that weights and measures enforcement is essential for the protection of the public, to insure that the quantity stated will be delivered by the seller and received by the buyer. We assure all enforcement agencies of weights and measures of our continued support and full cooperation in maintaining this objective.

\section{STATE COOPERATION IN A NATIONAL PROGRAM}

By R. J. NeAle, Weights and Measures Inspector, Agricultural Marketing Service, U. S. Department of Agriculture, Kansas City, Missouri

Within the last year, there was published the startling statement that 11 percent of the livestock scales tested by State Departments of Agriculture were inaccurate by 10 percent or more. The statement was based upon information from a few State weights and measures officials, who were quoted as saying that lack of testing equipment and of personnel was responsible for the situation.

Actually, the published statement presented an incorrect characterization of general livestock scale accuracy, for there are several States which do maintain effective control over such facilities; and, in any event, a scale would rarely be in such poor maintenance or 
repair that it would develop weighing errors as great as even 1 percent under representative test loads.

Nevertheless, as an indictment of some State weights and measures agencies, the statement did direct needed attention to an important phase of weights and measures enforcement which is seriously neglected in a few States and which receives indifferent attention in others.

At the request of your Conference secretary, I shall endeavor to cite the need for active participation by all States in a nation-wide program of livestock scale testing and inspection. I shall also mention deficiencies in the activities of some State jurisdictions, and suggest means for improving and extending scale testing services so as to protect the interests of all farmers and ranchers who produce and market livestock.

It is appropriate, I believe, to remind this Conference that in most States the testing of scales, as a part of weights and measures regulation, is a responsibility of the State Departments of Agriculture. Livestock is the principal cash crop in nearly all States. It is therefore reasonable to expect that all scales on which livestock is weighed for sale or purchase should be regularly and properly tested with adequate equipment by State agencies responsible for administering weights and measures regulations.

The total number of livestock scales in commercial use in all the States is estimated to be 3,500. Of this total number, 850 scales, located at the principal public livestock markets of the nation, are subject to Federal supervision. These may be disregarded in this discussion, since they are tested at intervals of not more than 6 months with standard weight test loads equivalent to the livestock loads weighed, and are maintained and operated under close supervision in accordance with official instructions. Over a period of three years, only one of these scales has been found to be in error by as much as 1 percent.

Of the remaining 2,650 scales, approximately 1,500 are in use at rural auction markets not subject to Federal supervision. They range in number from two or three in each of several New England States to as many as 150 in each of a few Corn Belt States. It is the livestock scales in this category which are commonly neglected in the scaletesting operations of some States and which were the subject of the criticism contained in the article previously mentioned. Many of these scales, located in rural areas not readily accessible to largecapacity test equipment, are of obsolete types, poorly constructed, neglected as to maintenance, and, in very many instances, not tested for intervals as long as two or three years. In consequence, farmers obliged to sell their livestock by weight in these areas do not have assurance that the scales have been tested to prove their weighing accuracy or inspected to discover mechanical faults which may cause serious weighing inaccuracies.

A final category of livestock scales consists of some 1,150 installations owned or operated by packers at processing plants or buying stations where they purchase livestock from farmers. Some of these scales, located in every State of the Union, are not tested for intervals of more than a year or with adequate test loads and, in consequence, the livestock purchased from farmers at these plants is not always 
weighed accurately. Reputable packers do endeavor to assure scale accuracy by having the scales tested by State or local agencies, but. in several States, the official agency is unable to test with required regularity or with sufficient test loads. Some packers find it necessary to engage the services of commercial testing agencies rather than a rait visits by the State agency, if they are to feel sure of the accuracy of their equipment.

The chief respects in which some States neglect their obligations to afford livestock producers the protection commonly provided for producers of other commodities sold by weight are:

1. Failure to test livestock scales at rural auction markets and packer buying stations at regular intervals, preferably as often as twice each year.

2. Failure to apply test loads representing the weight of the heaviest livestock loads commonly weighed.

3. Failure to apply strictly the conventional tolerances and to require repair, adjustment, servicing, or replacement of livestock scales found to be inaccurate and defective.

4. Failure to require that livestock scales be properly located, accessible to test equipment, with proper shelter, lighting, and visibility for weighers and market patrons.

5. Failure to advise scale owners on maintenance measures and to instruct weighers in balancing and weighing procedure.

6. Failure to exercise measures of surveillance, inquiry, and investigation to prevent careless, incorrect, and fraudulent weighing.

Quite recently there has been adopted, as an amendment to regulations under the Federal Packers and Stockyards Act, a requirement that packers owning or operating scales for weighing livestock in commerce shall have their scales tested by competent agencies, with adequate test loads, at intervals of not more than six months and that copies of test reports shall be furnished the Federal Department. It may therefore be anticipated that, in every State, packers will request or demand testing service from State agencies in order to comply with the new regulations. It is therefore suggested that those States not now equipped to provide this service may wish to acquire necessary persomnel and equipment and that other States may need to increase and expand their testing services.

The vital need for deroting increased attention to livestock scales throughout the nation has been discussed before this body in recent years by individuals representing the Federal Department of Agriculture and the States of Virginia and Minnesota. Each speaker on the subject has emphasized the need for State participation in a national program of lirestock scale testing and inspection, and has urged increased cooperation by State agencies. Some improvement has been effected, but more is needed in the interests of the livestock industry, farmers and ranchers, and of the prestige and repute of weights and measures regulatory agencies.

The Federal Department of Agriculture solicits continued and increased cooperation by the States in its endeavors to maintain livestock marketing on a sound basis of ethics and accuracy. This objective represents a challenge to State agencies of weights and measures enforcement-a challenge which can be met only if State agencies 
devote to livestock scales in rural areas an effort proportionate to the activities conducted in behalf of retail consumers in cities.

In conclusion, I express, on behalf of my superiors in the Department of Agriculture, appreciation for the willing cooperation rendered us by the States in the past.

\section{PREPACKAGED FOODS}

By S. C. Rowe, Food and Drug Administration, U. S. Department of Health, Education, and Welfare

When an invitation was first extended to me to address the Conference on the subject of "Prepackaged Foods," I accepted with the feeling that I could talk, in general terms, on the various aspects of the subject for any length of time allotted to me. Later, howerer, I received a letter requesting that particular attention be given to Section 403 (e) and Section 403 (f) of the Federal Food, Drug, and Cosmetic Act. The former deals with the quantity of contents statement and the latter with the conspicuousness of that statement upon the label. This was followed by a series of specific questions concerning the "quantity" requirements of the law and the regulations dealing with them. Consequently, I shall endeavor to confine my remarks to the matter of "quantity" in the package and its declaration on the label.

I am aware that many State and local laws are not identical in all respects with the Federal law. It would seem to me that it would be in the interest of all concerned to have uniformity in these statutes. Recently this Conference has adopted a Model State Law on Weights and Measures and a Model State Regulation for Package Marking Requirements, which appear to be substantially the same as the Federal requirements. It seems appropriate that we examine at this time this law and regulation in which we have a common interest, particularly as to pertinence thereto of court interpretations of the Federal law in the 40 years since the Net Weight Amendment to the old Act of 1906 became effective.

In the first place, each statute deals with commodities "in package form." Over the years there has been much discussion as to what constitutes a package or when the product may be regarded as in package form. The Federal statute does not define the term, but there have been a number of court interpretations. In $U$. S. v. Dr. J.L. Stephens Co. (203 F. 817) the court stated that the word " "package' means the package made up by the manufacturer for sale to the ultimate consumer which goes into the possession of the person who will use the article of food or drug. It means the bottle, or box, or other container, whatever it might be." In a recent case, $U$. S. v. $C$ harles $C$. Kocmond, et al (200 F. 2d 370; cert. den. 735, ct. 782) the Court stated "The common definition of a package is any container in which goods are packed, such as a box, case, barrel, or crate. See Webster's New International Dictionary, 2nd Edition." One definition under Canadian law states that a "package includes any box, bottle, basket, tin, barrel, case, receptacle, sack, bag, wrapper, or other thing in which any article is placed or packed." Another definition states, "package includes anything in which any food, drug, cosmetic, or device is wholly or partly contained, placed, or packed." 
Section 21 of Form 2 of the Model State Law states "that the term 'in package form' as used' in this Act shall mean commodity put up or packaged in any manner in advance of sale so as to constitute a unit quantity of the commodity for either wholesale or retail sale, exclusive, however, of an auxiliary shipping container enclosing packages which individually conform to the requirements of this Act. An individual item or lot of any commodity not in package form as defined in this section, but on which there is marked a selling price based on an established price per unit of weight or of measure, shall be construed to be commodity in package form." While this definition has not been subjected to court interpretation, it is my understanding that it was intended to include any product packed and marked for sale to the ultimate consumer regardless of wrapper. As I understand it, it would apply to a head of cabbage or cauliflower marked on the stem and for retail sale.

Now that we have the commodity in the package, what are the label requirements as to declaration of "quantity"? The Federal law requires an accurate statement of the quantity of contents upon the label in terms of weight, measure, or numerical count and provides for reasonable variations and for exemptions for small packages. Form 2 of the Model State Law under Section 19 does not use the word "accurate" but states that the declaration on the outside of the package shall be definite, plain, and conspicuous. It requires a statement of the net quantity of the contents in terms of weight, measure, or count, and, like the Federal law, provides for reasonable variations and exemptions as to small packages. In addition, Section 19 states that the qualifying words "when packed" or words of similar import shall not be used. In 1920 the Bureau of Chemistry (predecessor to the Food and Drug Administration) pointed out in a public announcement (S. R. A. 322 Chemistry 24) that the words "when packed" were of no significance, since the Federal law required full measure at the time the product was offered for shipment in interstate commerce or otherwise came within the jurisdiction of the Act. The announcement stated further that "allowance should be made in packaging products which are liable to change in weight so that the declaration of net weight will be true at the time the article becomes subject to the operation of the law." In other words, the term serves no useful purpose. It is regrettable that there are still a few packages on the market containing the words "when packed" upon the label. In regard to the use of the word "conspicuous" in Section 19 of the Model State Law, similar wording is used in another provision of the Federal law which I shall undertake to discuss later. (Sec. 403 (f)). So much for the requirements of the two laws.

Coming now to the regulations for package marking, I was unable to find any essential differences between the Model State Regulation and those used in the enforcement of the Food, Drug, and Cosmetic Act. It should be emphasized that these are interpretative regulations of consumer protection laws. They are intended to promote honesty and fair dealing in the interest of consumers and, at the same time, to be reasonable from an industry standpoint. Before the present regulations under the Federal law were promulgated, all interested parties were given an opportunity to comment upon them. They are practically the same as the regulations under the old Act of 1906. 
The allowable deviations from the label declaration of "quantity" have been discussed on numerous occasions before this Conference and I shall not take the time to go into a detailed discussion now. Nevertheless, for the benefit of new members, I will review briefly the discrepancies from the stated contents which are regarded as reasonable.

The permitted variations are of two general types: (1) such deviations from the stated weight or measure as are caused by ordinary and customary exposure after introduction of the article into interstate commerce; and (2) variations in weight, measure, or count caused by unavoidable deviations in weighing, measuring, or counting conducted in accordance with good commercial practice. The first type deals with packages which are not airtight. We are concerned here with moisture losses, which we call normal shrinkage. Under the second type where there is the customary declaration of contents, the average of the packages comprising a specific shipment must not fall below the declared amount at the time of shipment and no unreasonable shortage in any package is permitted even if compensated for by overages in other packages. Where the minimum quantity is expressed, there is no allowance below the declared minimum.

Now, allowances are made by the Food and Drug Administration for normal shrinkage after the product enters interstate commerce. The exact amount to allow in any case depends upon a number of factors such as the type and size of package, the temperature and humidity of the atmosphere to which the shipment is subjected, the length of time in storage, and the type of product. These variables make it impossible to specify allowances for general application which would be fair and equitable to all concerned. Nevertheless, the Food and Drug Administration has accumulated shrinkage data for many years, and any Federal, State, or local food and drug official is welcome to look over the file of this material at any of our field offices. These data represent different products comprising a portion of regular commercial shipments where a careful check was made of all factors which cause a loss of moisture content with resultant loss in weight of the product. They often afford a reliable basis for arriving at an allowance appropriate to a given set of circumstances.

When the shipment enters interstate commerce, it should be full weight or measure regardless of whether the container is airtight or not airtight. In this connection there has been some misunderstanding as to what constitutes an average declaration of the quantity of contents and what constitutes a minimum declaration. In applying these terms, if the statement is not qualified to show definitely that the quantity expressed is the minimum quantity, we consider the statement to express the average quantity. An average declaration means that there may be some packages over the stated quantity and some under, but that the average of all packages shall meet the label statement. The old regulation under the Federal law stated that the discrepancies should be "as often above as below the marked quantity." The magnitude of the variation is different for different products, but in all cases it should be in conformity with good commercial practice. In shooting a gun at a target, the bullseye is not hit every time. The variation around the mark depends upon the marksmanship of the individual doing the shooting and upon the accuracy of the gun. The same is true in aiming at a certain weight or measure. We call 
this factory control. A minimum declaration means that not a single package should be below the stated quantity and that the variation above the mark should not exceed the limits of good commercial practice. The minimum quantity might be expressed by some such statement as "not less than _-_._-_ fluid ounces." If the statement simply reads "Contents -..-_- fluid ounces" it is regarded as an average declaration. In this connection, when the word "ounces" is used alone, an ambiguity exists, for the reason that it may be interpreted to mean either fluid ounces or avoirdupois ounces. If the product is subject to the requirement that the amount be declared in terms of weight, the statement may read "Contents ------ ounces avoirdupois" (or the abbreviation "Avoir") or "Net Weight _-_-_-_ ounces." Either statement removes the ambiguity.

I should like to discuss briefly some of the other paragraphs in the regulations where it has been indicated to me that some explanatory remarks would be beneficial to weights and measures officials. First of all, let us consider the following sentence: "A statement of liquid measure shall be in terms of the United States gallon of 231 cubic inches and quart, pint, and fluid ounce subdivisions thereof, and, except in case of frozen food which is so consumed, shall express the volume at $68^{\circ}$ Fahrenheit $\left(20^{\circ}\right.$ Centigrade)." The question concerns the temperature of measurement in the case of refrigerated foods such as "fresh milk." It is my understanding that the temperature of $68^{\circ} \mathrm{F}$ was originally selected because it approximates the room temperature ordinarily used in packaging and merchandising liquid products. Some products, it is true, are packed and held for sale at temperatures above and below $68^{\circ}$ Fahrenheit, but, unless there was a common temperature for measurement, confusion and misunderstanding would result. In the case of fresh milk, which is ordinarily bottled at temperatures lower than $68^{\circ} \mathrm{F}$, there should be no difficulty in arriving at the correct quantity at $68^{\circ} \mathrm{F}$. On the other hand, where a product is packed hot, it seems not unreasonable to require an accurate measure at $68^{\circ} \mathrm{F}$.

Another paragraph states that the declaration "shall contain only such fractions as are generally used in expressing the quantity of food. $A$ common fraction should be reduced to its lowest terms; a decimal fraction shall not be carried out to more than two places." The question has been raised as to how one arrives at the proper fraction and whether or not decimals of a pound would be satisfactory rather than to use the term "ounces." In answering this, I would say that any fractions or decimals of a fraction should be in terms understandable to the consumer. I believe the word ounces or fractions of a pound are more informative to the ordinary consumer than decimals of a pound. For example, I think $1 / 4$ pound or 4 ounces are more informative than .25 pound. Some years ago I recall seeing ".93 gallon" on a can of olive oil. This, in my opinion, is not readily understandable to the ordinary consumer.

The constitutionality of the quantity of contents provision of the law has been attacked on several occasions. In the case of U.S. v. The Merchants Biscuit Co. (D. C. Code 1924) the court stated:

There can be no doubt as to what the producer or manufacturer must do under that provision and it is not uncertain because a "reasonable variation" shall be permitted. That does not mean that persons subject to the Act do not have to be accurate in their representations, and they do not 
have to ascertain and affix the weight, measure, or numerical count at the time they put up the package, etc. It does mean that if, due to causes over which they have no control, an unavoidable variation occurs after the goods leave their possession, then the law is not violated if the rariation is a reasonable one.

That part of the section which is attacked, therefore, imparts common sense or the rule of reason into the Act, and does not require the impossible. But for this provision we might be compelled to hold it unconstitutional . . . as imposing an intolerable burden, or an impossible requirement.

In 1932 it was the contention of the defendant in the case of $U$. S. v. Shreveport Grain and Elevator Co. (287 U.S. 77 ) that the statute was too indefinite and uncertain. The U. S. Supreme Court held that the regulations represented a long-continued practical construction of the Act on the part of those charged with its administration. The court stated among other things "those regulations which cover variations as well as tolerances and exemptions have been in force for a period of more than 18 years with the silent acquiescence of Congress." Only last year in U. S. v. Badger Fruit and Extract Co. (Dec. 11, 1953 E. D. Wis. No. 228 Crim. U), the defendants filed a motion to dismiss on the grounds that the provision did not meet the requirements of the Sixth Amendment of the Constitution. Apparently they felt that they had not been "informed of the nature and cause of the accusation." The district court stated "although defendants' motion refers to the statute, it is evident to the court that the defendants here are not attacking the validity of the statute itself. Their position is rather that, in view of the Shreveport decision, it is imperative for the Administrator to create a standard by making rules and regulations permitting reasonable variations, and that the rules and regulations found ... do not disclose a standard permitting reasonable variations. The court cannot agree with this contention. The court believes that the regulations in question establish adequate standards permitting reasonable variations in fulfillment of the purposes and provisions of the Act." The case has not yet been tried.

In citing court opinions in these cases, I do not wish to convey the impression that the Government has won all of its cases where quantity of contents is involved. Many cases have been lost for one reason or another. I do wish to point out, however, that no case was lost where the quantity of contents provision and regulations were attacked on constitutional grounds.

The Federal law declares a product misbranded "if any word, statement, or other information required by or under authority of this Act to appear upon the label or labeling is not prominently placed thereon with such conspicuousness (as compared with other words, statements, designs, or devices, in the labeling) and in such terms as to render it likely to be read and understood by the ordinary individual under customary conditions of purchase and use." There have been no court decisions on this provision so that we have had to use our own interpretation. Under paragraph (6) of the Regulations, reference is made to "the smallness or style of type." I wish I could give you a definite answer in regard to the size and style of type, but unfortunately it is entirely possible to have a size and style of type which is satisfactory under one set of conditions and quite unsatisfactory under other conditions. The color of the background as compared to the color of the type and the crowding of the label with 
designs, vignettes, or unnecessary written, printed, or graphic material all contribute to the relative conspicuousness or inconspicuousness of the declaration. Several weeks ago a retired employee of the Food and Drug Administration visited his old office and remarked that he thought he would have to get new glasses as he could no longer read the label on a small wedge of imported cheese which he brought with him. We looked at the label and concluded that there was nothing wrong with his eyesight. We couldn't read it either. When in doubt about a particular label, we like to try it out on a number of disinterested individuals to obtain their reaction to it. A general agreement of a panel either for or against the conspicuousness of the wording is very helpful in arriving at an estimate as to what the ordinary consumer would think about it.

To sum up: (1) It is desirable that weights and measures statutes be uniform and that court interpretations be utilized in their enforcement whenever possible. (2) Regulations should be in interest of consumers and, at the same time, be reasonable from an industry standpoint. (3) The quantity of contents statement should be informative to consumers and it should be conspicuously set forth upon the label in terms which the ordinary individual can understand.

Mr. Boyle. Mr. Rowe, would you consider it unreasonable or a hardship to require the word "contents" in combination with a statement of quantity on a package of food?

Mr. Rowe. The word "contents" would bear no effect on the requirement that the package contain the full labeled weight or measure.

Mr. Wrens. When a shipment, for example of 100 pound bags of potatoes, is placed in interstate commerce, when does the packer's responsibility for full weight end?

Mr. Rowe. Under the Federal Law I would say that the potatoes would be required to be full weight at the time of shipment. If a packer packed potatoes some time prior to shipment, he should overpack in a sufficient amount to allow for full label weight at time of shipment.

Mr. Ising. Is there in the Federal Law or Regulations a stipulation concerning the net-contents markings on small packages of foodthat is, certain small packages on which no content declarations are required?

Mr. Rowe. Yes, under exemptions for small packages, packages of food containing less than one-half ounce avoirdupois or one-half fluid ounce are not required to be labeled as to their quantity.

Mr. Kennedy (D. C.) : If a local distributor purchases a commodity subject to shrinkage from an out-of-state packer and stipulates that the conditions of the sale are for the merchandise to be f. o. b. the local warehouse, is the out-of-state packer responsible for full labeled weight to that warehouse?

Mr. Rowe. Once a commodity enters interstate commerce, that is, after it is beyond the control of the packer, the Federal Law provides for shrinkage losses.

Mr. Baucorr: What does the Federal Food and Drug Administration consider to be a reasonable shrinkage on potatoes in interstate commerce? 
Mr. Rowe: Over a period of years the Food and Drug Administration has accumulated data on this subject. We cannot set down an ironclad rule as to how much allowance should be made in every instance. Each case must be considered on its own merits. The amount of shrinkage will depend on the product itself, the package, the conditions to which it is subjected, and the length of time. We have conducted experiments over the years and we do have data on potatoes and other products. That data is not published but it is available to weights and measures officials upon request to our field office.

\section{REMARKS OF J. T. KENNEDY, CHIEF \\ WEIGHTS, MEASURES, AND MARKETS, DISTRICT OF COLUMBIA}

For some time we have administered a concentrated program of reweighing prepackaged meats. As you know, this method of merchandising in the meat industry has been growing very rapidly and apparently will continue to grow. We believe that we have an excellent example of the willingness of an organized group to cooperate in this effort toward full weight and correct labeling.

I would like to read into the record of this Conference a fine letter which the President and the Secretary of the Amalgamated Meat Cutters, Local No. 555, 433 Massachusetts Avenue NW., Washington 1, D. C., sent to all members.

DeAr Member: We sincerely hope you will thoroughly read and absorb this message, as it may be the means of saving the job of those who subscribe to its intent. We don't intend to infer that yours or any job is hanging in the balance unless you and/or others are guilty of the infraction we propose to discuss.

We want to emphasize the serious necessity and grave importance of complying with rules and regulations of both the Department of Weights and Measures and the Department of Health. Both are of equal importance although for the present priority is given to Department of Weights and Measures.

First of all, we don't propose to represent law enforcement officers, nor do we intend to interfere with their duties or responsibilities. We do, however, realize the positions our members are placed in when they run afoul of the law. Some have lost their jobs on this account and others stand to receive the same fate if caught. Most recently the Department of Weights and Measures, through its Inspectors, has cited several cases of "short weights" committed by our members and others. They are constantly checking and without warning; one never knows when or where-you may be on the list. You needn't be concerned if you're giving correct weights and prices.

WE KNOW IT'S AGAINST YOUR EMPLOYER'S INSTRUCTIONS TO "OVER CHARGE" OR "SHORT WEIGHT"; WE KNOW IT'S AGAINST THE LAW ; WE KNOW PEOPLE HAVE LOST JOBS; WE KNOW THE PUBLIC IS ENTITLED TO CORRECT WEIGHT AND PRICE; WE KNOW YOU WANT ACCURACY WHEN YOU MAKE A PURCHASE. Therefore why be a pawn or victim of doing the wrong thing? We know also that mistakes are made, but this is one time we just can't afford ANY MISTAKE. Think it over-is it worth losing your job by being either careless or overzealous?

Don't be misled or hoodwinked into doing something that may cost you your job. If anyone instructs, suggests or tells you to take "short cuts," we certainly want to know about it. If you're right, we'll back you to the hilt; however, if you're wrong, there's little or nothing that we can do. The laws are made to observe and protect; do your part.

Again we sincerely hope you accept this in the same spirit that it is given. Fraternally yours,

$$
\begin{aligned}
& \text { W. B. Strong. } \\
& \text { President. } \\
& \text { M. G. Curtis, } \\
& \text { Financial Secretary. }
\end{aligned}
$$




\section{CHECK-WEIGHING SCALES}

By C. A. BAKer, Director, Bureau of Weights and Measures, State of New York

I am informed by our secretary that there is considerable interest on the part of many weights and measures officials as to the advisability or practicability of requiring by law that scales be made available in our modern super markets for the use of customers who may wish to check weights of prepackaged items, especially meats.

As a starting point for discussion, I would like to quote the provision in our New York State law, as amended in 1951, that set up the requirement in relation to scales being made available for customers' use. Our law states as follows:

*** Whenever meat or meat products or cheese are packaged or wrapped by the retailer in advance of being exposed or offered for sale, an accurate scale shall be handily available to the purchaser of such packaged products for his use in checking the weight indicated.

I should like to comment very briefly on this requirement. First of all, there is no question in my mind that the basic idea or principle of this requirement is very much worthwhile. I believe we can all agree that the customers should, in all cases, have the opportunity to check packages that they may purchase, in order to see that the weight is correct, without the necessity of taking such packages to another grocery store or meat market, or the necessity of walking perhaps 150 feet to the front of the store in order to find a scale on which such packages may be checked.

In my opinion, the language used in our New York State law to set up this requirement is too indefinite and is subject to many interpretations, either by the merchant or by the judge, as to what constitutes a scale that "shall be handily available to the purchaser."

The merchant may feel that the term "handily available" is satisfactorily complied with by having a vegetable scale in the front of the store, which may be 100 feet or more away from the meat counter. The sealer or inspector may feel that this is a violation-that the term "handily available" means a scale that is directly adjacent to the meat counter. The judge may feel that both the inspector and the merchant are wrong and that "handily available" means a scale which may be located anywhere within 25 feet of the meat counter. In other words, the term "handily available" may be subject to as many different interpretations as there are people involved in the controversy.

When the amendment of the law was passed, I opposed it on the ground that the language used was too indefinite, not because the underlying principle was wrong. However, we accepted it because there were other matters involved in the same amendment which we were very desirous of having in effect.

Returning again briefly to the requirement that an accurate scale shall be "handily available" to the purchaser, for such prepackaged products, we have found that enforcement of the provision depends largely on the cooperation of the individual, the company, or the store manager with the local weights and measures official or our State inspector. Some of the larger chain food organizations have given us excellent cooperation in this respect and have made it a point to furnish an accurate computing scale located directly adjacent to the pre- 
packaged meat counter for the use of their customers. Some other concerns give us an argument and claim that any "accurate" scale, such as a large spring dial vegetable scale that may be in the front of the store, complies with the requirement of the law. In such cases there are only two courses of action open to the sealer or inspector. He must either accept the situation as it is, or cause the arrest of the store manager-an action which in most cases he is reluctant to take.

To sum up the situation, let me restate that in my opinion the principle involved is excellent, but that, if you contemplate either a provision of the law or regulation in this respect, the law or regulation should definitely state not only that the available scale must be accurate, but that it must be a computing scale having the same minimum graduation as those used by the merchant to prepackage the meat and, instead of saying that it must be "handily available," it should be stated that the scale be placed within definite limits by measureeither in feet or yards-from the prepackaged meat counter. Unless this is done, you are bound to run into difficulties in some instances in enforcing such a law or regulation.

I offer these comments in the hope that they may be helpful to those of you who may be interested or considering such legislation or regulations, and I am sure that general discussion of the various problems involved, by this Conference, may serve to clarify our thinking along these lines and possibly assist our Legislative Committee if its members wish to consider such an amendment to the Conference Model Law.

Mr. Crawford: Many merchants are voluntarily locating scales near self-service counters and placing on them signs that indicate the scales are provided for the convenience of the customer in checking the weight of any purchase. However, there remains the problem of determining or knowing the tare weight of the container and wrapping material.

Mr. KENNEDY : I do not believe it is proper to discriminate against markets with prepackage self-service counters. Surely if the customer has the right to checkweigh prepackaged meat items he has an equal right to checkweigh the contents in such items as bread, butter, coffee, etc.

Mr. BAKer: In order to have the assurance that our weights and measures laws are being complied with, we must have the assistance of the buying public. Obviously our staff is insufficient to inspect and check every store as often as we would like to. If we can interest customers in checking prepackaged items, they can be of great assistance to us in our efforts.

Mr. Mahoney: I believe this is a matter of education rather than legislation. When the customers demand that scales be made available for their checkweighing of prepackaged items, the markets will make such scales available.

Mr. Turnbulu: I think some officials are lax in enforcing the requirement that computing scales be so located as to be easily read by the customer. The sales and service forces of the scale companies could render substantial assistance in this regard. It would be my recommendation that every inspector of weights and measures enforce rigidly this requirement. 


\section{CANNED POULTRY}

By I. M. Lerr, City Sealer of Weights and Measures, Chicago, Illinois

Three years ago in this very room during the 36th National Con1ference, the subject of canned whole chicken was discussed. One address which left a particular impression upon my memory was that of Malcolm Jensen, at that time Sealer of Weights and Measures of the City of Madison, Wisconsin and at the present time of the National Bureau of Standards.

I wish to quote from Mr. Jensen's address-"A rery careful and accurate check on the contents of every brand of canned chicken available in Madison brought about some amazing conclusions. These cans which had labeled contents rarying from just under two pounds to four pounds were labeled to contain rarious types of chicken in rarious stages of preparation, and were found to contain an a verage of exactly 54.7 percent chicken by weight and 45.3 percent liquids. The percentage by weight of the chicken in the tested cans varied from 57.8 percent down to 48.9 percent."

Last week similar tests were made in Chicago. Our results were 55.2 percent chicken by weight, 44.8 percent liquid. In other words, conditions which prevailed in 1951 are unchanged in 1954, and, as far as I am able to find out, they were similar when canned chicken first came into popular usage in 1946.

I have examined the labels of perhaps a dozen brands of canned chickens and there is one thing they all have in common. They emphasize by prominence of illustration and size of type that the can contains a whole cooked chicken, and ofttimes the net weight of the contents of the can is likewise displayed prominently on the label. Undoubtedly, the information printed on the label meets the legal requirements or else the packers would hare been faced with Federal prosecution. I am not suggesting they are violating any law, but I do say with emphasis that Federal regulations which have to do with the labeling of food packages should be such that the average woman shopper should not be so easily misled to the belief that she is buying a $31 / 2^{-}, 33 / 4^{-}$or 4 -pound chicken when in reality slightly more than 50 percent of the contents of the package is chicken and the remainder water, preservatives, and condiments.

This may well spotlight the whole question of modern day merchandising of foods which has a marked tendency towards precooked and ready to serre foods. This means that we in weights and measures must be as modern in our concept of our duties as those in the processing of food are in meeting present day demands for this type product. We no longer face simple problems.

In the old days the butcher placed raw meat or poultry on the scale. Flour was sold in sacks at stated weights or loose by the pound. Likewise, the other ingredients could be easily weighed or measured in the presence of the housewife. She knew how much of each commodity she was receiving, but today with canned whole chickens, meat balls and gravy, roast beef and grary, eren complete turkey dinners in cellophane, she must be satisfied with "net contents" of the can. The label which merely states the net contents of a packaged food commodity (and not in what proportions or percentage by weight these items are contained in the package), is meaningless when that package 
contains several basic foods, such as meat or poultry, flour, rice, condiments, and water.

It is unfair and unrealistic to be meticulously careful that poultry sold over the counter be not a single ounce short of the weight charged, when, on the other hand, processors are permitted to sell the same commodity in cans where the weight of the fowl may vary as much as $8 \mathrm{oz}$.- -but of even more basic importance, this practice gnaws at the very vitals of our services to our communities-the principle of the exactness in weights in the exchange of commodities.

Mr. BADCOM: Mr. Levy, in the preparation of this paper perhaps you have developed some remedy. Would you care to give this Conference the benefit of any suggested remedy for this problem?

Mr. LeVY: In my opinion the remedy would be either more stringent interpretation of our present legal requirements or, if necessary, amendments to existing legislation. Since either of these suggestions is difficult to accomplish, I would suggest that we make definite efforts toward educating the buying public. It is not my recommendation that we in any way block the progress in the prepackaged food industry. Obviously there are many advantages to the consumer when such food items are available for purchase. 1954.)

(The Conference adjourned, to reconvene at 10 a. m. Wednesday, May 19,

\section{Third Session-Morning of Wednesday, May 19, 1954}

(A. V. Astin, President, and G. F. Austin, Jr., Vice President, presiding.)

\section{EVOLUTION OF GASOLINE PUMPS}

By WrLlIAM KeAY, Manager, Sales Service, Gilbert \& Barker Manufacturing Company, West Springfield, Massachusetts.

(Mr. Keay traced the history of the Gibert and Barker Manufacturing Company from its beginning in 1865 . Starting as a manufacturer of machines to make illuminating gas from gasoline, and as a marketer of gasoline, the company made its first non-measuring gasoline-dispensing pump in 1910. Before long, measuring pumps were designed, and the production of this type of equipment kept pace with the rapid increase in the number of automobiles in use. The "visible" pump was at the height of its popularity by 1926, and the electrically. operated meter unit was introduced in 1928. Recent developments include dual dispensers and remote-control systems. Mr. Keay's talk was illustrated with many excellent color transparencies.)

\section{REPORT OF THE COMMITTEE ON WEIGHTS AND MEASURES EDUCATION, PRESENTED BY C. M. FULLER, CHAIRMAN}

The report that your Committee on Weights and Measures Educa. tion has prepared deals with two subjects of immediate interest and concern to every weights and measures official.

Establishing good public relations and educating the people so that they have a keen realization of what this work means to them in their everyday lives are of paramount importance. Too frequently the general public and our higher public officials have not been sold on the true value of weights and measures administration. For that reason it is difficult to obtain adequate budgets and competent salaries.

We must sell ourselves and our service. Industry spends millions on advertising, publicity, and public relations, in order to arouse a 
demand for its products. We must enlighten the populace as to the value of our services if we are to receive the support and cooperation that are needed for the operation of successful departments. Fortunately, we are engaged in a work that is popular, once the people understand it. It pays real dividends and returns many times its cost.

The fields of publicity and public relations are large. They include exhibits, talks before groups and over the radio, television shows, articles in newspapers and periodicals, and annual reports.

We cannot cover the entire field in one report; it would be entirely too long. We are therefore concentrating on the phase that is especially appealing to the public-that of exhibits. Exhibits are valuable because they speak for themselves. They present information quickly and convincingly. They do not have to be elaborate to get results.

It is our aim to make this report practical, something that you can really use, by including ideas that have been used and pictures of exhibits that have been successful. We want to thank the many weights and measures officials who have responded to requests for photographs and material used in this year's project. Their cooperation has made our work a pleasure.

First of all, a good exhibit should attract the attention of the people and draw them nearer to see what it is all about. A device that has proved effective gives the appearance, from a little distance, of a blazing bonfire of confiscated scales. This effect is achieved by the use of a tall cone, constructed of chicken wire on a light framework and covered with bright red cloth. It is literally covered with old scales and illuminated from within by a strong electric light, which is caused to flicker on and off by either a flasher button or a revolving disk. Long red paper streamers at the top of the cone are kept fluttering by the current of air from an electric fan and appear to be flames.

A sure-fire drawing card is the use of a large person weigher on which the public will be given guaranteed accurate weights free of charge. Colored posters should call attention to this feature. We have seen as many as fifty people waiting in line for their turn. This gives the attendant a wonderful opportunity to interest visitors in other features of the exhibit and to answer questions.

A full-sized figure of a woman dressed in flowing robes, holding a small balance in one raised hand like the well-known figure representing Justice, makes an attractive centerpiece around which to arrange your exhibit. These figures or models, which cost about $\$ 100$ usually can be borrowed for the occasion, especially when a small placard gives credit to the store making the loan.

Colored transparencies, placed in frames and lighted from the rear, are outstanding. These can illustrate different phases of the work and inspection equipment. The widespread use of miniature cameras, taking $35 \mathrm{~mm}$ colored slides, places this facility within the reach of every official. Colored transparancies $8^{\prime \prime} \times 10^{\prime \prime}$ can be obtained from the small slides at a cost of about $\$ 3.00$ each. They can be used over and over again. The display box or frame, of any desired shape and size, can be constructed by your local electrician and carpenter. 
Small colored slides can be shown with a projector and screen, or they may be displayed in a self-contained cabinet unit which holds thirty slides, automatically changes them every six seconds, shows a picture about $16^{\prime \prime} \times 23^{\prime \prime}$, and operates in a lighted room.

The scope of the exhibit will depend upon the location and space allotted to it. It may be a roomy location at a fair or exposition, a booth at a food show, a vacant store window on a downtown street, or wall space for a display of posters and enlarged photographs. When the decision as to space has been made, plans can be made to utilize the area to the fullest advantage. Your ingenuity and knowledge of what is accomplished by the enforcement of weights and measures laws will suggest many ideas.

Facts should be presented in a manner that will draw people's attention, grip their imagination, hold their interest, and make them think. They like to see something in action. A good example was a leather measuring machine in a Massachusetts exhibit. Leather hides were run through this and it proved very intriguing to the spectators in the sense that it acquainted them with the means employed to measure accurately the surface areas of the hides, despite the fact that they were very irregular in shape and also, in some instances, contained large holes.

The contrast between the past and the present is always intriguing. A back panel on one side of this exhibit depicted a scene in the old "Lum and Abner" kind of corner grocery, with two characters sitting comfortably by a pot-bellied stove, and an antique scale of the "beehive" variety much in evidence on the counter. Directly in front of the painting was a collection of obsolete scales, including the actual "beehive" scale itself. The panel on the other side of the exhibit depicted a scale in a modern market. Several latest model computing scales were located in front of this, with a sign calling attention to the ease with which they may be read accurately and that there was no excuse for short weighing. Action was provided by an attendant who demonstrated methods of testing and reading the scales.

A similar idea was presented in an exhibit that featured the work of protecting the motorist. A backdrop entitled "Yesterday" showed the granddaddy of all service stations-simply a shed where gasoline was dispensed with a measure and funnel, located on a typical "Main Street" corner of early twentieth century. The other backdrop, "Today," showed a modern service station. Different pieces of testing equipment were on display. An automatic cabinet unit, located between the backdrops, projected colored slides. Posters and enlarged photographs gave additional information.

Your ingenuity will suggest other ideas. A sensitive analytical balance will show the difference in the added weight of a piece of thin paper after a name has been written on it with a soft crayon. This makes an interesting speculation, "How much weight does your name carry around here?"

Don't forget the drawing power of a person weigher. People like to get their accurate weight - they like to get it free-and they have a lot of fun commenting on the other fellow's weight.

A San Francisco store window framed an exhibit that was successful in creating considerable publicity and favorable comment. A large office balance, along with testing standards, were displayed with 
a number of attractive well-worded signs that described what was accomplished through their use. Over all, a large sign stated, "San Francisco's Department of Weights and Measures Saves You Money."

A wide-awake official will find opportune times and locations for an exhibit. Jacksonville, Florida, has a display in the City Hall Open House Exhibit. San Diego, California, takes advantage of the County Government on Display program at the Civic Center. Norfolk, Virginia, places an exhibit in the lobby of the City Hall for one week each year when the citizens are paying their taxes, and shows them what they are getting for part of their tax money.

Condemned and confiscated scales can be used to impress the public with the necessity for this work. However, care should be taken to bring out the fact that this is not a reflection on the majority of merchants who are strictly honest and who welcome the inspectors when they call. The merchants thus are assured that their own equipment is accurate and that they are protected from the "other fellow" who would cheat if he were not afraid of being caught. Many scales that get out of order through the wear and tear of constant use are weighing against the merchant.

If you possess some false scales that have been altered to give short weight, place them in a prominent location and demonstrate how they operate. They will attract plenty of interest and conversation. The same is true of containers with false bottoms or side walls, or other articles that have served as evidence in prosecutions.

"The Evolution of the Scale" would be a good subject for a display, beginning with the simplest form of balance and carrying through developments and early attempts in automatic devices, up to the modern computing scale.

Posters provide an effective method for putting your ideas across. When colored, they brighten up the exhibit. They do not have to be elaborate to attract attention.

A number of years ago, the Saturday Evening Post had a cover that is remembered to this day. It represented a scene in a butcher shop. A chicken was "resting-in-peace" on the hanging scale. 'The dear old lady buying the chicken was gazing soulfully up at the face of the scale, but her hand was underneath the platter, pushing up to make it show less weight. The butcher was also looking at the scale, but his hand was on the platter, pushing down to make it show more weight. It was called, "The Two-Way Ride." That makes a good poster. People enjoy a hearty laugh.

Call attention to your free weighing attraction by a poster. A number of ideas will occur here, such as a woman horrified at the indication of her weight, not knowing that a small boy behind her back has one foot on the scale, or a little girl weighing her pet pooch. Children and dogs are always appealing.

If you are displaying some of your test weights, tell the story of how they are used by a poster showing an inspector testing a scale and the wording, "For Your Protection. Test Weights like these are used in making -.--_- tests each year of scales in -.---- places of business." The same general idea can be used in connection with test measures for the inspection of gasoline pumps.

Basic rules to be observed by the careful buyer will be better remembered if they are illustrated. Some of these are: "Thrifty Buy- 
ers Check the Weighing of Their Purchase"; "See That the Indicator Starts on Zero Before Purchase is Weighed"; "Don't Let any Hand Rest on Scale when Purchase is Made"; "Read Statement of Net Contents on Every Package-The Smallest Appearing One May Contain the Most."

Impress the taxpayer with the fact that this is a real bargain in good government by a picture of an earnest young man presenting some statistics to a typical business man. The following statement is made: "An Investment that Pays Real Dividends! Less than ... . pennies pays your share for an entire year of this service which saves you many dollars."

Enlargements of action photographs, showing actual work in the field, are informative. When they are used, make the picture tell the story and keep the printed matter as brief as possible. Combinations of posters and photographs make good panel or wall exhibits.

An attendant, who is well versed in the work of the department, should be on hand to answer questions and to encourage visitors to look around. He should be genuinely interested in meeting the public and pointing out features of the display. A good personality, friendly and approachable, can mean much to the success of the exhibit.

If you have room at your headquarters, set up a permanent exhibit. Enlarged pictures of this can be mounted on cards, calling attention to various features and inviting the public to make a visit and learn more about their Department of Weights and Measures.

We urge you to welcome every opportunity to publicize the value and necessity of your work. Be a good salesman. Tell the people in your community. This will gain their enthusiastic support and cooperation for adequate budgets and competent salaries.

\section{Recommended Salary Schendle}

Two years ago, at the Thirty-Seventh National Conference, your Committee recommended a salary schedule for weights and measures personnel. This was the result of a careful study which took into consideration the salaries paid in governmental positions of comparable duties and responsibilities, as well as current wages paid by industry.

Since that time, there has been an increase in the cost of living which has been reflected by a consequent upward trend in the prevailing wage. In revising our recommendations of two years ago, we have heen guided by the advice of government analysts who maintain a constant record of current statistics.

We realize that the cost of living is not the same in all sections of the country, and for that reason there will be a difference in the prevailing wage. Thus the salaries in the following schedules are subject to modification according to local conditions.

You will recall from our previous report that we believe in the step-advancement plan, with annual advances over a period of years. This plan provides an incentive for continuous service. Provision also should be made in the larger departments for several grades of employees, the higher grades being filled from the lower ranks by promotional examinations. Such advancements build up morale and 
reward the ambitious men who are striving at all times to do better than average jobs. Thus, you will find a classification of "Trainee" listed in the first two charts for larger departments. This is the beginning rank, the bottom of the ladder. A trainee works under close supervision. He may drive a heavy-duty testing truck and handle the weights for the deputy in charge, or he may assist in wholesalemeter tests. The important thing is that he is learning the work and preparing himself to take a promotional examination in order to become a deputy.

Our recommendations must be as practical as possible; therefore, we are listing each item according to the "Five-Step Pay Plan" which has been adopted in so many jurisdictions. The original appoint. ment is made at the rate designated as the first step. Step advances should be granted at the end of one year of continuous satisfactory service in the same position, until the fifth step is reached.

Departments are grouped in five classifications according to size. While these could be broken down into many more groups, we believe that this gires enough material, without unduly lengthening the report, so that departments of any size can modify the schedules for their use.

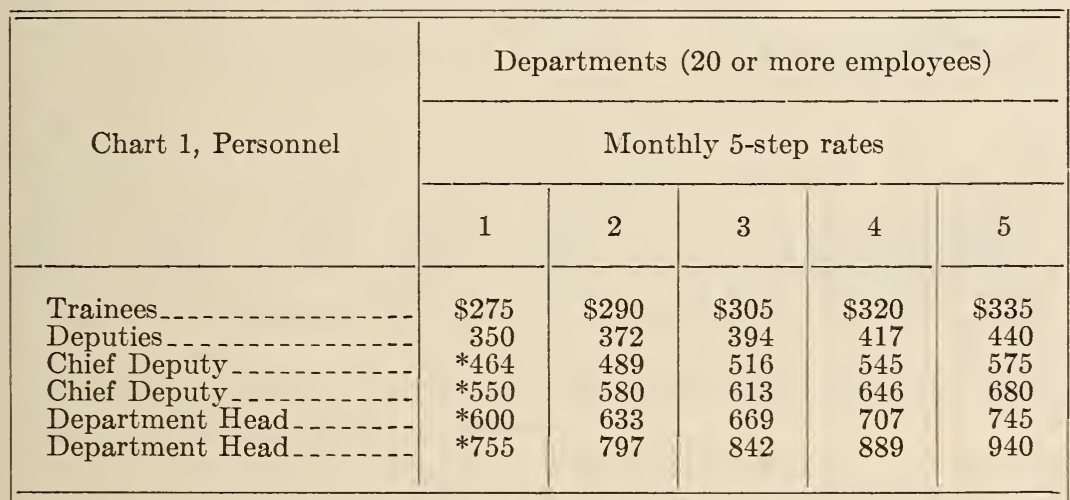

*According to size of department

If a "Three-Step Plan" is used, take the amounts shown under 1, 3, and 5 .

Some large-departments may also have other classifications such as "Junior Deputies," "Senior Deputies," "Senior Complaint Deputies," "Investigators," etc. Salaries for these classifications can be established in accord with the above.

Now, in every five-step plan, there will occur some situations where the fifth-step compensation for one position will be as much or more than the first step for the next higher position. When this occurs, the employee who is promoted is placed in the step that will give him an immediate increase in salary. For example, in the following chart, a deputy in the fifth step who was promoted to Chief Deputy, would enter that position in the second step, which would give him a raise from $\$ 440$ to $\$ 464$. 


\begin{tabular}{|c|c|c|c|c|c|}
\hline \multirow{3}{*}{ Chart 2, Personnel } & \multicolumn{5}{|c|}{ Departments (10 to 19 employees) } \\
\hline & \multicolumn{5}{|c|}{ Monthly 5-step rates } \\
\hline & 1 & 2 & 3 & 4 & 5 \\
\hline Trainees & $\$ 275$ & $\$ 290$ & $\$ 305$ & $\$ 320$ & $\$ 335$ \\
\hline Deputies & 350 & 372 & 394 & 417 & 440 \\
\hline Chief Deputy & $* 440$ & 464 & 489 & 516 & 545 \\
\hline Chief Deputy & $* 464$ & 489 & 516 & 545 & 575 \\
\hline Department Head. & $* 550$ & 580 & 613 & 646 & 680 \\
\hline Department Head.- & $* 600$ & 633 & 669 & 707 & 750 \\
\hline
\end{tabular}

*According to size of department

\begin{tabular}{|c|c|c|c|c|c|}
\hline \multirow{3}{*}{ Chart 3, Personnel } & \multicolumn{5}{|c|}{ Departments (6 to 9 employees) } \\
\hline & \multicolumn{5}{|c|}{ Monthly 5-step rates } \\
\hline & 1 & 2 & 3 & 4 & 5 \\
\hline $\begin{array}{l}\text { Deputies } \\
\text { Chief Deputy } \\
\text { Department Head.- }\end{array}$ & $\begin{array}{r}\$ 350 \\
440 \\
550\end{array}$ & $\begin{array}{r}\$ 372 \\
464 \\
580\end{array}$ & $\begin{array}{r}\$ 394 \\
489 \\
613\end{array}$ & $\begin{array}{r}\$ 417 \\
516 \\
646\end{array}$ & $\begin{array}{r}\$ 440 \\
545 \\
680\end{array}$ \\
\hline
\end{tabular}

\begin{tabular}{|c|c|c|c|c|c|}
\hline \multirow{3}{*}{ Chart 4, Personnel } & \multicolumn{5}{|c|}{ Departments (2 to 5 employees) } \\
\hline & \multicolumn{5}{|c|}{ Monthly 5-step rates } \\
\hline & 1 & 2 & 3 & 4 & 5 \\
\hline $\begin{array}{l}\text { Deputies. } \\
\text { Department Head }\end{array}$ & $\begin{array}{r}\$ 350 \\
445\end{array}$ & $\begin{array}{r}\$ 372 \\
469\end{array}$ & $\begin{array}{r}\$ 394 \\
494\end{array}$ & $\begin{array}{r}\$ 417 \\
521\end{array}$ & $\begin{array}{r}\$ 440 \\
550\end{array}$ \\
\hline
\end{tabular}

\begin{tabular}{|c|c|c|c|c|c|}
\hline \multirow{3}{*}{ Chart 5, Personnel } & \multicolumn{5}{|c|}{ Departments (1 man) } \\
\hline & \multicolumn{5}{|c|}{ Monthly 5-step rates } \\
\hline & 1 & 2 & 3 & 4 & 5 \\
\hline $\begin{array}{l}\text { Sealer or Inspector } \\
\text { Sealer or Inspector }\end{array}$ & $\begin{array}{r}* \$ 350 \\
* 417\end{array}$ & $\begin{array}{r}\$ 372 \\
440\end{array}$ & $\begin{array}{r}\$ 394 \\
464\end{array}$ & $\begin{array}{r}\$ 417 \\
489\end{array}$ & $\begin{array}{r}\$ 440 \\
516\end{array}$ \\
\hline
\end{tabular}


We recommend the above salaries as equitable and in line with present prevailing wages for comparable positions. They should enable us to recruit and retain men of excellent caliber for this valuable service.

(The presentation of the report of the Conference Committee on Weights and Measures Education was illustrated with many excellent projected slides showing weights and measures exhibits and displays.)

(The report of the Committee on Weights and Measures Education was adopted by the Conference.)

Mr. YarbroưGH: I believe the Conference Committee on Weights and Measures Education could perform a real service to weights and measures personnel by developing a series of adequate and accurate job descriptions. In many instances the salary rates are based upon job descriptions. Thus their importance is great.

Mr. FulLer: That is an excellent suggestion. The Education Committee will give consideration to the development of position descriptions.

\section{SERVICES OF THE NATIONAL BUREAU OF STANDARDS}

\section{By A. T. McPherson, Associate Director, National Bureau of Standards}

The National Bureau of Standards renders a number of services in addition to those relating to weights and measures, with which the members of the Conference are familiar. The law establishing the Bureau and subsequent amendments state clearly what these services shall be, whom they are for, and what charges shall be made for them. The amount of service in any category that can be provided in any given year is dependent on the funds appropriated by the Congress.

The various standardization activities which the Bureau conducts for the Government, science, industry, and the public are made possible by a great deal of basic research in physics, chemistry, mathematics, and engineering. This research results in many indirect and collateral benefits that go far beyond the direct services of the Bureau. The present discussion, however, is confined to those services that are rendered on direct request.

First and foremost among the standardizing activities of the $\mathrm{Bu}$ reau is the calibration of standards of measurements such as those listed in the accompanying table. Because of the vast number of instruments used in laboratories and manufacturing plants the $\mathrm{Bu}$ reau, insofar as possible, restricts its calibration service to primary standards, which themselves are used to calibrate the instruments that are employed for making measurements.

Many standards, particularly those relating to composition or properties, are most effectively made available through the distribution of standard samples.

The law provides that a charge shall be made for all calibrations and comparisons of standards with the national standards except those performed for the Government of the United States and State Governments within the United States. Currently, only one standard of a kind or type is calibrated without charge for any Federal laboratory in a given year. If, as a matter of convenience additional instruments or other standards are requested to be certified by a Federal 


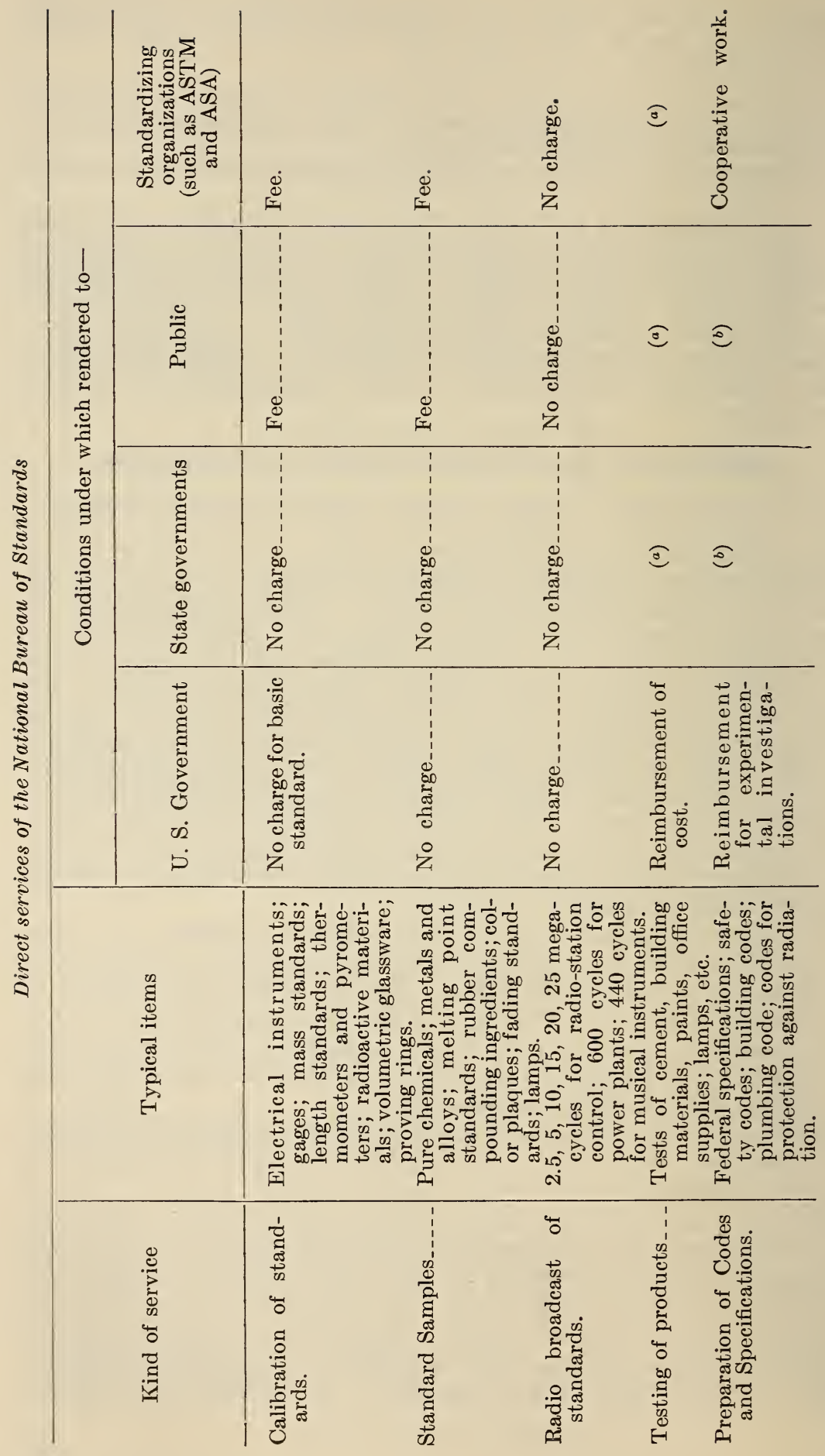




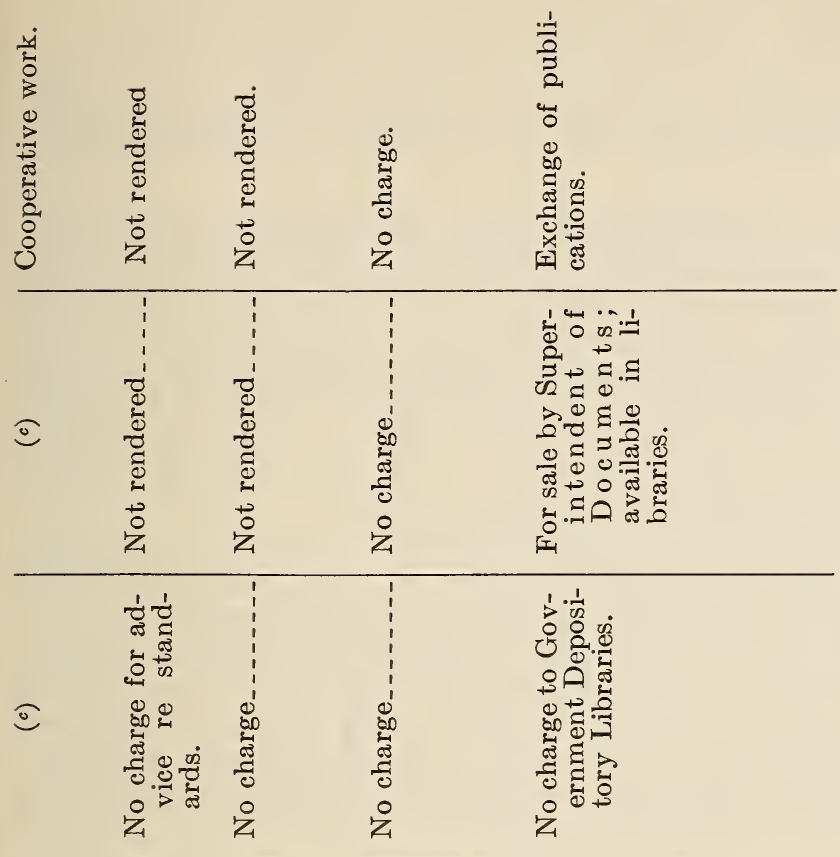

\begin{tabular}{|c|c|c|c|c|}
\hline 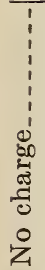 & 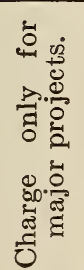 & $\begin{array}{l}1 \\
\vdots \\
\vdots \\
0 \\
0 \\
0 \\
0 \\
0 \\
0 \\
0 \\
0 \\
0 \\
0 \\
z\end{array}$ & 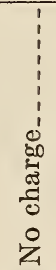 & 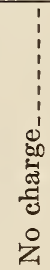 \\
\hline
\end{tabular}

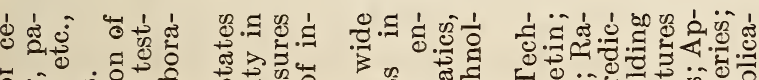

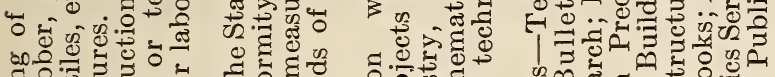

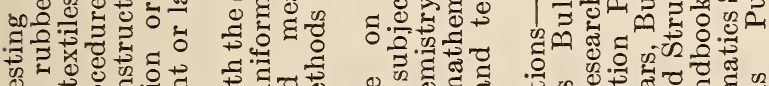
कु

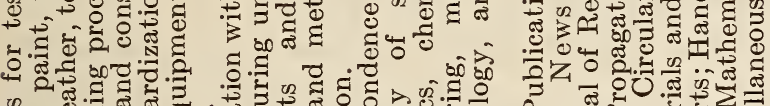
ข 过

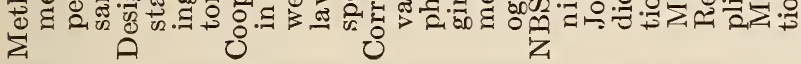
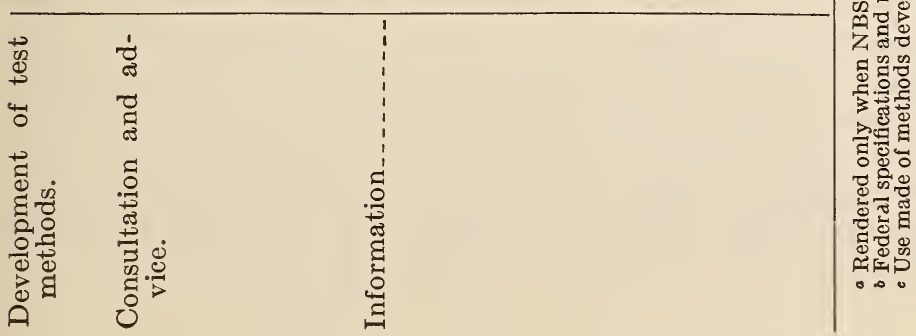
laboratory, a charge is made for the service. For State governments, however, no charge is made for any service that can be rendered.

Standards of time and frequency are made freely available to all who need them by radio broadcasts from stations WWV and WWVH. The primary standard of the Bureau is a quartz crystal clock operated on the basis of observations of star transits by the U. S. Naval Observatory.

The development of test methods, codes, and specifications are functions that are a natural outgrowth from the custody and maintenance of standards of measurement. Much of the work in this field is done for the General Services Administration and other Federal agencies but both the purchase specifications and the various safety and construction codes that result from the work are widely used by State, county, and municipal governments. In this activity the Bureau works in close collaboration with the A. S. T. M., and A. S. A. and many other national standardizing organizations.

The actual testing of commodities, however, is a service that is rendered only to Federal agencies except in those cases where the Bureau has special facilities that are not available elsewhere.

Because the Bureau covers broadly the field of the physical sciences its staff members are in demand for consultation and advice on many problems. The services rendered may take many forms as illustrated by the current work that is being done at the request of the Conference on a motion picture film showing methods of weights and measures inspection.

While consultative service as such is not available to the public, the Bureau answers many thousands of letters every week about scientific and technical subjects. Many of the inquiries relate to constants and properties of materials and other subjects directly in the Bureau's scope. In order to give the answers economically a variety of circulars and other publications have been issued. Much of the correspondence also relates to subjects that have been investigated by the Bureau so that frequent reference is made to the research papers and other publications which are for sale by the Superintendent of Documents and are provided without charge to depository libraries in the different States.

\section{ELECTROMAGNETIC FLOWMETER}

\section{By C. P. GrIfFIth, Vice President, Bowser, Inc., Fort Wayne, Indiana}

Methods of metering fluids have basically remained static for many years. As a rule, metering devices can be divided into two basic categories, (1) volumetric, and (2) inferential. Volumetric meters are usually some modification of a rotating disk, reciprocating piston, rotary, planetary or oscillating piston, or gear or lobed impeller. As a rule, these are considered positive displacement meters. Inferential meters measure some physical phenomena of the fluid which can be translated, through the necessary intermediary instrumentation, into some function of the quantity of fluid passing through a given pipe. Among these are crifice plates, pitot tubes, area meters, the thermal meters, and others. 
An ideal metering device probably would include the following specifications:

1. Independent of the physical properties of the fluid such as density, viscosity, temperature, etc.

2. Usable over the range of flow rates from zero to the maximum capacity of the meter.

3. Consume no energy from the fluid being metered.

4. Meter with a specified accuracy any substance that can flow through the meter.

5. Have no effect on the liquid being metered.

The electromagnetic mete more closely meets these specifications than any other means of metering liquids that is available at the present time. This new electromagnetic meter constitutes an altogether new approach to the art of liquid measurement.

The principle involved in this new meter comes from Faraday's Law, which states that "A voltage will be induced in any medium when moving through a magnetic field." Dr. Alexander Kolin of Chicago University was the first to suggest the use of this principle for fluid measurement. It is interesting to know that he has used this means to measure the flow of blood in the human body.

Continued research and experimentation has resulted in a commercially accepted instrument for the measurement of liquids.

This meter system consists essentially of a sensing device through which the liquid flows, an electronic amplifier as a means of amplifying the small generated voltage, and suitable means for recording and or indicating the volume of liquid passing through the meter.

The sensing device or portion of this meter that is contacted by the liquid that is being measured is extremely simple and has no moving parts whatever. It can be described as a spool or flow tube installed in the liquid-carrying conduit or pipe line. The internal diameter of this flow tube is the same as that of the pipe line; thus, this measuring device does not in any way restrict the flow. Two electrodes are inserted into the walls of this flow tube diametrically opposite each other. Associated with this flow tube, there is provided suitable means for creating a magnetic field.

The generated voltage measured as a result of the liquid flow is extremely small, and an electronic means is provided to amplify it to a point where it will do useful work. This energy operates, by means of electrical and mechanical components, the recorders, rate of flow indicators, quantitative indicators, or any combination of these indicators that may be required.

It will be in order to make a few general statements as to the types of liquids that can be measured by this meter. All aqueous solutions and most inorganic acids such as hydrochloric, sulfuric, nitric, phosphoric, etc., are sufficiently conductive. Many inorganic soluble salts such as sodium chloride, magnesium chloride, ammonium acetate, calcium sulfate, etc., can be metered successfully. Inorganic basic compounds such as sodium hydroxide, magnesium hydroxide, and potassium hydroxide are sufficiently conductive. Organic compounds may or may not be conductors, depending upon the amount of mixed or dissolved water in the compound. Among such compounds are found alcohols, aldehydes, ketones, aromatic acids, esters, and various other products. 
The electromagnetic meter is applicable to a range of metering problems that cannot be handled economically by existing equipment operating on any of the volumetric or inferential principles. This meter will handle most highly corrosive liquids, abrasives, slurries, liquids with solids in suspension, and a range of liquids which are normally measured under high temperature and high pressure. The simplicity of the metering element lends itself to a wide range of applications where explosion proofing, vapor proofing, high temperature, high pressure, liquid metals metering, and sanitary requirements are specified in a system installation.

Liquids that have a high electrical resistance cannot at this stage of this development be measured by this meter. Petroleum products come under this classification, and this meter is not as yet suitable for these products.

Suitable means are provided for the calibration of these devices.

Testing of these meters is accomplished by means of volumetric proving tanks such as are now used for testing positive displacement meters. Accuracy of measurement over a wide range of flows can be accomplished within your present tolerances for liquid measurement.

In conclusion, it may be well to mention some general facts relative to the electromagnetic meter. The meter handles a wide variety of liquids which cannot be handled by existing equipment. Varying conditions for high temperature and high pressure operation can be accomplished easily. Explosion and vapor proofing, and sanitary requirements can be designed into the unit. There are no moving parts or obstructions in the flow tube. A wide range of flow rates can be handled, the range being limited only to the pipe diameter. Measurement is not affected by the physical properties of the system. The metering element can be installed in almost any portion of the piping system while the indicating equipment can be located remotely, if so required. The system provides versatility of installation with many types of instrumentation available.

(Mr. Griffith's talk was followed by a demonstration of the electromagnetic flowmeter by Mr. Giczewski of Bowser, Inc.)

\section{SURFACE GAGING FARM MILK TANKS}

By W. M. SHanhouse, General Manager, S. S. Hunter, Inc., Syosset, New York

The liquid level indicator was developed primarily for use in the dairy field, specifically for the farm milk tanks and for mixing tanks. The aspects which make it unique are the qualities of simplicity, sanitation, accuracy, low cost, and ease of calibration and use. I believe you will recognize these qualities as I describe the instrument to you.

The essential part of the device is the probe. It consists of a 36inch clear plastic tube, which is non-toxic and non-absorptive. Sealed inside the tube is a scale, calibrated in thirty-seconds of an inch, and electronic equipment suitable for sensing the liquid surface. On the bottom end of the probe are two stainless-steel contact points, and a single terminal connection extends from the top. When assembled, the entire probe is hermetically sealed and cannot be disassembled or tampered with without damaging the tube beyond use.

The base consists of a stainless steel frame, welded to the top of the tank, which supports a magnifying element with a dual hairline refer- 
ence to preclude parallax effects. Affixed to this frame is an indicator light with a detachable electrical lead to the top of the probe. As a safety measure, all current is polarized and maintained below three milliamperes in operation, and below four milliamperes even if shorted. In addition to this, the device is constructed in such a manner that all exposed parts are grounded and no plus potential part can be exposed. Moisture, condensation, water, or complete immersion can harm neither the device nor operating personnel.

The third part is simply a neoprene "umbrella" which serves two functions. It forms a sanitary closure over the tank opening, preventing contamination by condensation, dirt, or insects. The "umbrella" also prevents the probe falling into the tank.

To operate, the sterile probe is inserted into the base, passing through the "umbrella." The pin jack is then pushed into the top of the rod and the instrument is ready for use. The probe is then lowered through the top of the tank until the indicator light flashes. This signifies that the probe has just contacted the top of the milk. At this point, the probe is then adjusted until one-half of the indicator is fully lighted, and the reading is observed. If the indicator is completely unlit, the operator knows he must lower the probe further. If both halves of the indicator light, he must raise the probe until only one-half of the indicator is lit. The reading is then compared with a chart calibrated for the particular tank. The entire operation has taken less than thirty seconds to obtain a clear and precise reading.

How accurate is the liquid level indicator? How sensitive is it? What tests have been performed? The instrument is sensitive to within 1/1000 of an inch, and the differential for surface detection, which can be set during manufacture to any predetermined amount, is normally adjusted to .015 inch. This means that accuracy is dependent solely upon readability. The design of the instrument eliminates any possible inaccuracy due to the meniscus effect of liquids. In actual tests performed, the liquid level indicator can be read within nine fluid ounces on a 100-gallon tank (one-seventh the allowable error) and 35 fluid ounces on a 600-gallon tank (one-fourth the allowable error). On a 500-gallon tank, readings were accurate to the nearest quart.

Does a drop of milk on the end of the probe affect accuracy? It doesn't.

Can the liquid level indicator penetrate foam, that is, can it ascertain the difference between foam and liquid? Yes, by using a very simple and inexpensive accessory which is available to those currently experiencing a problem with foam.

Can the scale be tampered with or changed in any way? No, thereby assuring a fair and accurate reading for both the farmer and the pick-up representative.

Are probes interchangeable? Yes, as all probes are manufactured within a tolerance of $1 / 64$ inch. This means that replacement requires a spot check only, not a complete recalibration of the tank.

Why is it easier to calibrate a tank with the liquid level indicator than with other gaging instruments currently being used? Our instrument will immediately detect cessation of motion due to the unsettled condition of the liquid during calibration. This eliminates the long waiting period otherwise necessary between readings to be certain 
a motionless condition exists. Furthermore, readings can be consecutively taken without removal or re-pouncing of the gage rod. Also, due to the clarity and sharp definition of the reading line, the problem of uncertainty is eliminated.

What is the sanitary advantage of this instrument? No part of the instrument is immersed into the milk. Only the very tip of the probe touches the fluid surface. Also, as many readings as desired can be taken without removing the probe from the tank.

It has been a pleasure to have been able to tell you about the liquid level indicator. We feel we have made a considerable improvement over the existing means of bulk milk measurement. This is attributed to the enthusiastic response with which our device has been received by both the farmers and the pick-up representatives. We do, however, leave it to you to judge its merits in the field.

In closing, I wish to express our appreciation for the extensive aid and outstanding cooperation of the many weights and measures and sanitation officials who have helped us develop our liquid level indicator to its present state.

(During this talk, Mr. Shanhouse demonstrated the S \& D Liquid Lerel Indicator.)

\section{FARM MILK TANK TESTING}

By F. M. Greene, Chief, Division of Weights and Measures, State of Connecticut

Milk producers throughout the nation are showing an almost overnight interest in the new method of handling milk in farm milk tanks.

Interest in the bulk method of cooling and pick-up has increased during the past two years, until now it has caught the interest of dairymen throughout the country. Because bulk milk cooling is on the increase throughout the country, some dairymen may be forced to enlarge their herds.

These farm milk tanks are available with a stainless steel liner or inner tank and either a stainless steel or a painted metal exterior with fiberglass or other insulation between the liner and the metal exterior.

The two common types of farm milk tanks are the direct expansion type in which the tank is cooled by direct contact with refrigerating coils and, secondly, the ice bank type in which water is used as a cooling medium. The refrigerating coils of the ice bank type are submerged in the water and build up reserve cooling capacity in the form of an ice bank. The refrigerating unit is smaller than that of the direct expansion type and is in operation more of the time. The larger refrigerating unit of the direct expansion type uses larger amounts of electric current to operate, but only for shorter periods of time.

The size of the tank to be used depends upon the size of the herd, the location of the farm, and the frequency of the tank-truck pick-up of the milk, which may be picked up every day or every other day. The tank purchased and installed may hold either two or four milkings. The farm milk tank selected should meet the requirements of all reguilating agencies of the State in which it will operate.

For the past several years, farm milk tanks have been calibrated by the field contact men from the dairies and producers' associations. Their equipment consisted of two 5-gallon test measures, similar to 
those used in testing gasoline-dispensing pumps. Some of these measures have bottom drain pipes inserted in the side or bottom, with a valve to close off the outlet when the measure is being filled. Other measures are filled from the top and emptied by pouring the contents. Charts are made up from the readings obtained from the indications shown on the gage rod when inserted into the tank, then withdrawn, and the height of the liquid noted as indicated on the gage rod. The charts show the readings in inches and parts of inches, and, in addition, the quantity in pounds.

Gallonage charts, when furnished by the manufacturer, indicate the volume measured in gallons. Similar charts are also made and compared with the manufacturer's chart by the inspectors from the State Division of Weights and Measures at the time the tests are made at the farm.

To avoid delays at the farm due to a shortage of water during the dry season, each inspector is equipped with a 275 -gallon tank of water on his truck to supplement or supply in entirety, if necessary, the water needed in testing the farm milk tank at the farm.

Farm milk tanks are being installed on producers' farms in the State of Connecticut at the rate of 20 tanks per month or 240 per year. The producers' association, which has about 2,000 members, estimates that, through their method of financing and in other ways, it is expected that for the next five years this schedule of 240 tanks per year will be continued.

To enable our department to test and seal these tanks annually, in addition to our other duties, it has been necessary, since 1951, to give this matter special study. It was necessary that we devise ways and means to accomplish this work with a minimum of time, personnel, and expense, and still obtain accurate results. At the present time we have been able to keep up with the new installations and are reducing the backlog of tanks installed beginning with the year 1950 .

We found that weights and measures officials in other States were either using 5-gallon test measures similar to those used in testing gasoline pumps or were witnessing the work done by field men from the dairies or producers' associations, and then sealing the tanks and charts.

We found also through inspection and study that under this system it was difficult to repeat the tests and obtain the same results. Differences of from $1 / 2$ gallon to 3 gallons in readings were obtained by the same men with the same equipment on the same tank with a time elapse of from 3 months to 9 months between two tests. It was also noted that, in testing a tank with such equipment, errors could be introduced in a number of different ways.

At the rate of 100 gallons per hour, this method requires about six hours to test a 600 -gallon tank. This meant one tank per day. Under this schedule, we could see that it would be impossible to keep up with the work with our staff and equipment. Thus, it seemed necessary that a different means of obtaining more accurate results must be devised.

After several months of experimenting with different methods and pieces of equipment, it was finally decided that the method of withdrawing the water from the tank eliminated the possibility of several errors experienced in the method previously described. After a search 
of the market and some experimenting, a controlled method of withdrawing water accurately in 5- or 10-gallon quantities was perfected. It was found that, with this equipment and properly trained personnel, results easily could be repeated.

We secured from the Seraphin Test Measure Company of Philadelphia two 10-gallon stainless-steel slicker-plate measures with spill collars located at the top of each measure, one-inch outlet valves, and adjustable legs for leveling. These measures empty in 45 seconds plus the standard drainage period. Later we purchased two 5-gallon measures of the same design and material. Through the use of stainless-steel slicker-plate measures, water can be withdrawn through a pump and measured accurately at the rate of 300 gallons per hour. With this method employed, one man can do the work of two. It has become possible to test two tanks at the same time in different locations by assigning one man to each job and equipping him with one 10 -gallon and one 5-gallon measure, tools, charts, and one pump complete with necessary hose, couplings, and check valves.

The tank is filled with water by the producer in advance of the inspector's visit, or if there is a shortage of water in the summer months, water may be supplied by the inspector from a 275 -gallon tank carried on a 1-ton panel truck. An average of two tanks may be tested per day by the use of this method and equipment.

Following is the procedure used in testing a new tank after its installation on the farm and prior to its use by the farmer. The tank is filled with water, either by the farmer in advance of the inspector's visit or by the inspector upon arrival at the farm. A reading is taken at capacity level. Water is pumped into a 5-gallon or 10-gallon stainless-steel slicker-plate measure that has been leveled. The measure is glassed, the faucet opened, and the water in the measure drained completely. The gage rod is powdered with Bon Ami and placed in the tank, with care being taken to seat the rod as prescribed by the manufacturer. The gage rod is then withdrawn and the wet line drawn across the rod noted and recorded. The faucet outlet valve on the measure then is closed and the measure again is refilled as before. This procedure is followed until all of the water has been withdrawn from the tank. The last gallon or two is withdrawn by gravity into a pail and measured to avoid emptying the hose line, which is to be kept full at all times.

Upon completion of the test, the gallonage chart furnished by the manufacturer or the owner is compared with the indications observed during the test and, if found to be correct, it is sealed. If a variance occurs and it becomes necessary to furnish another gallonage chart, one is completed, sealed, and delivered to the owner. The dairy or the producers association may use this chart as a basis for producing a chart reading in pounds.

It has been our experience that flat gage rods with dull finish are more easily read and record more accurately the level of liquid in the tank. Not all these rods have proper brackets in which they are seated when immersed in the liquid in the tank. Gage rods with over an inch sway at the bottom tend to produce erratic readings. Glossy finished rods are difficult to read and have a tendency to produce creep of the liquid on the surface and faulty readings. 
One year later, the same procedure is followed in making a similar test. If at this time a change in calibration is noted and a new chart is necessary, an additional inspection is made to locate the cause for the change. If it is necessary to reposition the tank, another test will be conducted, and, if indications obtained do not agree with those of the chart in use, a new gallonage chart is made and furnished to the owner.

Our experience in testing farm milk tanks indicates that the majority of the charts prepared in the field from tests made by the field contact men of the dairies and producers' associations are inaccurate in excess of the tolerance allowed. Indications have been found to vary from $1 / 2$ gallon to 3 gallons at some points on the chart, and invariably our readings are lower.

We believe our lower indications are the result of the absence of water turbulence, air, or surges in the tank at the time the reading is taken. It is necessary sometimes to wait as long as five minutes for water movement to subside when using the method of adding water to the tank prior to reading the indications on the gage rod. Errors also are caused by improper insertion and withdrawal of the gage rod, the use of improperly designed gage rods and gage rod brackets, and the creeping of water on the stick due to the application of a paste to the stick prior to immersion of the stick into the water.

The absence of leveling devices on the tank has made it difficult to install a tank in level and to observe later any change in the position of the tank. It is suggested that manufacturers of tanks would make their product more acceptable if they would add some of the following needed features:

1. Include spirit levels or leveling lugs on the sides and ends of each tank.

2. Provide methods for insertion of sealers' wire seals in the adjustable legs of the tanks.

3. Inscribe reference points on inside of tank which indicate the capacity filling point of tank. These marks should agree with capacity indications on gage rod and capacity indications on manufacturer's gallonage chart.

4. Furnish with each tank two copies of gallonage chart recorded in 5-gallon increments.

5. Improve the design and method of holding the gage rod stick to enable positive insertion repeatedly in same position without lateral movement of the rod.

6. Remove the glossy finish from the gage rod to reduce the possibility of liquid creeping on the rod and for easier reading.

7. Inscribe graduations on stick in a manner that they may be read easily.

8. Do not have the minimum graduations on the gage rod exceed the tolerance allowed for the volume at any reading on the gage rod.

9. Equip all tanks up to 600 gallons with $1 \frac{1}{2}$-inch outlet valves.

10. Calibrate all tanks when in level position.

Manufacturers' representatives having difficulty in selling their product, which in a few instances costs the producer 10 or 12 percent more than the tank of a competitor, have intimated that they must make a cheaper tank to meet this competition. We are experiencing at the present time a situation where the same two field men recalibrate a tank and obtain a different set of figures than they obtained one or two years ago. In many instances they attribute the difference to distortion of the tank occurring through its use over a period of time. We have been unable to prove this, as we must wait several more months before recalibrating new tanks completed in 1953. If at this 
time we find differences which cannot be accounted for in other ways, the manufacturers of the tank will be asked to produce the answer.

We are granting only tentative approval for the use or sale of farm milk tanks in Connecticut, and it is necessary that tank manufacturers obtain such an approval in advance of sale or use; otherwise their tanks may be condemned at time of installation.

It becomes the responsibility of the weights and measures officials to make sure of the proper construction of farm milk tanks. The tanks must be sufficiently stable that they will not distort under any conditions of lading. I do not believe we have been as careful as we should have been in our examination of the rigidity of these tanks.

(On Wednesday afternoon Mr. Greene demonstrated the calibration of farm milk tanks as described in his paper.)

(The Conference was adjourned, to reconvene at 10:00 a. m., Thursday, May 20,1954 .)

(During the afternoon of Wednesday, May 19, informal tours of the laboratories of the National Bureau of Standards were participated in by the delegates. Also during the afternoon an informal symposium on measuring liquefied petroleum gases was held on the Bureau grounds under the direction of Messrs. Bean, Eisemann, and Weaver of the Bureau staff. Following these discussions, some of the delegates were transported to Rockville, Maryland, where were demonstrated two methods of testing liquid meters dispensing LPG. A motion picture, in color and with sound, was shown to a group of the delegates by Mr. J. Ellis Bowen. This film depicted the various activities of a local weights and measures official.)

(On the evening of Wednesday, May 19, an informal party was held at the Sheraton-Park Hotel, the Conference headquarters, for those attending the Conference.)

\section{Fourth Session-Morning of Thursday, May 20, 1954}

(F. M. Greene, Vice President, Presiding)

\section{REPORT OF THE COMMITTEE ON LEGISLATION, PRESENTED BY M. A. NELSON, CHAIRMAN}

The Committee on Legislation met on the morning of May 17 with representatives of industry and others interested in legislation. The following items were discussed.

1. Uniform Weight Certificates for Movement of Household Goods by the Armed Forces-Representatives of the Department of Defense, including all branches of the Armed Forces, stated that they had a problem in obtaining proper certified net weights in connection with the transportation of household goods, etc.

Upon their suggestion that a uniform certificate of weight be established, the truck companies took exception for various reasons, among them that laws in certain States would prohibit licensed weighmen from making out such certified weight certificates. The Committee knew of no such State laws. This committee from the Department of Defense was commended upon their plan to draft a uniform certificate of weight showing the gross, tare, and net weights, and were advised by the Committee on Legislation to submit this draft to Mr. W. S. Bussey, Chief of the Office of Weights and Measures, for his constructive criticism.

It is the recommendation of this Committee that all weights and measures departments-State and local-cooperate with the Armed Forces in assisting them to secure proper certified weight certificates. 
2. Quantity Statements on Cans and Packages of Tobacco.-A representative of the Internal Revenue Service, Mr. Norman T. Morsell, stated that the bill which would change the method of taxing tobacco in the issuing of stamps for that purpose has passed the House of Representatives and is now in the Finance Committee of the Senate. This bill, if enacted, would not be effective before January 1, 1955 . The bill would provide for the Secretary of the Treasury to promulgate regulations governing the statement of net contents on packages of tobacco.

It is the recommendation of this Committee (a) that no action be taken at this time relative to the labeling of package tobacco and (b) that recommendations to the Alcohol and Tobacco Tax Division be made that regulations be promulgated to require a statement of the net quantity.

3. Amendment to the Model Law to Cover Special Labeling on Random-Size Packages.-

The Committee recommends that no amendment to the Model Law to cover special labeling on random size packages be approved. This recommendation is made because the Committee does not feel that it is practical at this time.

However, after the formal meeting of the Committee, the following suggestion has been submitted. It is being presented to the Conference for their further study, without any Committee recommendation.

That the Model Law be amended as follows:

Sec. 19a. Same: Declarations on Random Packages.-That in addition to the declarations required by Section 19 of this act, any commodity in package form, the package being one of a lot containing random weights, measures, or counts of the same commodity and bearing the total selling price of the package, shall bear on the outside of the package a plain and conspicuous declaration of the price per unit of weight, measure, or count.

4. Proposed State Law on Liquefied Petroleum Gas as Adopted by the Council of State Governments.-The Committee does not feel that the proposed State law on liquefied petroleum gas as adopted by the Council of State Governments would infringe upon the rights and duties of weights and measures officials to check liquefied petroleum gas meters. Meter manufacturers now seal new meters leaving their plants. A similar situation should exist with the manufacturers of liquefied petroleum gas meters.

The Committee does, however, feel that any effort to legalize the seals used by manufacturers should be resisted.

The Committee recommends that seals of approval should be applied only by an authorized weights and measures official after a competent test has indicated that the device is accurate.

5. Standardization of Prepackaged Commodities.-Relative to the standardization of prepackaged commodities, the Committee feels that such standardization is desirable, but that the standardization program can best be worked out with the individual industries concerned rather than attempting an orer-all standardization program. No recommendations are being made at this time on the standardization of packages for prepackaged commodities.

(The Report of the Committee on Legislation was adopted by the Conference.) 


\section{LPG METER TESTING IN MIAMI, FLORIDA}

\section{By H. E. How ARD, Supervisor, Division of Weights and Measures, Miami, Florida}

The problem of testing equipment and procedures for liquidmeasuring devices dispensing liquefied petroleum gases (LPG) has been before the National Conference many times and as early as the 30th Conference in 1940. In Miami, Florida, we first started studying this problem seriously after the 35th National Conference in 1950, when we heard Mr. J. E. Brenton discuss the situation in California.

Up until that time, we in Miami, Florida, had been studying and experimenting and had concluded that, in any gravimetric method of meter testing, the two primary factors are specific gravity and temperature. We decided to effectuate the following testing procedure: (1) determine the temperature of LPG being delivered through the meter under test, (2) obtain the specific gravity of the liquid from the bills of lading on tank car shipments, and (3) apply correction factors io determine what the LPG should weigh and compare with the actual weight of the meter determination.

We learned that the laboratory analyses listed by shippers were fairly accurate.

About that time we decided to look into the feasibility of testing LPG meters at public service stations. It then became necessary to develop portable equipment and to arrive at an understandable definition of "specific gravity." First we decided that the specific gravity of a given liquid may be said to be the ratio of a given volume of that liquid to a like volume of distilled water at some standard temperature. This definition introduced the need for accurate determinations of three things, (1) volume, (2) weight, and (3) temperature.

For our volume standard we designed and had constructed a "specific-gravity standard" which is a container with a capacity of one gallon, calibrated to an accuracy of 0.2 per cent or two drams of volume. It is equipped with a "multivalve" which includes (1) a back pressure intake valve, (2) a safety valve (215 pounds), (3) a bleeder valve, and (4) an outlet shutoff valve. Accurate temperature determinations are made available through the use of an immersion-type thermometer set in the specific-gravity standard.

For accurate weight determinations we procured a bench-type beam scale, 300-pound capacity with a 3-pound fractional beam with $1 / 4$-ounce graduations, and a counter-type beam scale, 22 -pound capacity with a fractional beam with $1 / 4$-ounce graduations.

It also was necessary to design report forms and conversion charts.

Thus we had a 1-gallon standard measure which we could use to isolate 1 gallon of LPG and to make possible accurate temperature determinations. Then, by applying the temperature correction factor, the weight of 1 gallon of LPG could be adjusted to $60^{\circ} \mathrm{F}$. Based on our definition of specific gravity, we could divide this corrected weight by 8.32823 (the weight of 1 gallon of distilled water at $60^{\circ} \mathrm{F}$. and in air) and arrive at the specific gravity of the LPG passing through the meter.

Using our special equipment and an empty tank or cylinder (readily obtainable at LPG warehouses and storage plants), we are able to conduct a 20-gallon test on a LPG liquid meter as follows : 
1. Connect inlet of one gallon standard to outlet of meter under test.

2. Connect outlet of one-gallon standard to inlet of empty cylinder.

3. To fill the one-gallon standard and purge cylinder of air, pump about two gallons of LPG through the system.

4. Disconnect and weigh cylinder to establish tare weight.

5. Reconnect system as before and pump desired gallonage through the meter under test.

6. Disconnect and weigh cylinder to establish gross weight.

7. Disconnect and weigh one-gallon standard and record weight and indicated temperature.

8. Consult conversion tables for corrected weight per gallon.

9 . Compute weight of meter delivery by multiplying meter reading by corrected weight per gallon.

10. Determine difference between result obtained in step 9 and net weight of liquid in cylinder-This is the meter error expressed in terms of weight.

The foregoing procedure can be followed either at a bulk plant or in retail service stations.

\section{REPORT OF THE COMMITTEE ON TRADING BY WEIGHT, PRESENTED BY J. F. TRUE, CHAIRMAN}

The Committee on Trading by TVeight has encouraged all State agencies to promote trading by weight rather than by the bushel.

This is an old question. We find that it was considered by the Chicago Board of Trade as far back as 1867. We are encouraged that the movement is gaining ground. In most jurisdictions there are many legal weights per bushel of various grains and seeds; yet practically all of these commodities are sold by weight and a good dea] of it is even advertised by weight with no mention of the bushel.

The Southern Weights and Measures Association is proposing a revised constitution and by-laws that provide for a Committee on Trading by Weight. WVe hope that positive action will be taken at the next meeting of the association.

It is hoped that all of the State and regional weights and measures associations or sealers' associations will consider the problem of trading by weight rather than by the bushel.

We recommend that all States review their State laws and see if it would be possible to remove the legal weights per bushel for a number of items which are now sold by weight. This might be an entering wedge to remove bushel weights from all commodities.

It has' been called to our attention, as well as to the attention of the Committee on Methods of Sale of Commodities, that small seeds are often sold by measure, using a graduated flask in connection with a chart, to determine avoirdupois weight by dry measure. This may fall in the category of the Committee on Methods of Sale of Commodities rather than in the category of this Committee, but we do want to call it to the attention of the Conference because we feel that it is entirely wrong and should be outlawed by all jurisdictions.

(The report of the Committee on Trading by Weight was adopted by the Conference.)

H. R. 8357-TO AMEND U. S. STANDARD CONTAINER ACT OF 1928

(See also pages 60,89 , and 91 )

Mr. BLICKLeY: I have read in the newspapers of a proposed amendment to the U. S. Standard Container Act of 1928. This amendment 
would include as a standard container the $3 / 8$-bushel hamper and round stave basket. I would recommend that this Conference go on record as condemning such action. I believe the best method would be for the Conference Resolutions Committee to bring forth a resolution in opposition to the enactment of this amendment. A copy of the resolution should be sent to the Speaker of the House, the President pro tem of the Senate, and the President of the United States.

(At this point a motion was introduced by Mr. Crawford and seconded by Mr. Blickley to the effect that the Conference go on record as opposed to the passage by the Congress of House Bill H. R. 8357.)

Mr. Greene: Mr. Bussey has made the suggestion that this matter be referred to the Conference Resolutions Committee, where it can be studied and a resolution, if appropriate, be drawn up and presented for Conference action.

(The original motion was withdrawn by the maker and the seconder, and a motion was introduced by Mr. Crawford, seconded by Mr. Blickley, and adopted by the Conference to the effect that the matter of the proposed amendment to the U. S. Standard Container Act of 1928 be referred to the Conference Resolutions Committee.)

Chatrman Greene: It would be my recommendation that each member of this Conference make effort to contact the office of his Senator and to voice opposition to this amendment.

Mr. Busser: I know that this body wants to be deliberate in its actions and to be sure before any official action is taken as to recommendations to the Congress. I would commend the Conference on its objective viewpoint as demonstrated in this discussion. I might suggest that the Chairman of the Resolutions Committee contact and have discussions with representatives of the U. S. Department of Agriculture and others who might have interests in the matter. We shall be pleased to be of assistance.

Mr. Whittington: Could Mr. Bussey advise us as to whether or not contact was made with the National Bureau of Standards by the Congress prior to action on this amendment?

Mr. Busser: I do not recall any direct contact with the Congress concerning this matter. The Department of Commerce requested the Director, National Bureau of Standards, for his opinion on the amendment. At that time we discussed the matter with officials of the U.S. Department of Agriculture. We learned that the Department of Agriculture was not sponsoring the amendment, neither were they opposing it.

\section{PROGRESS REPORT ON LPG METER TESTING}

By L. L. KenNedy, Chairman, Weights and Measures Committee, American Petroleum Institute, Elizabeth, New Jersey.

This is the second time I have had the honor of addressing the $\mathrm{Na}$ tional Conference on Weights and Measures. I have derived great pleasure from attending these conferences for a long number of years. I have seen the problems with which you have been faced grow in magnitude and complexity. I have seen you collectively and individually cope with such problems and successfully overcome them to the satisfaction of all concerned. 
The last paper I presented here covered the same general topic I want to discuss with you further today. Before I get into that I would like to take a little time to brief you on the function of the American Petroleum Institute and explain the part the A. P. I. Committee on Weights and Measures plays in direct connection with the several sealers, city, county, and State and the National Bureau of Standards.

The American Petroleum Institute, incorporated in the District of Columbia, is an association of some seven or eight thousand oilmen. It is the oilman's forum, information bureau, technical clearing house, and national trade association.

The objects of the Institute as stated in its charter are (1) to afford a means of cooperation with the government in all matters of national concern, (2) to foster foreign and domestic trade in American petroleum products, (3) to promote, in general, the interest of the petroleum industry in all its branches, and (4) to promote the mutual improvements of its members in the study of the arts and sciences connected with the petroleum industry.

There are four main divisions of the Institute, namely, Production, Refining, Marketing, and Transportation.

Who does the work of the American Petroleum Institute? The major part of the Institute's work is done by volunteer oilmen through its hundreds of working committees and subcommittees, whose membership, incidentally, totals several thousands. In general, the Institute assigns to a working or functional committee no activity unless it has previously been proposed and urged by a group of oilmen who are interested in the problem or the subject matter, and unless substantial sentiment for the activity has developed within the industry. If, for instance, a project is approved, a committee of experts from the oil industry is set up. Once the committee is set up and subcommittees have been appointed, they remain in existence until there is no longer any need for them, then they are disbanded. However, members of any committee must annually be elected and appointed so as to avoid continuance of inactive groups.

I do not have time to outline the scope of all the activities of the Institute. However, broadly speaking, it enters into the field of standardization, design, care, and correct practices in use of equipment, engineering, and technology ; fundamental research, safety, and fire protection; protection of petroleum facilities; waste disposal; testing methods and specifications; measuring; sampling; etc.

Now, as I said, committees are formed only when there has previously been substantial sentiment for the activity. This particular situation occurred when, as all of you will recall, the Southern Weights and Measures Association made a formal proposal to the National Conference through the Committee on Specifications and Tolerances that the tolerance on retail gasoline pumps be reduced. A temporary A. P. I. Committee was hurriedly formed to work with the National Conference in studying this proposal. Since then our Weights and Measures Committee has been set up on a permanent basis.

So that you might know the extent of this committee, its scope, and the area that it covers, I would like to take time here to name the members of the committee and the companies that they represent. 
They are not, I might say, in the clerical bracket of their companies. 'They are men who can make decisions in committee meetings and their companies will stand by these decisions. The committee includes M. M. Beckes, Socony-Vacuum; K. W. Birkin, Sinclair: Harold Cooper, Union Oil Company, California; R. G. Emmett, Pure Oil; W. T. Brown, Shell Oil; Carl Helston, City Service; R. W. Hird; Continental; William Keen, Atlantic Refining; Bill McCoy, Gulf; H. A. McKim, Standard Oil Company, California; Maurice Parker, Central-West Oil Corporation; R. H. Tolson, Texas Company; H. F. Utzerath, Standard Oil Company, Indiana, and F. J. Heller, Phillips Petroleum Company, Bartlesville, Oklahoma. You can see that the committee is representative of the oil industry in the United States.

As far as the scope of the committee is concerned, we are now charged with the responsibility for development and liaison between the oil industry and weights and measures officials. We naturally, as a committee, cannot undertake to handle individual problems. Such problems should be handled at the local level. We believe the oil industry is now more aware of the value of closer contact with the local sealers. If a local problem develops into one of great magnitude, we would appreciate advice to that effect. By this method both the sealers and industry can preclude the possibility of undesirable legislation being placed in the State or other statutes.

In the short time of the committee's existence, we believe we have solved amicably and to mutual satisfaction some problems which had been of long standing between your Conference and our committee. I am sure we can go forward along that same line.

Now we come to the question which has been a real tough one-the proving of LPG liquid-metering systems. Your Specifications and Tolerances Committee and our A. P. I. Weights and Measures Committee, have been working diligently on the problem for over a year.

It is extremely difficult for an industry with as many different companies as the petroleum industry to coordinate a problem of the magnitude of the one we were faced with. A tremendous amount of effort on the part of a great number of people is involved. Many groups and subgroups must be set up and put into action, and many meetings held. Correspondence on the matter in my file alone is quite voluminous'. Suffice it to say without going into any detail of the workings of all involved, we, the representatives of the American Petroleum Institute, are happy to report that just yesterday at Denver, the Institute's Division of Marketing voted that it is both proper and necessary for the A.P. I. to participate in sponsoring a research project to develop inexpensive, simple, and accurate methods for testing LPG metering systems. The Liquefied Petroleum Gas Association and the meter manufacturers probably will be invited to participate. And, of course, the proper representatives of this Conference will be consulted so that we may have the benefit of their knowledge and experience in the conduct of this research project.

When this Conference meets again next May, it is my hope that you will have a report from the petroleum industry that the research project is well under way and that substantial progress' has been made in the direction of a solution to this perplexing problem. 


\section{SPECIAL TEST FOR VEHICLE TANK METERS}

By J. A. Parron, Assistant Sealer of Weights and Measures, Norfolk, Virginia. (Presented by 0. T. Almarode, State Inspector, State of Virginia.)

National Bureau of Standards Handbook 44, Specifications, Tolerances, and Regulations for Commercial Weighing, and Measuring Devices, in N. 2.1. of the code for vehicle tanks equipped with meters, requires, among other things, that "Special' tests, to develop the operating characteristics of a meter and the operating elements associated therewith, shall be made as circumstances require ..."

During the past six months, O. T. Almarode, State Weights and Measures Inspector, and I have been conducting an extensive survey in Norfolk, Virginia, on meters installed on vehicle tanks equipped with manifolds. During these tests we used a 100-gallon portable prover. This survey has been especially directed to the "special" tests. Based on NBS Handbooks 44 and 45 , we have conducted three types of "special" tests during the testing of some 184 vehicle-tank meters.

1. Slow Test.-Meter discharge rate controlled at the hose nozzle to 15 gallons per minute for a meter smaller than two inches in rated size, and to $20 \%$ of the marked maximum rate for a meter two inches and over in rated size. Meters marked with a lower minimum rate are so tested.

2. Air Eliminator Test.-This test was begun with the supply line coming from a compartment containing approximately 50 gallons of liquid. After the compartment had been pumped dry and the meter had ceased to operate, the empty compartment line was closed, the line to a full compartment was opened simultaneously, and the test run continued.

3. Valve Tests.- (a) After the system was completely full, about 10 gallons of product were delivered into the prover from a full compartment. The valve leading from the full compartment was closed and a line from an empty compartment opened fully. This would shut off the supply of liquid and admit a full supply of air to the meter. At this point, the valve in the line to the full compartment was opened slightly and the empty compartment valve was left fully open.

This procedure introduced, by comparison, more air than product, caused wide emulsification, and deprived the meter of its normal supply of liquid. The flow through the meter obviously was reduced.

The meter was allowed to operate in this manner until approximately 75 gallons, or in some cases the full 100 gallons, were indicated.

(b) Another special valve test conducted during the survey started with a compartment containing approximately 50 gallons of product. The contents of this compartment were pumped through the meter and into the prover-until the supply was exhausted. The valve in the line to the empty compartment was left wide open while the valve to a full compartment was opened fully to supply product to complete the 100-gallon test run.

Of the 40 meters given these special valve tests, not one was found to perform within the special test tolerance, and errors ranged up to 20 gallons overregistration on a 100-gallon test.

Although the results of these special tests were quite surprising to us, we learned later that meter manufacturers have been aware of the situation for a long time. In some instances the meter sales 
literature has recommended the installation of selector-type valves in manifold systems.

Mr. McBrIDE : Speaking particularly in relation to the selector-type valves, we first looked into the problem back in the 1930's. On a vehicle tank the several compartments lead into a manifold, thence into a common line and through the meter. At that time delivery of fuel oil through a meter for retail sales was a problem new to the industry and to weights and measures officials. We conducted a number of experiments similar to the crack-valve test described in the preceding paper. It was our experience that widely different volumes resulted. Our final solution was a requirement that a selector control be installed, either a series of valves or a three-way plug-type valve. The effect of that type installation was that the liquid could be drawn only from one compartment at a time, because the valve could be opened from only one compartment at a time. With this installation you eliminate the possibility of having more than one compartment open and leading to the meter at the same time.

Chairman Greene: In Connecticut we have run a number of tests similar to those described by Mr. Parron. These tests have been made both on pump-operated meters and on gravity meters. Our experience has been that large errors will be found, especially on gravity installations, when tests of this nature are performed.

Mr. Thompson (Virginia) : I would like to know how many States do require selector-type valves on these manifold hookups.

(The Chairman requested a show of hands.)

Chairman Greene: The show of hands has indicated that selectortype valves are required in the States of California, Massachusetts, New Jersey, and Pennsylvania.

Mr. Smith (New Jersey): I believe the tests described by Mr. Parron are proper. Meters that will not perform within the allowable tolerances when tested in this manner should be rejected.

Mr. Wenmann: I think many of you will agree that this is not specifically a problem of meter inaccuracy. It is a problem of the complete installation.

\section{REPORT OF SPECIAL FLOUR COMMITTEE, PRESENTED BY J. P. McBRIDE, CHAIRMAN}

At the 38th National Conference on Weights and Measures, a paper was presented by Mr. Herman Fakler of the Millers' National Federation entitled "Flour Weights." This paper went into some detail on the whole problem of flour weights and contained four specific recommendations looking toward uniform practice in the 48 States and requested that the Conference appoint a special committee to consider these proposals and make a report thereon at the 39th National Conference. The recommendations made were as follows:

1. Concentrate check-weighing of flour at primary points of distribution where large quantities of flour are available. Mill, wholesale, and chain warehouses, and other jobbing outlets are examples.

2 . Follow the Federal regulations and procedures, and make allowance for reasonable weight variations.

3. Arrange to obtain accurate moisture analyses of representative samples of any questioned flour stocks.

4. Promptly notify the mill involved when the weight of its flour stocks is questioned. 
The Conference response was a vote to have the President of the Conference designate a committee made up of three weights and measures officials, one of whom to be chairman of the committee, three representatives of the milling industry to be selected by the Millers' National Federation, a representative of the Federal Food and Drug Administration, and Chief of the Office of Weights and Measures, National Bureau of Standards, the latter two designated as consultants to this committee, to report back with specific recommendations to the 39th National Conference. This committee was organized and immediately commenced its work by interchange of correspondence and sent out a circular letter to weights and measures officials throughout the country, soliciting information and comments on this problem. The same request was incorporated in news letters of weights and measures associations. As a result of this request, varying opinions were received from the weights and measures officials, ranging from no allowance for moisture loss, overage in packaging in anticipation of moisture loss and for compensation thereof, cognizance being taken of moisture loss by marking on the containers moisture content at the time of packing, and fixation of maximum moisture content.

The Committee held a meeting on February 25, 1954, which included a visit to one of the principal flour mills and observations were made in relation to the method of original weighing, spot-check weighing, and packaging, as well as to moisture-content determinations. The various submitted suggestions, recommendations, and test runs which included moisture-test determinations, some of which showed errors were due to causes other than moisture loss, were considered. 'The most provocative feature of this commodity, however, is the so-called moisture variation due to the hygroscopic nature of flour. Over the years, adequate study has been made on this phase and data in relation thereto has been presented to several Conferences. The Committee felt that it had no specific function in relation to this phase, as this is an already-established fact, and our efforts in this direction would be repetitious and serve no purpose. Your Committee therefore took as its basis of operation, consideration of the four procedural recommendations hereinbefore referred to.

A further request was sent out to the weights and measures officials for supporting data in the form of tests, including moisture-content runs, and response to this was very good in volume of material from the States participating. This work represented thousands of reweighings of all sizes of flour packages in the individual States. For this cooperative work on behalf of those interested States, your Committee is deeply appreciative. However, less than half the questionnaires sent out were returned, and your Committee feels that the cross section represented by the replies was not truly representative of the entire country. Additional phases of the subject were also introduced in this subsequent survey, all of which leads your Committee to the conclusion that, in all equity, further study of the problem must be made. To this end, we have enlisted the support of the Statistical Engineering Laboratory of the National Bureau of Standards, which agency has cooperated with the Conference on previous occasions, and it is respectfully requested that this Committee be continued for another year to afford opportunity for further exploration of the problem. We do, however, point out that this Conference adopted 
at its 38th meeting, on recommendation of your Legislative Committee, a Model State Regulation governing commodities in package form, the pertinent parts of which, in relation to this question, are as follows :

Variations from the stated weight or measure shall be permitted when caused by ordinary and customary exposure, after the commodity is sold and delivered by the manufacturer, packer, or distributor, to conditions which normally occur in good distribution practice and which unaroidably result in change of weight or measure.

This factor should, therefore, receive consideration in your reweighings of flour during the interim period pending the final report of your Committee.

(A motion was made, seconded, and adopted to the effect that the Special Flour Committee be continued for 1 year.)

\section{REMARKS OF C. D. BAUCOM, NORTH CAROLINA}

Mr. Chairman, I have a matter that I would like to bring to your attention. This matter has to do with graduating the indicating elements of scales in tenth pounds. It is a fact that we now are dividing the gallon into tenths on computing gasoline pumps. I believe that soon we likewise will be dividing pounds into tenths. Such division is simple of application, it also reduces the machinery required in the manufacture of a computing or printing mechanism. I recommend that we prepare our laws and regulations so that they will not be stumbling blocks when manufacturers of scales have developed the mechanisms to indicate in tenth pounds and submultiples of tenth pounds. Therefore, I have prepared a rough draft resolution which I will refer to the Conference Resolutions Committee.

Some of you hare had the privilege of inspecting some of the new ticket printing computing scales. They require a manual transfer of figures from the indicating element of the scale to a keyboard similar to those on typewriters or comptometers, and, in that transfer, there is always the possibility of the human error. I believe it will be possible to manufacture completely automatic, ticket-printing computing scales through the use of tenth pounds.

(The Conference was recessed until 2 p. m.)

\section{Fifth Session-Afternoon of Thursday, May 20, 1954}

(J. A. BorLe, Vice President, Presiding)

\section{H. R. 8357-TO AMEND U. S. STANDARD CONTAINER ACT OF 1928}

(See also pages 53,89 , and 91 )

Chairmax Boyle: In compliance with the action of this Conference, through its Committee on Resolutions, W. A. Kerlin of Alameda County, California and H. C. Hulshoff of Niagara County, New York have left the meeting in order to appear before the Committee of the Senate that is considering the Bill to add the three-eighths-bushel hampers and round-stave baskets to the Standard Container Act. 


\title{
REPORT OF THE NATIONAL CONFERENCE COMMITTEE ON NOMINA- TIONS, PRESEN'TED BY J. T. KENNEDY, CHAIRMAN, AND ELECTION OF OFFICERS
}

The Nominating Committee presented the following motion which was adopted by the Conference: "That there be created under the heading of 'Officers' a Chaplain of the National Conference on Weights and Measures and that such Chaplain be nominated and elected in the same manner as other officers."

The Committee submitted the following nominations for office in the National Conference to serve during the ensuing year, or until such time as their successors are elected.

\section{OFFICERS}

For President: A. V. Astrn, Director, National Bureau of Standards.

For Vice Presidents: IV. L. DANiels, of Seattle, Washington; G. L. JoHnson, of Kentucky; J. Roy Jones, of South Carolina ; C. A. Lyon, of New Hampshire ; A. O. Oslund, of Union City, New Jersey ; J. W. ReEse, of Iowa.

For Secretary: W. S. Bussey, National Bureau of Standards.

For Treasurer: G. F. Austin, Jr., of Detroit, Michigan.

For Chaplain: R. W. SEARLes, of Medina County, Ohio.

For members of the Executive Committee: C. D. BAucom, of North Carolina; T. C. Beck, of Oklahoma; J. M. Dietz, of Union County, New Jersey ; M. M. EMmrick, of Illinois; E. R. Fisher, of Rhode Island; J. T. HARPER, of Terre Haute, Indiana ; H. C. Hulshoff, of Niagara County, New York; ElviN LeEMAN, of Wyoming; W. F. MAsinda, of Tolland County, Connecticut; A. J. MAYER, of Louisiana; C. C. MUNDY, of Richmond, Virginia; M. O. NICKon, of Dearborn, Michigan; W. E. G. RherN, of Cincinnati, Ohio; W. B. SteELE, of Oregon; A. M. Thomas, of Montgomery County, Maryland.

\author{
(Signed) J. T. KenneDY, Chairman, \\ J. A. BERNARD, \\ V. D. CAMPBELL, \\ H. E. CRAWFORD, \\ J. P. LEONARD, \\ I. M. LEVY, \\ J. F. True, \\ Committee on Nominations.
}

(The report of the Committee on Nominations was adopted and the officers were elected unanimously.)

\section{REPORT OF THE COMMITTEE ON ME'THODS OF SALE OF COMMODI- TIES, PRESENTED BY J. E. BRENTON, ACTING CHAIRMAN (J. G. ROGERS, CHAIRMAN)}

Your Committee on Methods of Sale of Commodities submits its report to this Conference. As has been stated before in our reports, uniform laws, uniform interpretation, and uniform inspection procedures are not only desirable, but they are essential in our weights and measures work. This can only be accomplished through the cooperation of industry as may be concerned, the public, and weights and measures officials. The cooperation of industry, and the understanding and realization on the part of the public, concerning the important part weights and measures occupy in everyday life has been very good and is increasing each year.

The following items are presented for your consideration and such action as the Conference may deem appropriate.

1. Liquid Fertilizer.-A liquid fertilizer that does not have at $80^{\circ} \mathrm{F}$ a pressure exceeding one atmosphere pressure may be sold by either weight or volume. 
2. Seeds.-Shall be sold by net weight, and when in package form with contents exceeding $1 / 4$ avoirdupois ounce, the net quantity shall be declared on the container together with the identification of the producer or packer.

Mr. LyoN: Would there be any possibility that some seeds might better be sold by count?

Mr. Brenton: It is our specific recommendation that seeds be sold by net weight.

Mr. R. E. MeEK: There is a very serious danger in selling seeds by the count. I do not think that we would object to a dozen or so seeds being sold by count, but there always is a possibility that some one might want to sell several hundred or several thousand. I certainly do not believe it is reasonable to expect weights and measures officials to count that number of seeds.

Mr. Busser: It is the recommendation of the Committee that seeds in package form be sold by weight. This would not prohibit a supplemental statement giving the number of seeds in the individual package; however, if the package contains $1 / 4$ ounce or more, the net weight must be declared thereon. Packages containing less than $1 / 4$ ounce would come in the same category as certain small packages of other commodities and the quantity statement would not be required. If the statement of quantity appeared on a package containing less than $1 / 4$ ounce of seeds, the labeling laws would require that such statement be accurate.

3. Sale of Seed, Using a Graduated Flask.-It is the opinion of the Committee that, due to the variable weight and character of seed, the use of a graduated flask or other capacity measure for the purpose of determining the weight of seed is most certainly not consistent with good weights and measures principle and should not be condoned as a commercial practice.

4. Sale of Meat by the Piece.-It is the Committee's unanimous opinion that meat should be sold by net weight, meaning the actual weight at the time of transfer of custody, and frowns upon any statement to the contrary.

Mr. R. W. Searles: I would like to have this Conference go on record regarding a statement found on most invoices from meat packers. This statement stipulates that certain meats shall be sold by gross weight. I am sure we all agree that we cannot permit a retail meat dealer to wrap meat and then weigh and price the wrapped item. Why then should we permit the meat packers to sell to the retail distributor by gross weight? The meat packers have stated that this printed statement appearing on the invoice constitutes a contract; however, some courts have held that private contracts cannot be made contrary to existing law. Other courts have ruled otherwise.

Mr. Greene : It has been the interpretation of the Attorney General of Connecticut that no private contract can circumvent any law in the State.

Mr. McBride: It would be my recommendation that this matter be referred by Mr. Searles to the Conference Resolutions Committee.

5. Gear Lubricants.-When sold on the retail level and delivered directly to the transmission or differential of an automotive vehicle, shall be sold by volume, the quantity to be determined by a mechanically operated devico approved, inspected, and sealed by a weights and measures official.

When sold in package form, the gear lubricant may be sold either by volume or by weight, providing, however, that the container shall bear thereon a clear, legible statement identifying the net quantity as contained therein. 
6. Cedar Closet Lining in Package Form.-It is the recommendation of the Committee that the statement of quantity should identify the actual area of coverage of the cedar closet lining as may be contained in individual containers.

7. Hickory Wood Chips.-It is the recommendation of the Committee that hickory wood chips shall be sold on the basis of net weight.

8. Peat Moss.-It is the recommendation of the Committee that peat moss shall be sold on a basis of cubical content and containers shall be marked in terms of cubic feet or cubic inches. There shall be an allowable tolerance in excess or deficiency not to exceed $3 \%$ of the stated package volume. Packages of peat moss shall be marked with the name and address of the producer or packer. It is also our recommendation that packages containing in excess of $1 / 10$ of a cubic foot of peat moss shall be packed with a compression ratio of not less than 2 to 1.

Mr. Blickley : It would be my recommendation that the Committee report on this item be amended by adding at the end thereof the following sentence: "It is our recommendation that, when the contents of a package is less than one cubic foot, the statement of quantity silall be in terms of cubic inches." I so move.

(This motion was accepted by the Acting Chairman of the Committee, was seconded, and was adopted by the Conference.)

Mr. J. T. KenNeDY: I am interested in learning the process for determining the 2 to 1 compression ratio as stated in this recommendation of the Committee.

Mr. Brenton: The compression ratio is suggested by the Committee because peat moss can be "fluffed up" and statements of volume made meaningless.

9. Acetylene Gas in Cylinders.-It is the recommendation of this Committee that acetylene gas shall be sold by net weight or by cubic foot. However, there suall be attached to the cylinder a tag on which there shall be placed the weight of the cylinder before charging and the weight of the cylinder after charging, and the number of cubic feet per pound.

10. The Fractional Terms of Ounces.-When used in connection with the quantity determination on commodities in packåge form, shall be in elements of the ounce divisible by the number two (2) or a power of the number 2 .

NoTE.-The purpose of this recommendation is to prohibit the use of odd fractions such as, for example, the $1 / 3$ of an ounce.

11. Preheated Fuel Oils.-Following the specification recommendation as submitted in the report as presented during the 38th National Conference on Weights and Measures, it is the Committee's recommendation that preheated fuel oils shall be sold by net weight or by volumetric measurement based on the U. S. standard gallon of 231 cubic inches, its multiples and binary submultiples. The measurement shall be corrected to $60^{\circ} \mathrm{F}$., utilizing Table 6 , as published by the American Society for Testing Materials.

12. Liners in Ice Cream Containers.-The Committee inspected containers including liners intended for factory-packed ice cream, and it is the opinion that the use of such liners does not constitute any violation of current weights and measures laws or regulations.

13. Stationery and Envelopes.-It has been brought to the attention of the Committee that there have been instances in connection with the sale of stationery and envelopes in package form where the numerical count has been decreased through the removal of a portion of the contents. Notwithstanding the fact that the package was remarked, such practice is not condoned by this Committee.

14. The Value of Net Weight.-It is the unanimous opinion of the Committee, and we urge each and every one of you to exercise strict local supervision in maintaining the unquestioned value of net weight in designating the quantity of contents as may be contained in the package or wrapping.

(In its tentative report the Committee requested information and expressions of opinion on the sale of meat and poultry in plastic wrappings and casings.)

(The report of the Committee on Methods of Sale of Commodities, as amended, was adopted by the Conference.) 


\section{FABRIC-MEASURING DEVICES}

By F. M. RAYMund, Assistant County Sealer of Weights and Measures, Los Angeles, California

The measuregraph for the measurement of the length of material was first introduced to this Conference in 1916. Ever since that time, it has been in general use in the sale of yard goods in department stores all over the nation.

Inaccurate measurement of fabrics has been a problem for store owners since the first yardstick was invented, and before. The introduction of many new fabrics has accentuated this problem, and, at this time, some additional recommendations and thought well may be given to modifying the measuring device.

The mechanism of the measuregraph, as it now is constituted, consists of a measuring roller several inches long which is connected through a gear train to the length-indicating elements. An idler roller is located opposite and is held in contact with the measuring roller. The fabric to be measured is drawn between the two rollers, which are held in contact by spring pressure.

Spring pressure is set by the manufacturer at $2 \frac{1}{2}$ pounds. The problem that has confronted us in California has been the satisfactory measurement of such materials as seersucker, georgette crepe, and the like. These materials will stretch if tension is applied, and also, with the $21 / 2$ pounds pressure on the rollers, the high spots of the material are ironed out; thus shortages occur as great as 6 to 8 inches on 10 yards of material.

The Measuregraph Company recognizes this deficiency in their machine, but claims that this classification of difficult materials represents only about 5 percent of all yard goods. The remaining 95 percent can, in reality, be classed as solid warp material, and this, without question, can be measured satisfactorily by mechanical means.

The 5 percent, consisting of these difficult fabrics, is what we now are concerned with.

The critical point of the inconsistencies in measuring these materials is the pressure of the rollers of $21 / 2$ pounds on the fabric. The Measuregraph Company states that this high pressure on the rollers is not necessarily maintained because it is needed on the fabrics, but that the testing tape used by most of the sealers, though accurately calibrated, is more similar to a piece of thin linoleum than to the average piece of fabric material. This hard glossy tape would slide through without accurately registering if the pressure of the rollers were reduced below $21 / 2$ pounds. The $21 / 2$ pounds on the rollers is maintained, therefore, not necessarily for the measurement of the fabric, but in order to accommodate the type of tape used; this amount of pressure otherwise could be reduced.

To remedy these discrepancies in measuring difficult fabrics, the following two suggestions are offered:

1. That a proper test tape of the utility-cloth type be used, thereby making it possible for the manufacturer to use a lower pressure on the roller.

2. That Regulation S. 6, in Handbook 44 regarding the limitation of the use of the measuregraph be strictly complied with and that the device be clearly marked as to its limitations. 
Mr. Crawford: My experience has indicated that our testing tape, used for determining the acculacy of fabric-measuring devices, is very accurate and very practical if properly used. Of course, it is necessary that the testing tape be drawn straight through the machine.

Mr. Slodgh: We have found that, even if a fabric-measuring device is accurate, it must be used properly. Elastic materials or materials with glossy surfaces must be handled very carefully or incorrect measurements will result.

\section{WEIGHTS AND MEASURES APPROVAL SEALS}

\section{By M. W. Jensen, National Bureau of Standards}

The Committee on Weights and Measures Education in its report to the 38th National Conference suggested that the National Bureau of Standards endeavor to obtain for weights and measures officials information about approval seals. Apparently the three principal problems with seals encountered by officials are in relation to adhesive niaterials, color, and marking. Some seals have been difficult to apply, some have not remained set, some have faded excessively, and some have surfaces on which it is difficult to mark the date and initials of the inspector.

Since there seemed to be no generally satisfactory specifications for approval seals, it was decided that the Bureau would conduct an investigation to see if it could be determined whether there are currently available approval seals that are entirely satisfactory for the purposes intended, or if manufacturer's of textiles, papers, plastics, and adhesives have better material to offer. Incidental to these questions, the investigation would be designed to determine something regarding the colors and marking means.

Samples were accumulated from weights and measures offices, known suppliers of seals, and manufacturers of papers and adhesives. The seals were grouped by material, adhesive, and color, and preparations were made for a test approximating service conditions.

It was necessary to consider the various surfaces to which approval seals are expected to adhere. Apparently the most common are glass (gasoline dispenser face covers, computing and dial scale faces, etc.), porcelain (many small-capacity scales and gasoline dispenser faces), enamel (gasoline dispenser housings, repainted scales of all kinds), and plastic materials being used as scale housings. The difference between the surfaces of glass and porcelain is so slight as to be not worthy of consideration.

Letters to the manufacturers of retail gasoline dispensers resulted in a gathering of specifications for the paints used on pump housings. Fortunately these various coatings were fairly representative of good grade outside enamel, sample panels of which were available in the NBS Organic Coatings Section. The panels on hand had been exposed, and consequently were samples of surfaces such as would be encountered in retail gasoline dispensers in use.

At this point there had been selected for the test three surfaces (glass, enamel, and plastic) and some 38 different types of seals. The simples to be tested included such materials as soft, glossy, and varnished paper, a plastic impregnated paper, several cloths, and a composition coated cloth. Adhesives fell into two general categorieswater soluble and pressure sensitive. 
Two additional items seemed worthy of consideration in the investigation-surface preparation and overcoating material. In order to give every sample an exactly equal start on the general exposure test, rigid control of the surfaces was imperative. Each surface was cleansed carefully, first with carbon tetrachloride (a solvent) and then with a commercial window cleaning liquid that contained alcohol. After having been cleaned, the surfaces were protected from the atmosphere and from handling. Two of each of the 38 sample seals were applied as nearly alike as possible to each of the three surfaces (glass, enamel, plastic). The method of applying the seals with water soluble adhesive might be worthy of special mention. A small pencil type envelope moistener was used, and the surface, rather than the adhesive, was wetted. Some advantages of this procedure are (1) the moistener is inexpensive, readily available, and convenient to fill and carry, (2) since the wet sponge end is applied to the surface on which the seal is to be placed, it remains reasonably clean and does not clog with glue, and (3) rubbing the surface with the wet sponge tends to further clean the area. In addition to these, this method offered the advantage in our test of providing like surfaces and methods of application - controlled conditions of test.

In order to determine the value of seal overcoating, two of each of the 38 sample seals had been applied to each of the three surfaces. A very common and readily available clear overcoating material obtainable in an aerosol-type dispenser was selected. This is an acrylic resin and is easily handled. One of each of the samples was overcoated with the clear spray. In this connection, mention should be made that a few of the seals were found with paper dyes that ran when the seals were overcoated. Also, the inspector should be warned that some enamels, especially when freshly applied, will be attacked by the acrylic resin solution. If the overcoating is to be used on an enamel surface, it will be desirable to test the effect of the spray on an inconspicuous area.

Since in most instances, the seals must be susceptible to marking, and, since marking materials are themselves subject to fading and obliteration, eight very common marking means were selected for test. These included graphite pencils of several hardnesses. ballpoint pens, wet ink, wax pencil, and stamp pad ink. Two large samples of plastic impregnated paper were marked with each of these items, and again one of these samples was sprayed with the clear overcoating.

It is generally agreed that surface preparation has much to do with the retention qualities of any adhesive; nevertheless, we decided to include a small test on this factor. To several glass panels was applied generously petroleum oil; to several others was applied animal fat. A pair of each of these specially prepared surfaces was cleaned in four different ways-(1) dry wipe with cloth, (2) wipe, water wash, and wipe dry, (3) wipe, window cleaner wash, and wipe dry, and (4) wipe, petroleum solvent wash, and wipe dry. Twin samples of water soluble adhesive and pressure sensitive seals were applied to each of the specially prepared surfaces, and then single samples were sprayed with the acrylic resin.

In a discussion of method of application, it should be noted that seals with water soluble adhesives require more care in application and that serrated or sawtooth edges are more difficult to attach firmly than are smooth edges. 
With the samples all applied to the surfaces, the only remaining part of the test was the actual exposure and periodic observation. In order to make use of available exposure racks, the panels were exposed on the top of the Chemistry Building on the grounds of the National Bureau of Standards. On this facility, the panels were exposed at 45 degrees from the vertical, facing due south. Admittedly, this is a much more severe exposure than weights and measures approval seals normally would be subjected to; thus, it is to be expected that deterioration of both adhesive and color would be accelerated. It is reasonable to assume that any seals that would serve for the oneyear period under these special conditions would be expected to remain in place and retain both color and print for at least the same length of time under normal service conditions. Observations of the exposed seals have been made monthly and detailed records maintained.

In the meantime, the possibility of a very much accelerated indoor test seemed worth considering. For this, one large glass panel was prepared to receive twin samples of each of the seals under test. Here again, considerable care was exercised in the preparation of the surface. To the glass panel we re-applied two each of the 38 selected samples. One of each of them then was covered with the sprayed acrylic overcoating.

It is extremely difficult to simulate outdoor exposure during an indoor accelerated test, and in this test the value is limited by the extent to which the results are verified by the outdoor test. A test was designed wherein the samples were subjected alternately to saturated steam and hot dry air. In a partially closed container, the top of which was the glass panel, steam was circulated until the surface of the panel was thoroughly wetted, and then dry heat was introduced until the glass and samples were dry. This process was continued for 23 working days, during which close inspection of the samples was made twice daily.

The results of this test indicated that the order of retentive qualities of the various sample seals is as follows, with the samples with best retention being listed last:

1. Soft paper, water adhesive, uncoated.

2. Varnished paper, water adhesive, uncoated.

3. Gloss paper, water adhesive, uncoated.

4. Soft paper, water adhesive, coated with acrylic.

5. Cloth, water adhesive, uncoated.

6. Gloss or varnished paper, water adhesive, coated.

7. Cloth, water adhesive, coated.

8. Composition coated cloth, water adhesive, uncoated.

9. Composition coated cloth, water adhesive, coated.

10. Paper or plastic impregnated paper, pressure sensitive, uncoated.

11. Paper or plastic impregnated paper, pressure sensitive, coated.

It should be pointed out that such conditions as ultraviolet rays, driving rain, wind, dirt, low temperature, mopping, and the like could not be included in this special limited experimental test.

While the special test was being designed and conducted, the exposure test was under way. As of the preparation of this report, five monthly observations have been made and patterns are beginning to form. Conclusions offered in this report are tentative only and are subject to alteration in the later and final report which will be made after the completion of the twelve monthly observations. 
It has been learned that, regardless of the material or the adhesive, proper surface preparation is essential. Nothing available today will stick and remain set to a dirty or oily surface. In most instances, a wipe, water wash, and wipe procedure will be sufficient to provide a suitable surface for holding a seal.

Also apparent is an order of permanence of the various mediums of marking. Of those tested, the mark that will stay legible for the longest period of time is that of a very soft graphite pencil. Second best is a good quality rubber stamp pad ink. Neither the ballpoint pens nor the wet inks tested remained legible under outside exposure. All of the markings under test remained legible for a longer period when under the acrylic overcoating than when exposed directly to the elements.

Concerning desirable qualities of the various materials and adhesives, it has become apparent that only the pressure sensitive seals will remain on an enamel surface when subjected to the conditions imposed by the extreme exposure test. In fact, at this point, there may be sufficient evidence to draw somewhat of a parallel between the special indoor steam and heat test and the outdoor exposure test. As yet no data from the outdoor exposures can be drawn to compare the uncoated with the coated samples. It appears, however, that the order of life expectancy outdoors probably will be from shortest to longest as follows:

1. Soft paper with water-soluble adhesive.

2. Gloss or varnished paper with water soluble adhesive.

3. Cloth with water soluble adhesive.

4. Composition coated cloth with water soluble adhesive.

5. Good quality hard finish paper with pressure sensitive adhesive.

6. Plastic impregnated paper with pressure sensitive adhesive.

It is significant that, thus far, there is no indication that the "special" samples (those prepared as a result of recommendations from manufacturers of adhesives and papers) are in any way superior to seals already on the market. Moreover, it is probable that the exposure test will indicate that some of the seals now available will remain adhered to the surfaces and hold their colors for the full year as required.

From the standpoint of color fastness of paper dyes, it is possib!e to refute some oft-heard statements. Of the primary and secondary colors-that is, red, yellow, blue, orange, green, and purple-there is none more fugitive or none more fast than any other. In writing purchase specifications for approval seals, it is advisable to set certain standards of fastness under outside exposures. Thus, such specifications should include the requirement that both the paper dye and the printing ink be such as to withstand outside exposure for at least one year.

In general, at this point in the investigation, it is possible to recommend the use of any of the following materials: (1) Plastic impresnated, high gloss, varnished, or composition coated paper, and cloth, with or without composition coating; (2) good quality adhesive, either pressure sensitive or water soluble that, after set, resists moisture; (3) paper or cloth dyes that will withstand outdoor exposure; and (4) a clear over-coating where severe conditions are anticipater. Once again it must be emphasized that the very finest material, top 
quality adhesive, and fast dye all are of no value unless and until the surface to which the seal is to be applied is properly cleaned. Lack of adequate surface preparation undoubtedly is the principal cause of seal loss.

The investigation heretofore described did not include decalcomanias, even though they are used as weights and measures approval seals in many jurisdictions. Decalcomanias will remain in place and retain color if properly applied to a smooth and clean surface.

This is in the nature of a progress report. It is planned that a final report of the exposure tests will be made available to the 40th National Conference on Weights and Measures.

\section{REMARKS OF DR. M. JACOB, DIRECTOR, SERVICE DE LA MÉTROLOGIE, MINISTÈRE DES AFFAIRES ÉCONOMIQUES, BRUXELLES, BELGIUM}

I was very glad to be invited to your Conference and it is a great pleasure for me to be able to attend it. I must first apologize for my poor English and my very, very bad enunciation. You in the United States have only one language but we in so small a country as Belgium have three official ones, French, Dutch and German. We have also other languages in the Belgian Congo. This is certainly an obstacle in making the United States of Europe. I hope for a United States of the World. But the difficult thing is not an impossibility and you American friends have proven it already many times. The principal condition is to develop a feeling that all men are brothers.

Weights and measures officials are much more than many others conscious of this truth. When they speak to sealers or other officials coming from other countries they find that technical differences between local conditions when they really exist, are slight as a whole. A first step in common work between all people of the world regarding weights and measures has been already made for the fundamental units and standards and this cooperation has been very useful to all, but this is not enough. In each country the weights and measures authorities have to study the conditions required to provide for good weights and scales, correct measures of all kinds, accurate meters, etc.

These conditions include the disposal of well organized services and offices, the inauguration of laws and regulations, the approval of types and the testing of the devices when they are new and also particularly when they are in use. These problems are closely connected with the question of prepackaged goods, in bottles, cans and packages of all kinds.

You find it very useful to gather every year in order to learn from one another about the solutions that have been given or that are to be given to all these products. Your solutions are also very interesting to other countries. I have read your reports for 30 years but I may perhaps tell you that in other parts of the world some interesting solutions may also be given to these very problems. The question of the units, metric or not metric, needs only a slight change in the selection of scales. In Belgium we use many American gasoline pumps. There is only a slight difference in the mechanism. The construction is very similar to yours. Therefore, in order to give a solution to these same problems not alone in Europe, we have already decided to sign the convention creating the International Organization on Metrology about which Mr. Crittenden spoke to you during 
the conference last year. We expect to receive very shortly the acceptance from many other countries and afterward we would have world conferences on practical weights and measures in the same manner as your national one, with the same freedom of each state or country, and with the same advantages of mutual information for everyone.

As a matter of fact, this cooperation would also result in a great uniformity in laws and regulations and practice and it would also be an important advantage for the American manufacturers in weighing and measuring devices who know they must comply with the different regulations in the various countries of the world.

\section{REMARKS OF H. E. HOWARD, CITY OF MIAMI, FLORIDA}

I would like to discuss briefly a matter concerning the weight of liquefied petroleum gas. While we were investigating the dispensing of LPG in Miami, we learned that freight charges for LPG shipped in tank cars was being based on weight that, in turn, was based on a weight per gallon of the product. In the Miami area we use mostly propane gas, the weight per gallon of which is 4.247 pounds. We learned that freight charges were being based on a figure of 4.7 pounds per gallon, or a difference of 0.45 pound per gallon. This amounts to 10.6 percent. An investigation of the companies in the area as to the amount of gallonage they received in shipment in one year and the number of tank cars involved in the shipments indicated a total of approximately $14,000,000$ gallons of LPG. At 0.45 pounds per gallon, this amounts to $6,300,000$ pounds of freight charged for but not shipped.

\section{REMARKS OF DAVID HELLER, NATIONAL ASSOCIATION OF SCALE MANUFACTURERS}

The National Association of Scale Manufacturers has recently embarked upon an educational publicity program about weighing devices, their use, their new applications, and why all scale users and the general public have real interest in scale accuracy. An important part of this program is to educate the public to the substantial benefit received from weights and measures inspection and enforcement.

We are also trying to educate business executives to the fact that weights and measures inspection represents a real protection for them-that it protects the vendors from giving away their profits in inadvertent overweight just as much as it protects the public from short weight.

Let me give you a couple of concrete examples of how this program works to the advantage of weights and measures officials. Some months ago, Mr. Arthur Sanders, Executive Secretary of the National Association of Scale Manufacturers, spoke in Richmond, Virginia on "Proving the Value of Weights and Measures." As a result of a press release prepared on this talk a Richmond newspaper carried a story with a five-column head. The story quoted Mr. Sanders to the effect that weights and measures inspection does not cost the people of Richmond a nickel, but, instead, it saves them millions of dollars every year by prohibiting losses on the things they buy and sell. 
Let me give you a second example. In a recent press release we sent to more than 700 newspapers, magazines, and news syndicates, we inserted the following paragraph:

By and large, the Nation's weights and measures officials are doing a superb job, but they face an almost impossible job in protecting the public from getting less than it pays for and in protecting the merchant from giving away his product. The Nation would make a great net saving by making larger appropriations for more weights and measures officials to do the job that must be done.

The manufacturers of scales are firmly behind you, the weights and measures officials of the Nation, in your effort to rid the country of the inaccurate and worn-out scales, and we are trying to make our support practical by building a firm foundation of public support for the work you are doing. Among the articles and press releases we have sent to thousands of publications, not a single one has neglected to put in a plug for more money and more personnel for you and the people in your departments.

You can give us a great deal of assistance in our efforts to educate scale users and the public to the importance of weighing accuracy by giving us the facts, by telling us about striking case histories or examples of weighing errors which have cost somebody substantial sums of money, or by telling us about merchants who have lost money because their scale was "slow" and giving away profits until you tested it and put it right. I am sure that each of you has had in his experience many outstanding examples that illustrate the value of weights and measures enforcement and of accurate scales.

You also can help your own cause by letting the newspapers in your city know what you are doing, how you are protecting the people of the city by vigilant and courageous enforcement of the weights and measures laws. The net result will be the building up of solid public and legislative opinion regarding the importance of weights and measures supervision.

(The Conference was adjourned, to reconvene on Friday, May 21, 1954, at 10 a. m.)

\section{Sixth Session-Morning of Friday, May 21, 1954}

(G. F. Austin, JR., Vice President, Presiding)

\section{REPORT OF THE OUTGOING EXECUTIVE COMMITTEE, PRESENTED BY G. F. AUSTIN, JR.}

The Executive Committee elected by the 38th National Conference on Weights and Measures held an open meeting in this hotel on Monday, May 17. The meeting was called for the purpose of discussing arrangements for the National Conference. At that time, two major items were brought up, (1) social activities of the Conference, and (2) city in which the Conference should be held.

Under item 1, the possibility of scheduling a Conference banquet was raised as a result of a suggestion by Mr. Baucom of North Carolina. After considerable discussion, the Executive Committee decided to make no firm recommendation on this matter to the incoming executive Committee. 
Under item 2, there was raised the possibility of holding the $\mathrm{Na}$ tional Conference in cities other than Washington. On this point, the Executive Committee decided to recommend that Washington continue to be the site of National Conferences because the Conference is sponsored by the National Bureau of Standards and all detail arrangements are administered by staff members of that organization.

Mr. HagGart : I would like to recommend that definite efforts be made by all weights and measures officials to increase the amount of publicity received by the National Conference and by individual departments.

Mr. BAdCOM: I suggested that the Conference Committee consider the possibility of planning a banquet to replace the informal Conference party for the reason that it is my thought that greater publicity would be received if a banquet is held.

Mr. Christie: One of the reasons that the Executive Committee did not recommend the banquet is that obviously such an event would increase the cost of the Conference to all those who desire to attend such an affair.

Mr. Crawford: I want to discourage the thought of considering other locations for future Conferences. It appears to me that both the success and the growth of the Conference are due largely to the material assistance received from the National Bureau of Standards. Such assistance would not be possible in any location other than Washington.

\section{INVESTIGATION OF AXLE LOAD WEIGHING}

By D. R. TATE, National Bureau of Standards

Weights and Measures officials are becoming increasingly familiar with problems involved in determining axle loads of motor vehicles. The importance of the task can be appreciated if one considers that an expected development is the extension of the method to the deternination of weight for tolls on major toll highways.

We have been asked to make an investigation of these methods for determining axle loads and gross weights by multiple draft weighing. Motor trucks have increased in length from the 24 feet or so of a few decades ago up to 50 feet or more. Since scales having platforms long enough to weigh such trucks are not commonly available at highway check points, individually measured axle loads must often ke added up to determine the gross weight. The determination of individual axle loads is, of course, a feature of modern highway traffic regulation.

A typical incident arising from the shortcomings of the multiple draft method occurs when a truck driver stops at a State weighing station and is given a ticket because his truck is overweight. He had had his truck checked, just before starting his trip, on scales which he had every reason to believe were accurate. Now he finds that he is 1,500 or 2,000 pounds beyond the limit. He feels that he has been mistreated and that it is up to the weights and measures officials. to regulate the weighing in such a way that this cannot happen.

One thing basic to any measurement problem is the determination of the constancy of the quantity being measured. All of us, when we think of weight, have the feeling that the object being weighed must 
be very constant and that if any discrepancy occurs between two weighings, it is usually the scales or the operators which are at fault. When we use the term "axle weight," the listener infers that we are measuring just such a constant and repeatable quantity. The National Bureau of Standards, therefore, made its introductory experiments a study of the constancy of "axle weights."

We conducted our experiments using a scale installation located near Woodbridge in the state of Virginia. R. D. Thompson, Supervisor of Weights and Measures for the Virginia Department of Agriculture, and J. P. Mills, Jr., Traffic and Planning Engineer for the State Highway Department of Virginia, together with members of the staff of the American Trucking Associations, Inc., cooperated in the experiments. The installation consists of three independent scales, two 24-foot platforms with a 10-foot platform between them. 'This installation permitted us to weigh a tractor-trailer combination in a number of positions such that in each position, although the nxles were on different scales, all axles were weighed simultaneously. With a truck in a single position we could weigh the front axle, the driving axle and the trailer axles. We weighed 30 trucks, 23 of them with tandem axles on trailers and 7 of them with single trailer axles, in from 16 to 20 different positions depending on the number and spacing of the axles.

In not every case were we able to weigh all axles simultaneously, but we found all the results useful in the study.

Variations in axle load measurements can arise from three possible causes: errors in the scales, the scales not operating properly because of constraints introduced by the truck, or variations in the axle weights themselves. We eliminated the possibility of errors in the scales by calibrating them before and after the test. During the calibration, the errors did not exceed 20 pounds, the minimum graduation, at any location. We eliminated the possibility of the accuracy of the scales being affected by the truck by totalling all axle weights obtained simultaneously to see whether the gross weights so obtained agreed between different positions. On the average the gross weights so calculated varied by 50 pounds for each truck. Since this value was within the limits which might arise from the sum of the individual scale errors, the results indicated reliable performance. The scales were calibrated again at the conclusion of the experiment, the calibrations agreeing very well.

The approaches to these scales are fairly level and the scales are provided with concrete platforms. We felt that the fluctuations observed were indicative of those one might expect from trucks running on a level roadway.

The results of some of our tests are given in the following table. 
Observed variation in axle weights of tractor-trailer combinations

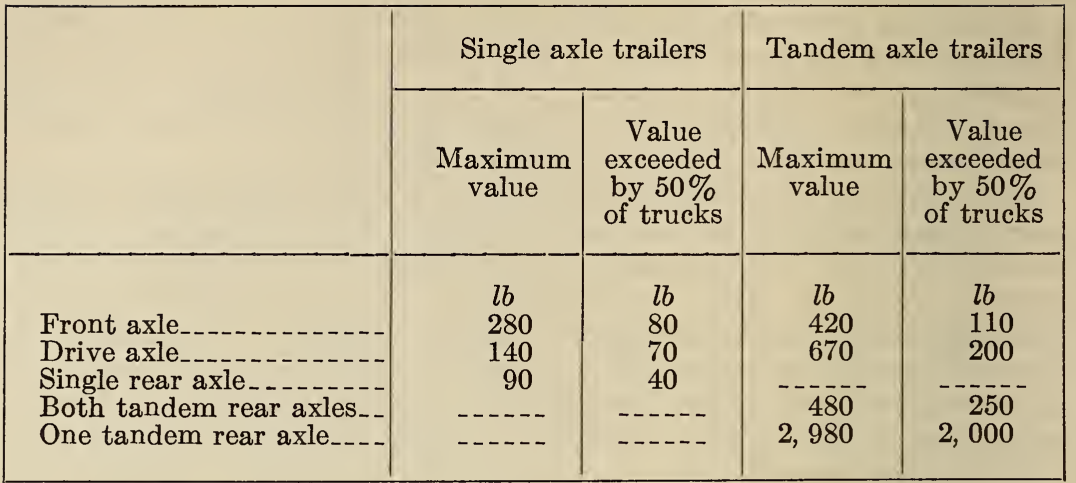

These results were obtained from tractor-trailers having a single front axle, a single drive axle, and either single or tandem rear axles on the semitrailer. The first and third columns give the maximum variation observed. The second and fourth columns give the variations shown by more than 50 percent of the axles tested.

With tandem axles, the variation was more pronounced. The fourth and fifth lines show fluctuations of a single member of the tandem and the shifting between front and rear members of the tandem pair.

A last item is of interest to those who have sometimes made the assumption that the load is shared equally between the members of a tandem; in one case a difference of 7,350 pounds was observed and 50 percent of the trucks differed by at least 1,200 pounds.

These variations are the kind one must expect whenever and wherever axle loads are weighed. Note that they appeared spontaneously as the trucks moved slowly across the three scales. They are, therefore, the minimum amount of scatter which one can expect in a multiple draft weighing. No matter how accurate our scales or how careful the weighmaster, these variations are bound to appear.

It has been my personal feeling that a term such as "axle weight" is undesirable because it suggests the weight of an axle as a fixed and definite quantity, subject to accurate and repeatable measurement. Weight, defined as the sum of the gravitational forces acting on all the particles of a body, certainly is a fixed and definite quantity, but this results in repeatability only when the entire body is placed on the scale platform.

If a body such as a truck is supported partly on the ground and partly on a scale, the quantity measured by the scale is not a weight but merely a load reaction. It is that portion of the total weight which happens to be on that wheel or axle at the moment. The fact that this value may, under different conditions of topography, vary anywhere between zero and nearly the total weight of the truck does not mean that the values read from the scales are inaccurate.

The experiments which we have described above show that when a truck is moved over a fairly smooth and level roadway, axle load reactions may vary by amounts as great as 500 or 600 pounds. Shifts among pairs of tandem axles may exceed 2,500 pounds. It follows 
that adding a number of such values, subject to random variation, will result in a summation at least equally variable. For this reason we do not consider multiple draft weighing an accurate method for determining the gross weight unless all axles are weighed simultaneously. It is, however, a necessary and accurate method for determining the instantaneous load reaction of a single axle.

Mr. Hansen: In Minnesota we have issued a regulation to the effect that multiple-draft weighing is not acceptable for determining the weights of commercial loads. Such a regulation is necessary because our experience has indicated that inaccuracies are probable when weights are determined by this method.

(Mr. Baucom demonstrated on the blackboard the effect of brake application in determining axle loads.)

Mr. RezNeK: We had one carrier make a study in which he took a sealed tank truck and had it weighed on 65 certified scales, successively, over a three-day period. The results of these weighings varied on the front axle 1,230 pounds, on the drive axle 2,339 pounds, and on the tandem axles 1,280 pounds. On twelve of the 65 scales, a violation of the weight regulations was indicated. This is a very real problem to all truckers, who realize that their vehicles may be weighed in one place and found legal and then travel a few miles, only to be weighed again and found in violation.

Mr. Christie: In New Jersey our legislature has provided for a 5 percent tolerance on axle overloads. We have noticed that the greatest variations occur in the so-called ten-wheel tandem truck.

Mr. KrbBex: As a representative of the American Trucking Associations, I want to state that the truckers are not complaining, but, on the other hand, are interested in getting down to the root of this problem. We recognize that there is a problem both in wheel and axle-weight determinations. I am very much encouraged that the National Bureau of Standards has instituted this investigation, since, generally speaking, the scales seem to be accurate, but the methods of weighing might be subject to question. Since tolerances are allowed on the devices, perhaps tolerances also should be allowed on the procedures. We have found that variations in axle weights may be caused by merely starting a vehicle or by making a turn. I want to assure this Conference that the American Trucking Associations will be glad to cooperate toward the solution of this problem.

Mr. R. W. Searles: In Ohio, up until two years ago, we had a maximum axle-weight allowance of 18,000 pounds. On top of that, a 1,000-pound enforcement tolerance was allowed. It appeared that many of the truckers were loading to the full 19,000 pounds, and soon truckers made request to the State legislature that 19,000 pounds be made the legal limit without any stipulated tolerance. With that accomplished, many requests now are being received for a tolerance on top of the 19,000 pounds.

I would contend that it is the responsibility of the individual truckers to see that their loadings are such as to allow for normal variations in axle weights.

Mr. Christie: In New Jersey, only specially trained men are allowed to enforce the axle-weight law. They are permitted to weigh only under certain conditions with loadometers, and, when in doubt, 
they move the vehicle to a location where axle weights can be determined on platform scales. These enforcement officials have found that axle loads can be determined with loadometers within 150 pounds if great care is exercised.

Mr. Kibbex: I have found this discussion very enlightening, because I did not realize that such large variations were possible in the weight determination of an axle. I am quite sure that many truckers are not aware of these variations.

\section{REPORT OF THE COMMITTEE ON SPECIFICATIONS AND TOLERANCES, PRESENTED BY R. E. MEEK, CHAIRMAN}

The Committee on Specifications and Tolerances of the National Conference on Weights and Measures held no general meetings during the year. On several occasions two or more members of the Committee did take advantage of being together for other purposes to discuss Committee problems. During the month of September 1953 the Committee Chairman and Secretary met with the Committee on Weights and Measures of the American Petroleum Institute to discuss the problem of equipment and methods for testing fluid meters dispensing liquefied petroleum gases. Otherwise, the Committee functioned throughout the year through correspondence among the members and among weights and measures officials and representatives of industry and business.

This report to the 39th National Conference on Weights and Measures represents current Committee conclusions in relation to matters referred to it by the 38th National Conference and to those matters brought to it from other sources.

The tentative report of the Committee was prepared and distributed in advance of the Conference in order to give all interested persons adequate opportunity to study its contents prior to the meeting. The Committee invited comments and suggestions on the subject matter of the report and on any other matters within the purview of the Committee.

The Committee was in open session, preliminary to the preparation of its final report, at the Sheraton-Park Hotel, Washington, D. C., beginning at 10 a. m., Monday, May 17, and continuing until 4:30 p. m.

In accordance with the resolution adopted by the 38th National Conference on Weights and Measures, which expanded the activities of the several standing committees to include the furnishing of necessary leadership in bringing about the official adoption and enforcement of Conference recommendations, your Committee on Specifications and Tolerances has done everything that it considered appropriate to encourage the several States to adopt officially and to enforce the codes of specifications, tolerances, and regulations for commercial weighing and measuring devices previously adopted by the Conference.

The Committee is glad to report that encouraging response was received from several jurisdictions. Some State departments have reported official action during the year, while several others currently are in the process of promulgating these codes. Your Committee realizes that the full cooperation of each State, county, and city department is essential to effectuate efficient and uniform weights and measures administration throughout the United States. The Com- 
mittee strongly recommends that those States that have not already officially adopted the Conference codes initiate such action as soon as is practicable.

The Committee on Specifications and Tolerances offers the following recommendations to this Conference:

\section{LINEAR MEASURES}

A strict interpretation of general specifications G-S.4.2.3. and G-S.4.3. would prohibit commercial linear measures with subdivisions less than $1 / 16$ inch. It is beliered that such an interpretation was not the intention of the Conference and that, accordingly, paragraph S.4. of the code for linear measures should be clarified to eliminate the possibility of this interpretation.

For consistency of language, the Committee proposes also to change the phrase "shall not be" to read "shall be not" in two places in paragraph S.4.

The Committee recommends, therefore, that paragraph S.4. of the code for linear measures be amended to read as follows:

S.4. Graduations.-Graduations shall be perpendicular to the edge of the measure. Line graduations shall be not wider than 0.03 inch. Raised graduations shall be not wider than 0.12 inch at their widest point. On any measure, the width of the graduations shall not exceed one-fourth the value of the smallest subdivision of the measure. The requirements of general specifications G-S.4.2.3. and G-S.4.3. shall not apply to linear measures.

\section{TAXIMETERS}

It has come to the attention of the Committee that there exists some lack of understanding among weights and measures officials and others, of the justification for the taximeter tolerance structure under which there is no tolerance on overregistration of mileage except when the rehicle tires are worn. Moreover, the Committee has been asked to consider establishing a tolerance of 1 per cent, or some other value, for mileage overregistration, to be effective regardless of the condition of the vehicle tires. The Committee has re-examined the question of mileage tolerances rather thoroughly, and has concluded that no change in tolerance values should be made. The Committee wishes, however, to record at this time some of its reasons for this conclusion.

A taximeter invariably registers a charge for an increment of mileage in advance of the corresponding vehicle travel. Assuming errorless taximeter performance, a passenger might be required to pay a full fare increment for an amount of transportation anywhere from nothing to a full mileage increment. It would be only by the merest chance that he would get the full measure for which payment is required. On the average, he would get short measure equivalent to one-half of a mileage increment. (It was brought out during the open hearing of the Committee that, if a tolerance on mileage overregistration is allowed, in some instances a passenger would be charged for the succeeding increment before he had completed the distance corered by the current interval.)

Tire slippage, underinflation of tires, and heavy vehicle loads all tend toward orerregistration of the taximeter. To require "no tolerance on orerregistration" when an official test is made (except in relation to tire wear, as will be discussed later) seems to be the least that should be done to give the taxicab passenger fair treatment. 
Tire wear is inevitable when a vehicle is operated. Tire wear tends also toward taximeter overregistration. It is considered to be a reasonable estimate that, by the time a tire is discarded as a result of wear, its original effective circumference will have been reduced by approximately 2 per cent. This fact is translated into fair practice for taxicab operator and passenger by the method prescribed in the code for determining the mean effective circumference of the tire. This same fact is recognized in the requirement that a tolerance on overregistration of 1 percent is to be allowed if the vehicle tires are worn.

Notwithstanding the requests for an increase in mileage tolerances for taximeters, the Committee has authentic information to the effect that taximeters can, without difficulty, be so maintained as to perform consistently within the normal 4 per cent range (plus 100 feet under specified circumstances) now prescribed in the code.

The Committee is advised that an additional test procedure or test method is now being employed in one or more jurisdictions. To give formal recognition to this form of taximeter test, the Committee recommends that paragraphs D.13. and D.14. of the code be amended and rearranged, with the addition of a new definition, as follows:

\section{D.13. RoAd TESTS.}

D.13.1. Actual Road Test.-A test similar to a wheel test, except that the mechanism is actuated as a result of vehicle travel.

D.13.2. Simulated Road Test.-A' test similar to a wheel test except that the vehicle wheel or wheels which actuate the taximeter rest in a cradle formed by rollers, one of which is a mileage-measuring element.

D.14. WHEEL TEST.-A test of the entire taximeter assembly when mounted on a vehicle, the road results being computed from the counted number of revolutions of the wheel or wheels actuating the taximeter and the mean effective circumference of tire. The vehicle remains at rest during this test.

Having given considerable thought to procedures for the testing of taximeters, the Committee is of the opinion that the code should be strengthened by adding certain new requirements, including a new section under "Nотеs" dealing with these procedures. A slight moditication of one tolerance paragraph is also needed to bring about complete uniformity of tolerance requirements. The Committee recommends the adoption of these changes in the following form:

S.11. INTERFERENCE.-The construction of a taximeter shall be such that there will be no interference between the time and the mileage portions of the mechanism at any speed of operation corresponding to a vehicle speed faster than the speed at which the basic rate of mileage revenue equals the basic waiting-time rate; specifically, the registration of a taximeter in the "Hired" condition shall agree with its performance in the "Time not recording" condition within 1 percent.

N.2. Testing Procedures.

N.2.1. Interference Test.-As part of the bench test if such a test is made, otherwise as a part of such other test as is made, a special test shall be made to check for possible interference between the taximeter time and mileage mechanisms, a condition that may develop at relatively slow speeds of vehicle operation. This test consists of a comparison of taximeter performance for a nominal 1-mile interval when the taximeter is in "Hired" (time-recording) condition. with its performance for a like interval when the taximeter is in "Time not recording" condition; performance under these two conditions of operation shall be in agreement within the limit specified in S.11. Throughout this test the mechanism shall be operated at a speed corresponding to a vehicle speed of 2 or 3 miles per hour faster than the speed at which the basic mileage revenue rate equals the basic waiting-time rate.

N.2.2. WORN TIRES.-For purposes of tolerance application on an actual or simulated road test, a vehicle tire shall be considered to be "worn" when and after the tread wear is equivalent to approximately one-half the normal useful 
life of the tire. (Normally the half-life point of tire wear is reached only after the tire has been operated for at least 10,000 miles.)

N.2.3. Effective Tire CrRCUMference.-In computing road results on a wheel test and in calculating the required values for change gears, the mean effective circumference of tire shall be used. This shall be determined as follows: 1 . Mount upon a vehicle a new tire of the size, kind, and make in use, and inflate this to normal operating pressure. 2. Cause the tire to describe exactly at least three complete revolutions upon a smooth surface. 3. Measure the total distance advanced by the tire. 4. Divide this distance by the number of revolutions made, to establish the average distance advanced per revolution. 5. Subtract 1 percent from this average distance.

T.1.2. ON WHEEL AND ROAD TESTS.-With respect to distance computed, indicated, or actually traveled, no tolerance on overregistration, except that on a road test or simulated road test, if the tires actuating the taximeter are worn (see N.2.2.), the tolerance on orerregistration shall be 1 percent of the interval under test; and the tolerance on underregistration, 4 percent of the interval under test with an added tolerance of 100 feet whenever the initial interval is included in the interval under test.

R.2. INFLATION OF Vehicle TiRES.-The pressure in vehicle tires that actuate a taximeter shall be maintained at not less than the normal operating pressure established in advance for such tires by the operator of the vehicle. Such pressure shall in no case be less than the pressure recommended by the tire manufacturer for a tire of that particular size, kind, and make.

\section{LIQUID MEASURES}

The Committee received a suggestion for amendment of the code for liquid measures. The amendment proposed was that the words "installed horizontally" be added to paragraph S.3.1., after the comma, following the word "wire" in line three.

According to information furnished the Committee, there have been only a limited number of instances encountered in which the indicating element was not mounted perpendicular to the vertical axis of the measure. In these instances, agreement from the manufacturer to correct the faulty condition was readily obtained. No specific case involving this defect has been reported in recent months. It is assumed, therefore, that such failures are not of common occurrence.

As a general principle, the Committee adheres to the policy of keeping codes of specifications and tolerances as short and nonrestrictive as practicable. Avoiding changes to an established code to meet relatively minor and accidental situations, which may arise infrequently, is a long established Committee policy. Especially does the Committee wish to refrain from recommending code changes in those cases where a reasonable interpretation of existing requirements provides an adequate remedy.

In the case under discussion, the provisions of the General Code are considered to provide adequate grounds upon which an official can require correction of the faulty condition in question. Paragraphs G-S.2., G-S.3., and G.S.4.1. are applicable in this case. 'Therefore, the Committee recommends no amendment of the code for liquid measures.

\section{LIQUID-MEASURING DEVICES}

The Committee received a request to study the desirability of providing that the "value of the smallest unit of indicated delivery on a retail liquid-measuring device shall not exceed one pint."

The recommendation resulted from the use of certain liquidmeasuring devices for the purpose of dispensing fuel oil, to customers' 
containers, in 5- and 10-gallon lots. These devices were graduated only to $1 / 2$ gallon, or, in some instances, 1 gallon.

Retail liquid-measuring devices may be used for a very wide variety of purposes. The specific limitation suggested would be undesirable in certain instances. Some uses would require graduations with lower values, while others would not demand one-pint indication. Further, under G-R. 3. SuitabiLity of EQuipuent, the enforcement official has wide latitude in exercise of experienced judgment in matters of this kind.

The Committee does not deem an amendment necessary, and so recommends.

The present definitions for "Retail Device" and Wholesale Device," paragraphs D.2. and D.3. of the code for liquid-measuring devices, are not fully satisfactory because they overlap to some extent. Under these definitions, there are border-line cases where it is difficult to decide with certainty whether a device should be classed as a "retail device" or as a "wholesale device." Any such uncertainty is undesirable because tolerances and test procedures are different for these two classes of devices.

The Committee recommends that paragraphs D.2. and D.3. be amended to read as follows:

D.2. Retarl Device.-A device designed for single deliveries of less than 100 gallons and, in addition, any device designed or used for retail deliveries of motor fuels to individual highway vehicles.

D.3. Wholesale Device.-Any device other than a retail device.

For many years, most retail liquid-measuring devices used for dispensing motor fuel have been equipped with automatic zero-set-back interlocks. As early as 1935 the National Conference has considered amending the code to require interlocks. The interlocks in most general use were covered by patent rights, and the Conference has a long-standing policy against requirements leading to patent monopolies.

The Committee now has been informed reliably that all current patent rights and agreements that relate to the mechanisms for zeroset-back interlocking will have expired prior to July $1,1957$.

In response to continued requests from weights and measures officials, and in order that manufacturers, users, and the officials may be placed on notice regarding this requirement, the Committee recommends the adoption at this time of a new specification, with a delayed effective date, as follows:

S.10.5. ZERo-SET-BACK INTERLOCK.-Effective July 1, 1957, a retail device of the meter type used for dispensing motor fuel shall be so constructed that, after a particular delivery cycle has been completed by movement of the starting lever to its shut-off position, an effective automatic interlock will prevent a subsequent delivery being started until the indicating elements have been returned to their correct zero position.

\section{GREASE-MEASURING DEVICES}

Under the terminology now current in the oil industry, and in view of the developments in the field of automatic automotive transmissions, the term "transmission oil" as used in paragraphs A.1., D.1., and S.5.2. of the code for grease-measuring devices is no longer appropriate. It is proposed, therefore, to modify these paragraphs by substituting the term "transmission lubricant" for the term "trans- 
mission oil" and to introduce a new clause in paragraph A.1. specifically excluding devices for measuring motor (crank-case) oil and automatic-transmission fluid.

Accordingly, the Committee recommends that paragraphs A.1., D.1., and S.5.2. of the code for grease-measuring devices be amended to read as follows:

A.1. This code does not apply to (a) devices constructed to weigh grease or transmission lubricant and to deliver such material by weight, (b) devices designed solely for the high-pressure lubrication of bearings and similar parts, (c) devices designed to measure motor (crank-case) oil and automatic-transraission fluid (automotive), and (d) devices used solely in operations for which a flat rate is charged, no variation in the charges being made because of the varying amounts of lubricant delivered.

D.1. Grease-Measuring Device.-A mechanism or machine designed to measure grease or transmission lubricant and to deliver such material by definite volume.

\$.5.2. Limitation of Use.-If a device is intended to measure accurately only certain types or varieties of greases or transmission lubricants, its limitations shall be clearly and permanently stated on the device.

\section{VEHICLE TANKS}

The Committee was requested to define the term "nominal compartment capacity" as used in paragraph S. 10.4. of the code for vehicle tanks.

By dictionary definition it is clear that "nominal" has as one of its principal meanings "named or stated." It is the opinion of the Committee that the use of "nominal" in this sense is widespread and that this meaning is generally understood and accepted. The Committee agrees that it is in the sense of "named" or "stated" that the word "nominal" is used in the phrase "nominal compartment capacity." Therefore, the Committee feels that no special definition of this phrase is needed in the code.

As a specific interpretation of the questioned phrase, the Committee recommends that "nominal compartment capacity" as used in the code for vehicle tanks shall be understood to mean the named or marked capacity of the compartment. This means the marked capacity to the indicator, or the capacity by which the compartment is designated and which is required by specification S. 11.2. to be conspicuously stated.

With respect to tolerances for vehicle tanks, table 1 now specifies for compartment capacities over 1,000 gallons, tolerance values of 1 pint (on first test) and 1 quart (on subsequent test) "per 200 gallons"; this can be interpreted as prescribing a continuation of the step system set up earlier in the table, or it can be interpreted as prescribing a proportional system at the rate of so much for 200 gallons. Under the latter interpretation, the tolerance on first test on a compartment of a capacity of 1,050 gallons, for example, would be 7 pints plus $1 / 4$ pint.

The Committee believes that there is no necessity for determining errors and applying tolerances on vehicle tank compartments with a precision greater than 1 pint. The Committee believes also that the "step" system of tolerances, as set up in table 1 of the code for compartment capacities up to 1,000 gallons, should likewise be followed for compartment capacities greater than 1,000 gallons. 
Accordingly, the Committee recommends that table 1 be amended by adding "or fraction thereof" to the final entries in the second and third columns, making the table read as follows:

TABLE 1.-Tolerances on vehicle-tank compartments used as measures

\begin{tabular}{|c|c|c|}
\hline \multirow{2}{*}{ Compartment capacity } & \multicolumn{2}{|c|}{ Tolerance } \\
\hline & On first test & On subsequent tests \\
\hline $\begin{array}{l}\text { Gallons } \\
200 \text { or less } \\
201 \text { to } 400, \text { incl } \\
401 \text { to } 600 \text {, incl } \\
601 \text { to } 800 \text {, incl } \\
801 \text { to } 1,000 \text {, incl } \\
\text { Over } 1,000\end{array}$ & $\begin{array}{c}\text { Pints } \\
4 \\
4 \\
5 \\
6 \\
7 \\
\text { Add 1 pint per } 200 \\
\text { gallons or fraction } \\
\text { thereof. }\end{array}$ & $\begin{array}{c}\text { Quarts } \\
2 \\
3 \\
4 \\
5 \\
6 \\
\text { Add } 1 \text { quart per } 200 \\
\text { gallons or frac- } \\
\text { tion thereof. }\end{array}$ \\
\hline
\end{tabular}

PRINTING ERROR IN HANDBOOK 44

The Committee has discovered an error in composition in the heading for Table 2 of the Code for Vehicle Tanks (Handbook 44, page 81). A careful check of the original records on file at the National Bureau of Standards definitely indicates that the error does not represent Conference action, but rather was made during preparation of printer's copy.

This error is the inclusion in the heading for Table 2 of the Code for Vehicle Tanks of the words "on Single-Compartment Tests."

The words quoted were properly included in the tentative report of the Committee in 1949. There were also included the special tolerance paragraphs dealing with single-compartment tests and multiple-compartment tests. In the final report of the Committee in 1949, consolidation of these two paragraphs was recommended. It was also recommended that the heading of Table 2 be appropriately changed to read, "Maintenance Tolerances for Vehicle-Tank Meters." The Conference concurred in these recommendations.

Unfortunately, the old table heading, instead of the new one, was used when the copy for the printer was prepared. This mistake has only now come to our attention.

Mr. Bussey has assured the Committee that, when Handbook 44 is reprinted, the proper heading will be used for the table in question. In the meantime, it is recommended that all holders of Handbook 44 strike out, on page 81 , in the heading of table 2 , the words "on SingleCompartment Tests."

\section{FARM MILK TANKS}

The tentative code for farm milk tanks was adopted by the 38th National Conference and has been available for one year. During that time there have been some mechanical developments. Also, the members of the Committee have had some experience with tanks in service and have received reports of the experiences of other weights and measures officials. 
Two important qustions continue to arise in discussions of this code. The first involves the propriety of indicating on the chart the number of pounds of milk rather than the number of gallons of milk corresponding to the linear readings on the gage rod. The second question involves the interval on the gage rod throughout which graduation of the rod is to be required-half-capacity to full-capacity, or some other interval.

As to the values on the chart, the Committee believes that the requirements of the code as now written are adequate and proper. In this relation, the Committee adheres to the position set forth in its tentative report to the 38th National Conference, as follows:

In the first place, a farm milk tank is not a weighing device. It would be impossible for a weights and measures official truthfully to certify that one of these units will deliver a given number of "pounds." The specific gravity of milk varies; therefore, 231 cubic inches of milk will not, in all instances, weigh the same. Your Committee feels that these devices should be certified by weights and measures officials as volumetric measuring devises only. They should insist that the official charts, which bear the official seal of approval of the weights and measures department, contain quantity values in "gallons" only. If the buyer and seller choose to convert "gallons" to "pounds," by using an arbitrary conversion figure, this they should do under private contract. It is not necessary to show "pounds" on the chart approved by the weights and measures official for this to be accomplished.

Accordingly, the Committee recommends that no change be made in the code with respect to the characeer of values to be shown on the chart.

As to the present requirement that a gage rod "shall be graduated throughout an interval corresponding to at least the upper one-half of the tank capacity," the Committee's feeling is as follows: At least this amount of graduation is desirable in order to provide necessary flexibility in adjusting the use of the device to ordinary fluctuations in the amount of milk produced. More than this amount of graduation is not needed in many cases.

Added graduations on the rod and correspondingly greater effort in calibration of a tank and preparation of a chart result in greater cost to a tank purchaser. If this added expense is not necessary, it should not be required by weights and measures officials. However, since the Committee realizes that there will be some instances in which graduation of a rod between the half and full tank capacity points will be inadequate to meet the existing or anticipated requirements of a particular user, it is proposed that this contingency be recognized in the code. Accordingly, a change in the language of paragraph S.2.1., to accomplish this result, is recommended by the Committee.

The Committee is informed that no manufacturer of farm milk tanks is now making, or anticipates making, tanks equipped with gage tubes. It is not considered advisable to complicate the code by including requirements designed to meet contingencies that are not probable, even though they are possible. The Committee recommends, therefore, that references to gage tubes, now in the code, be deleted.

The Committee is cognizant of a recent development in the form of a novel surface gage for indicating the level of liquid in a milk tank. It appears that this type of device should be recognized in the code. Accordingly, the Committee has drafted a definition and requirements for surface gages and brackets therefor, and recommends that these be added to the code as D.3., S.1.4., and S.2.2. 
For completeness, it is recommended that a definition for "gage rod" be added to the code as D. 2.

It is recommended that a sentence be added at the end of paragraph S.1.1. relative to maintenance of level when a tank contains varying amounts of liquid.

The Committee believes that materials other than metal may be found to be fully as satisfactory as metal for gage rods and gage-rod brackets, and recommends that in paragraphs S. 1. 3. and S. 2. 1. the requirement for "metal" be deleted.

It is found that the requirement of paragraph S.2.1. for "suitable and rigid design" of a gage rod is adequately covered by paragraphs G-S.3. and G-S.4.1. of the General Code; accordingly, it is recommended that this requirement be deleted from paragraph S.2.1.

A contradiction was found to exist in paragraph S.2.3. relative to the clear space between successive graduations. It is recommended that this be eliminated by inserting a specific requirement for minimum clear interval, and then eliminating the cross reference to paragraph G-S.4.3. of the General Code.

There is presented below the full text of the code for farm milk tanks amended according to the foregoing recommendations. The Committee now recommends that this amended code be finally adopted.

\section{FARM MILK TANKS}

\section{A. APPLICATION.}

A.1.-This code applies to farm milk tanks, as defined, only when these are used, or are to be used, under an express contract between the producer and the purchaser and on the premises of the producer, for the commercial measurement of milk or other fluid dairy product. If such measurement is accomplished by means of a fluid meter, this code does not apply; in such case the meter shall be subject to the applicable provisions of the code for liquid-measuring devices.

\section{DEFINITIONS.}

D.1. Farm Milk TANK.-A unit for measuring milk or other fluid dairy product, comprising a combination of (1) a stationary tank, whether or not equipped with means for cooling its contents, (2) means for reading the level of liquid in the tank, such as a removable gage rod or a surface gage, and (3) a chart for converting level-of-liquid readings to gallons; or such a unit in which readings are made on gage rod or surface gage directly in terms of gallons. Each compartment of a subdivided tank shall, for purposes of this code, be construed to be a "farm milk tank." (These units are variously known commercially as "farm bulk milk tanks," "farm cooling tanks," "farm holding tanks," and "producers tanks.")

D.2. GAGE RoD.-A graduated, "dip-stick" type of measuring rod designed to be partially immersed in the liquid and to be read at the point where the liquid surface crosses the rod.

D.3. Surface Gage.-A combination of (1) a stationary indicator and (2) a movable, graduated element designed to be brought into contact with the surface of the liquid from above.

\section{S. SPECIFICATIONS.}

S.1. Design. (See also S.2.4.)

S.1.1. LEVEL.-A farm milk tank shall be in normal operating position when it is in level. The tank shall be equipped with suitable special means by which this level can be determined and established, such as a permanently attached twoway or circular level, a plumb bob, leveling lugs, or the like; or the top edge or edges of the tank shall be so constructed throughout as to provide an accurate reference for level determinations. The tank shall be so constructed that it will remain in level under all normal conditions of lading. 
S.1.2. Discharge Valve.-A farm imilk tank shall be equipped with a disharge valve through which the tank may be completely emptied when the tank is in level.

S.1.3. GAgE-Ron Bracket.-If a farm milk tank is designed for use with a gage rod, a substantial gage-rod bracket shall be rigidly and permanently attached to the tank. The bracket and rod shall be so designed that, whenever the rod is placed in engagement with the bracket and released, the rod will automatically seat itself at a fixed height and will hang in a vertical position with a clearance of not less than 3 inches between the graduated side of the rod and the tank wall which it faces.

S.1.4. Surface-Gage Bracket.-If a farm milk tank is designed for use with a surface gage, a substantial surface-gage bracket shall be rigidly and permanently attached to the tank. The bracket and gage shall be so designed that, when the gage assembly is placed in engagement with the bracket, the indicator, if not permanently mounted on the tank, will automatically seat itself in correct cperating position, and the graduated element will be vertically positioned and will be securely held at any height to which it may be manually set.

S.2. Indicating Means.

S.2.1. GAGE RoD.-When seated on its bracket, the gage rod shall not touch the bottom of the farm milk tank. The rod shall be graduated throughout an interval corresponding to the gallonage range within which the tank is to be used, and in no case shall this range be less than the upper one-half of the tank rapacity.

S.2.2. Surface GAGE.-When properly engaged with its bracket and set to its lowest position, the surface gage shall not touch the bottom of the farm milk tank. The gage shall be graduated throughout an interval corresponding to the gallonage range within which the tank is to be used, and in no case shall this range be less than the upper one-half of the tank capacity.

S.2.3. Spacing and Width of Graduations.-On a gage rod or surface gage, the spacing of the graduations, center to center, shall be not more than 0.0625 $(1 / 16)$ inch and not less than 0.03125 (1/32) inch; the graduations shall be not less than 0.005 inch in width, and the clear interval between adjacent edges of successive graduations shall be not less than 0.015625 (1/64) inch. (See also G-S.4.2.3.)

S.2.4. Values of Graduations.-On a gage rod or surface gage, the graduations may be designated in inches and fractions thereof, or may be identified in a numerical series without reference to inches or fractions thereof. In either of these cases there shall be provided for each such rod or gage and each farm milk tank with which it is associated, a gallonage chart showing values in terms of gallons of liquid in the tank, corresponding to each graduation on the rod or gage. If a rod or gage is associated with but one farm milk tank, in lieu of linear or numerical-series graduations and gallonage chart, values in terms of gallons of liquid in the tank may be shown directly on the rod or gage. The value of a graduated interval (exclusive of the interval from the bottom of the rank to the lowest graduation) shall not exceed 1 gallon for a tank of a nominal capacity of 500 gallons or less, and shall not exceed 2 gallons for a tank of a nominal capacity of more than 500 gallons.

S.3. GAllonAGL CHART.-A gallonage chart shall show values at least to the nearest $1 / 2$ gallon for a farm milk tank of a capacity of 500 gallons or less, and at least to the nearest 1 gallon for a tank of a capacity of more than 500 gallons. All letters and figures on a chart shall be distinct and easily readable, the chart shall be substantially constructed, and the face of the chart shall be so protected that its lettering and figures will not tend easily to become obliterated or illegible.

S.4. Installation.-A farm milk tank shall be rigidly installed in level without the use of removable blocks or shims under the legs. If the tank is not mounted permanently in position, the correct position on the floor for each leg shall be clearly and permanently defined.

S.5. IdENTIFICATION.-A farm milk tank and any gage rod or surface gage and gallonage chart associated therewith shall be mutually identified, as by a common serial number, in a prominent and permanent manner.

\section{N. NOTES.}

N.1. Calmbation.-Farm milk tanks shall be originally gaged and officially tested "to deliver.",

N.2. Testrng Medrum.-Water shall be used as the testing medium in gaging and testing farm milk tanks. 
N.3. Approval Seals.-When a farm milk-tank installation is officially tested and approved, the gage rod or surface gage, and the gallonage chart if a chart is utilized, as well as the tank itself, shall be suitably marked to indicate such approval.

\section{T. TOLERANCES.}

T.1. Minimum Tolerance Values.-On a particular farm milk tank, the maintenance and acceptance tolerances applied shall be not smaller than onehalf the value of the minimum graduated interval on the gage rod or surface gage.

T.2. Basic Tolerance Values.-Basic maintenance and acceptance tolerances on underregistration and on overregistration shall be as shown in table 1.

TABLE 1.-Maintenance and acceptance tolerances for farm milk tanks

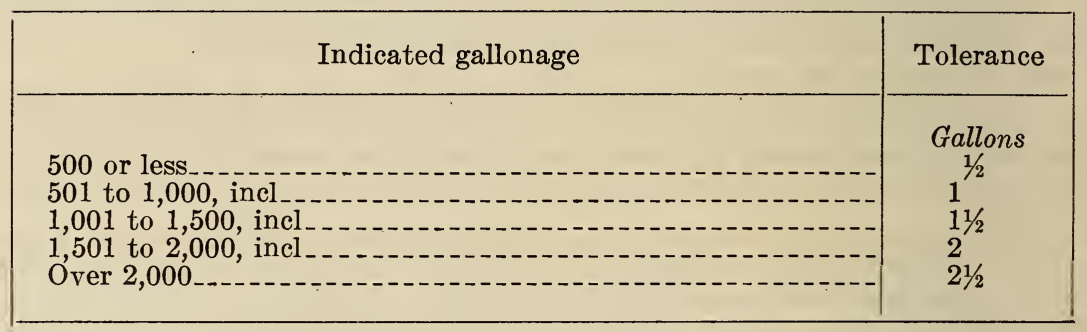

\section{R. REGULATIONS.}

R. 1. Lever Condition.-A farm milk tank shall be maintained in level.

\section{SCALES}

In 1952 the National Conference amended paragraph R.5. of the scale code by deleting the word "retail," thus prohibiting the use of an uncompensated spring scale for any sale of foodstuffs other than fruits and vegetables. For consistency, a similar change should be made in the marking requirement stated in the second sentence of paragraph S.4. of the code. Also, it is no longer necessary to retain in that sentence a statement of a long-past effective date.

Accordingly, the Committee recommends that the second sentence of paragraph S. 4 . be amended to real as follows:

A small-capacity uncompensated spring scale other than a straight-face spring scale shall be conspicuously marked to show that the scale is illegal for use in the sale of foodstuffs other than fruits and vegetables.

\section{TOLERANCES FOR UNCOMPENSATED SPRING SCALES}

Although the Committee is not prepared to recommend that any action be taken this year with respect to tolerances for uncompensated spring scales, it does desire to advise all parties at interest that this subject has been receiving consideration and that it is probable that the Committee will make recommendations concerning such tolerances to the 40th National Conference in 1955.

From 1913, when tolerances for scales were first presented to the Conference, until the present, much more liberal tolerances have been recognized for uncompensated spring scales than for somewhat similar scales of other types of construction. This differential was justified for many years, when expediency dictated that the uncompensated spring scale be retained in commercial service. Such current need is now questioned. 
The Committee is informed of ample availability, at reasonable cost, of compensated springs and compensated spring scales that will perform within the tolerances for small-capacity scales. However, the Committee does not have enough data upon which to base a specific recommendation.

It has been suggested by a number of weights and measures officials, as well as by representatives of manufacturing interests, that the special tolerance concessions in question be withdrawn. The Committee is mindful of the inconsistency of permitting relatively large errors on one scale because of its design, and of requiring much better performance by another scale because of its design, both scales having comparable capacities and subdivisions and both being used for weighing the same commodities.

During the coming year the Committee hopes to receive, from various sources, expressions of opinion on this question. It is suggested that this topic be considered at meetings of officials and of manufacturers' representatives and that a consensus be developed among these groups and reported to the Committee for its guidance. The recommendations of individuals also will be welcome.

\section{REGULATIONS}

It has been suggested to the Committee that paragraphs R. 4.2. and R. 4.3. do not adequately cover the case of a scale having both weighbeam and reading-face elements. As these regulations are now written, the requirement is satisfied on such a scale if graduations having the stated minimum value are provided on only one element-that is, on either weighbeam or reading face. A similar situation exists as between the fractional bar of the main weighbeam elements and the tare weighbeam elements of a scale not equipped with a reading face. It appears that each of the several indicating elements on these scales should be complete within themselves and should comply with the requirement for the value of the minimum graduation.

There are certain attachments to weighbeam-type livestock and vehicle scales, known as "quick-weighing" or "tell-tale" attachments, that serve a special and useful purpose. These attachments are so connected to the weighing mechanisms that they operate independently of the weighing elements. The principal purpose of these devices is to speed up weighing operations, by facilitating the proper positioning of the weighbeam poise. The attachment is never to be used for the complete weighing operation. The weighing operation is always to be done with the weighbeam, independently of the attachment. By reason of their special character, these attachments should, in the opinion of the Committee, be exempted from the normal requirements regarding the values of minimum graduated intervals, but should be graduated in a particular manner to avoid any confusion or inadvertent reading errors in use.

Accordingly, the Committee recommends that Regulations R. 4. 2. and R. 4. 3. be amended to read as follows:

R. 4. 2. On LiveSTock Scales.-The value of the minimum graduation of the main weighbeam elements, of the tare weighbeam elements, and of the readingface elements on a livestock scale shall be not greater than 5 pounds. Provided, That the reading face of any "quick-weighing " or "tell-tale" attachment auxiliary to a weighbeam shall be uniformly graduated into intervals of 5 pounds or less, 100 pounds, or some integral multiple of 100 pounds, and no others. 
R. 4. 3. ON VEHICLE SCALES.-The value of the minimum graduation of the main veighbeam elements, of the tare weighbeam elements, and of the readingface elements on a vehicle scale shall be not greater than 20 pounds. Provided, That the reading face of any "quick-weighing" or "tell-tale" attachment auxiliary to a weighbeam shall be uniformly graduated into intervals of 20 pounds or less, 100 pounds, or some integral multiple of 100 pounds, and no others.

Mr. BAUCOM : Mr. Chairman, will you please differentiate between the "quick-weighing" and "tell-tale" attachments stipulated in these provisos, and the automatic balance-indicating and over-and-underindicating mechanisms found on many beam-type scales.

Mr. R. E. MeEK: The devices covered in these two Regulations are supplemental elements that tell the scale operator the approximate weight on the platform. This is to aid him in more rapid positioning of the weighbeam poise. The actual weighing is done on the weighbeam.

The "attachment" is not connected to the weighbeam, and both weighbeam and attachment operate entirely independently of each other. The hook-up is made from a lever having a ratio of 2 to 1 , similar to the conventional shelf lever. However, the customary fulcrum bearing of this lever, instead of being rigidly supported from the weighbeam shelf or other fixed support, is supported by the load connection to the attachment. This results in the following situation: With respect to the weighbeam, the lever in question is fulcrumed at one end-the end that is supported by the load connection to the attachment. With respect to the attachment, the lever in question is fulcrumed at the other end-the end that is supported by the load connection of the weighbeam. Thus this lever acts in a dual capacity. When a force is applied to the load pivot of the lever (transmitted from the scale platform) this force is transmitted simultaneously and equally to the weighbeam and to the attachment. The indications of the attachment are not changed by manipulation of the weighbeam poise, and the weighbeam indications are unaffected by the indications of the attachment; as stated before, each of these elements operates independently of the other. The attachment does not in any way indicate the balance condition of the weighbeam, as is the case with balance indicators and over-and-under indicators.

(Additional comments on this recommendation of the Committee were made by Mr. Hansen and Mr. Whittington.)

\section{REPRINT NATIONAL BUREAU OF STANDARDS HANDBOOK 44}

The Committee is informed that it is the present intention of the National Bureau of Standards to reprint Handbook 44 as soon as practicable after the adjournment of the 39th National Conference. The new edition of the Handbook will be expected to serve at least during the ensuing 5 -year period. It is desirable that the new Handbook be in the best possible form. To this end, it is the request of the Committee that the Conference authorize the customary and necessary editorial latitude by adopting the following resolution:

Whereas it is probable that National Bureau of Standards Handbook 44 , containing the specifications, tolerances, and regulations for commercial weighing and measuring devices as adopted by the National Conference on Weights and Measures, will soon be republished by the Bureau; Therefore be it

Resolved, That, in the preparation of copy for the republication of National Bureau of Standards Handbook 44, the Conference Committee on Specifications and Tolerances be authorized to make such changes in wording, punctuation, 
and arrangement of the material adorted by the Conference, without changing the meaning or effect, as may be considered advisable in the interest of clarity, brevity, consistency, simplicity, and good form, and as may be dictated by good editorial practice.

(The report of the Committee on Specifications and Tolerances was adopted liy the Conference.)

Mr. R. E. Mesк : I would like to point out that the Conference Committee on Specifications and Tolerances does have on its agenda, for consideration during the coming year, some matters that were presented to it too late for full consideration prior to this Conference. The Subcommittee on Vehicle Tanks of the Americal Petroleum Institute submitted to the Committee various recommendations for amending the vehicle-tank code, as did a special committee of the West Central Region of the North American Gasoline Tax Conference. These recommendations were received by the Committee subsequent to the completion of the tentative report of the Committee and too late to allow full investigation and consideration prior to the 39th National Conference. 'The suggestions are being retained on the agenda of the (ommittee and will be studied prior to the 40th National Conference on Weights and Measures.

The Committee is grateful to representatives of these two groups, to other Conference associate members, and to weights and measures officials who appeared before the Committee during its open meeting on Monday. All of the data presented at that time has been and will continue to be helpful to the Committee in its studies and deliberations.

Mr. REZNEK : Carriers of petroleum products are very much concerned with the code requirement that only a single marker be allowed in each vehicle tank compartment. Many vehicle tanks must be operated contrary to State laws if they are equipped with only one marker. Some of the reasons are (1) A tank designed and calibrated to carry liquid of a certain density then is required to carry product of a different density, (2) the vehicles must travel from State to State and the axle weight laws in the several States differ, and (3) in the northern part of the country, so-called frost laws require that weights be reduced as much as 25 or 30 percent during the spring thawing. It is not our desire to violate any laws, but, if we are required to operate with only one marker in a compartment, we find that we cannot live up to the various State laws. This is a matter of vital importance, as you can understand.

\section{H. R. 8357-TO AMEND U. S. STANDARD CONTAINER ACT OF 1928}

(See also pages 53,60 , and 91 )

Mr. KerLin : I would like to report on the Senate hearing that was attended by Mr. Hulshoff and myself at the direction of this Conference. We were greeted and treated most cordially, and the feelings of this body were expressed to the Committee of the U. S. Senate. Representatives of the U. S. Department of Agriculture were present and were interrogated. The Committee of the Senate lield the matter open until this Conference could take formal action. 


\title{
REPORT OF THE NATIONAL CONFERENCE COMMITTEE ON RESOLU- TIONS, PRESENTED BY W. A. KERLIN, CHAIRMAN
}

\author{
APPRECIATION TO THE STAFF OF THE NATIONal BUREAU OF STANDARDS
}

Whereas, the success of the 39th National Conference on Weights and Measures has been due in large part to the sympathetic leadership of Dr. A. V. Astin, Director of the National Bureau of Standards. to the wholehearted cooperation of the staff of the Bureau, and especially to the thoughtful planning and diligent efforts of Mr. W. S. Bussey, Chief of the Office of Weights and Measures, Mr. M. IV. Jensen, Assistant Chief of that office. and their immediate assistants, Therefore, be it

Resolved, That this 39th National Conferens on Weights and Measures record its sincere appreciation of the services rendered to the Conference by Dr. Astin, Mr. Bussey, Mr. Jensen, and other members of the staff of the National Bureau of Standards.

\section{APPRECIATION TO COOPERATING OFFICIALS}

Whereas, it is recognized that attendance at the meetings of the National Conference on Weights and Measures by weights and measures officers and other persons directly concerned with weights and measures administration in the States, counties, and cities, is made possible in large degree br the interest and cooperation of the governing officials of those jurisdictions, Therefore, be it

Resolved, That this 39th National Conference on Weights and Measures record its gratitude for such interest and cooperation br these gorerning officials and for this evidence of their support of constructire weights and measures supervision throughout the United States.

\section{appreciation to those participating in the Program}

Whereas, the 39th National Conference on Weights and Measures is mindful of the valuable contributions to its success made by the speakers on the program, by those who have exhibited and demonstrated derices of interest to weights and measures officials, and by its standing and special committees, Therefore, be it

Resolved, That this 39th National Conference on Weights and Measures express and record its sincere thanks to all individuals and agencies that have participated in the formal program and the auxiliary erents of its meeting.

\section{APPRECiATION TO THE PRESS}

Whereas, the corerage of the proceedings of the 39th National Conference on Weights and Measures in the newspapers of the City of Washington is much appreciated by those in attendance at the meeting, Therefore, be it

Resolved, That this 39th National Conference on Weights and Measures record its thanks to the press of the City of Washington for its contributions to the success of the Conference.

\section{APPRECIATION TO THE SCALE JOURNAL}

Whereas, the Scale Journal has consistently made most raluable contributions to the promotion of weights and measures administration in the United States by the publication of a wide rariety of material related to that important activity; and

Whereas, the Scale Journal has been particularly helpful in connection with the meetings of the National Conference on Weights and Measures by carrying advance publicity and by publishing accounts of the proceedings; Therefore, be it

Resolved, That this 39th National Conference on Weights and Measures record its thanks to the management of the Scale Journal for its sustained policy of cooperation with the Conference and its consistent support of the Conference program for sound weights and measures supervision.

\section{INTERNATIONAL PROGRAM ON LEgaL METROLOGY}

Whereas, the members of the National Conference on Weights and Measures hare listened with much interest to the message of Dr. M. Jacob, President of the Provisional International Committee on Legal Metrology, wherein he out- 
lined the plans and progress made toward promotion of world uniformity in weights and measures requirements; and

Whereas, the National Conference on Weights and Measures is founded upon the concept of the promotion of uniformity in weights and measures regulations, laws, procedures, and practices in the United States; Therefore, be it

Resolved, That this 39th National Conference on Weights and Measures does extend its sincere thanks to Dr. Jacob for appearing before it and informing it of the world program upon which the Provisional International Committee on Legal Metrology is engaged ; and, be it further

Resolved, That this Conference does express its sympathy with this program and its desire to cooperate in furthering its objectives.

\title{
SALE OF MEAT BY GROSS WEIGHT
}

Whereas, many State weights and measures statutes specify that sales of commodities by weights shall be made by net weight; and

Whereas, in the meat industry a practice has been observed wherein certain meat products are sold by gross weight so indicated by printed notices on sales slips, orders, and invoices ; Therefore, be it

Resolved, That this 39th National Conference does go on record as being opposed to this practice and does solicit the cooperation of the meat industry in bringing about a correction so as to cause the sale of meat products in accordance with all existing laws and ordinances.

\section{H. R. 8357}

Whereas, H. R. 8357, being an Act to amend the Standard Container Act of May 21, 1928, is presently before the 83d Congress, Second Session; and

Whereas, it is the considered opinion of the 39th National Conference on Weights and Measures, representing 39 States and the District of Columbia in meeting assembled on the 21st day of May, 1954, at Washington, D. C., that this proposed legislation is not in the public interest for the reason that the contemplated new $3 / 8$-bushel size container will tend to facilitate the perpetration of fraud in that the consuming public cannot readily distinguish the differences between this proposed new size of $3 / 8$ bushel and the $1 / 2$ bushel size heretofore authorized by the Standard Container Act of 1928 and may therefore be victimized by an unscrupulous vendor offering as and for $1 / 2$ bushel a container of the size of $3 / 8$ bushel ; Therefore, be it

Resolved, That this the 39th National Conference on Weights and Measures places itself on record as opposed to the enactment of said H. R. 8357.

\section{REPRESENTATIVE AT SENATE HEARING}

Whereas, with respect to the resolution adopted by the 39th National Conference on Weights and Measures regarding H. R. 8357, it appears probable that a Committee of the Senate of the United States may desire oral testimony from a member of this Conference relative to the said resolution; Therefore be it

Resolved, That this 39th National Conference on Weights and Measures does appoint as its representative for this purpose Mr. John P. McBride, Director of Standards of the Commonwealth of Massachusetts, and be it further

Resolved, That if further hearings are held, Mr. McBride is authorized to attend and present testimony as the representative of this National Conference, and the Treasurer of the Conference is authorized to reimburse Mr. McBride for the necessary expenses incidental to such representation.

\author{
(Signed) W. A. Kerlin, Chairman, \\ W. A. BAERWOLF, \\ L. C. Carpenter, \\ H. C. HulshofF, \\ F. E. MCKINNEY, \\ P. E. NYSTROM, \\ WiLliam WATERMaN, \\ Committee on Resolutions.
}

(The report of the Resolutions Committee was adopted by the Conference.) 


\section{REPORT OF THE NATIONAL CONFERENCE 'TREASURER}

MAY 1, 1954.

Balance on hand May 1, 1953 $\$ 1,194.45$

RECEIPTS :

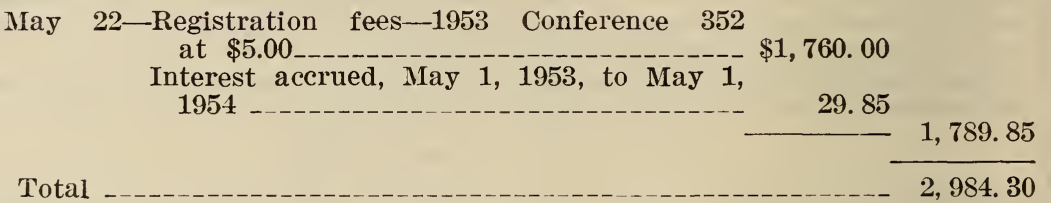

Disbursements :

May 19-22, 1953-

Expenses of 38th National Conference-_-_...

Balance on hand May 1, 1954

$1,495.06$

(Signed) JоH N P. McBRIDE, Treasurer.

(The report of the Treasurer was adopted by the Conference.)

(The Thirty-ninth National Conference on Weights and Measures adjourned sine die at $11: 45 \mathrm{a} . \mathrm{m}$.)

\section{MEETING OF THE EXECUTIVE COMMITTEE OF THE CONFERENCE}

Immediately following adjournment of the 39th National Conference on Weights and Measures, a meeting was Leld of the officers, the newly elected members of the Executive Committee, and the chairmen of the standing committees. Present at the meeting were six of the ten officers, seven of the sixteen Executive Committee members, three of the fire chairmen of the standing committees. The meeting was presided over by President A. V. Astin and by Treasurer G. F. Austin, Jr.

Among the decisions reached by the Executive Committee were the following: Dates of 40th Conference: The Secretary of the Conference was authorized to select the date of the Conference.

Place of 40th Conference: The Conference Secretary was authorized to explore the hotel situation and complete negotiations for a suitable headquarters hotel. Program: Program assignments were left to the discretion of the Secretary.

Social Activities: (pertaining to Wednesday evening) Details of social evening, including refreshments, to be arranged by the Secretary.

Ladies' Entertainment: It was decided that the Conference continue to have some form of entertainment for the ladies and that the Secretary siould arrange a suitable program.

Attendance Chairman: Mr. J. Roy Jones of South Carolina was elected attendance chairman.

General Suggestions: The subject of the color of badges was brought up. It was decided that the colors should remain as they are at present-white for members, green for associate members, and pink for ladies. Another action was to the effect that Mr. Searles, Conference Chaplain, be notified of the serious illness or death of any sealer so that a card could be sent.

Mimeographing of papers, etc.: It was decided to leave to the discretion of the Secretary just what papers should be mimeographed for distribution, according to their usefulness.

\section{PERSONS ATTENDING THE CONFERENCE}

\section{Delegates-State, City, and County Officials}

\section{ALABAMA}

State

W. C. BEatty, State Inspector of Weights and Measures, Clayton.

T. H. Grles, Field Investigator, 1008 East Clinton Street, Huntsville. 
California

State

County :

Alameda

Kern

Los Angeles

San Diego

State

County:

Fairfield

Tolland

City :

Bridgeport

Hartford
James E: Brenton, Chief, Bureau of Weights and Measures, Department of Agriculture, Mull Building, Sacramento.

William A. Kerrin, County Sealer of Weights and Measures, 333 Fifth Street, Oakland.

A. D. Rose, County Sealer of Weights and Measures, 1116 E. California Avenue, Bakersfield.

Charles Morris Fuller, County Sealer of Weights and Measures, 3200 N. Main Street, Los Angeles.

Frank M. Raymund, Assistant County Sealer of Weights and Measures.

Herbert J. McDade, County Sealer of Weights and Measures, 1480 F Street, San Diego.

\section{COLORADO}

Harry N. Duff, Supervisor, Weights and Measures Section, Division of Markets, Department of Agriculture, 3130 Zuni Street, Denver.

\section{CONNECTICUT}

Frant M. Greene, Chief, Division of Weights and Measures, Food and Drug Commission, State Office Building, Hartford.

Frank J. Delaney, State Inspector of Weights and Measures.

William E. Sheehy, County Sealer of Weights and Measures, County Court Building, Bridgeport.

Alvin Coger, Assistant County Sealer of Weights and Measures.

Ernest R. Wilson, Assistant County Sealer of Weights and Measures.

Fred E. McKinney, County Sealer of Weights and Measures, County Court Building, 95 Washington Street, Hartford.

William F. Masinda, County Sealer of Weights and Ieasures, West Willington.

Lours SNow, City Sealer of Weights and Measures, 925 Main Street.

Nathan Kalechman, City Sealer of Weights and Measures, City Hall.

DELAWARE

State

Ralpir Wine, Director, Bureau of Markets, State Board of Agriculture, Dover.

JoHn L. Clough, Director, State Laboratory.

\section{DISTRICT OF COLUMBIA}

Weights, Measures, and Markets

300 Indiana Avenue, N. W.

Washington

District

J. Thomas Kennedy, Chief.

James G. DANCE, Assistant Chief.

J. M. Boucher, Supervisor.

J. T. BENNICK, Inspector and Investigator.

W. W. BrandT, Inspector and Investigator.

L. F. Brooks, Inspector and Investigator.

IV. R. Connelius, Inspector and Investigator.

L. F. GNоттA, Inspector and Investigator. 
F. C. HARBoUR, Inspector and Investigator.

K. G. HAYDEN, Inspector and Investigator.

W. H. JENnings, Inspector and Investigator.

T. B. Middeton, Inspector and Investigator.

B. A. Pettit, Inspector and Investigator.

F. M. WARNER, Inspector and Investigator.

W. W. WELLS, Inspector and Investigator.

\section{FLORIDA}

State

City :

Jacksonville

Miami

State Division, Departinent of Agriculture, Nathan Mayo Building, Tallahassee.

HowARD E. CRAWFORd, Inspector of Weights and Measures, 431 West 8th Street.

HARveY E. How ARD, Supervisor of Weights and Measures, Cocoanut Grove Station, P. O. Box 708.

Merrill D. Williams, Inspector of Weights and Measures.

\section{GEORGIA}

J. W. D. Harvey, Assistant Chemist, Department of Revenue, State Office Building, Atlanta.

\section{ILLINOIS}

State

Merrill M. Emerick, Assistant Superintendent, Division of Foods, Dairies and Standards, Emmerson Building, State Fairgrounds, Springfield.

City : Chicago

Irvine M. Levy, City Sealer of Weights and Measures, Room 608 City Hall.

Frank J. Fitzgerald, Chief Deputy Sealer of Weights and Measures.

JoHN Dillon, Supervising Deputy Inspector of Weights and Measures.

\section{INDIANA}

State

RolunN E. MeEk, Director, Division of Weights and Measures, State Board of Health, 1330 West Michigan Street, Indianapolis.

Lorenzo A. Gredy, State Inspector of Weights and Measures.

E. Howard Hudelson, State Inspector of Weights and Measures.

County :

Grant

St. Joseph

Vigo

Reuben C. Parks, Inspector of Weights and Measures, Court House, Marion.

BERT S. CiCHOWICZ, Inspector of Weights and Measures, City Hall, South Bend.

William H. Roberts, Inspector of Weights and Measures, Room 5 Court House, Terre Haute.

City :

Fort Wayne

Gary

Indianapolis

Kokomo

James A. Hilgemann, Inspector of Weights and Measures, 301 South Clinton Street.

Cleo C. Morgan, Sealer of Weights and Measures, City Hall, Room 204.

Harry H. BRUnNer, Supervising Inspector of Weights and Measures, Room 2, City Hall.

IvaN R. Frazer, Inspector of Weights and Measures, City Building.

Terre Haute
JoHn T. HARPER, Inspector of Weights and Measures, Room 205, City Hall. 


\section{IOWA}

State Des Moines.

A. R. MILEs, State Inspector of Weights and Measures, Madrid.

\section{KANSAS}

State

J. Fred True, State Sealer, Weights and Measures Division, State Board of Agriculture, 420 West 9th Street, Topeka.

City : Topeka

A. A. Haggart, City Sealer of Weights and Measures, City Building.

\section{KENTUCKY}

State

George L. Johnson, Director, Division of Weights and Measures, Department of Agriculture, State Office Building, Frankfort.

Walter C. Caldwell, State Inspector of Weights and Measures, Waynesburg.

City : Louisville

William H. Ising, Chief, Division of Weights and Measures, Department of Public Safety, City Hall.

\section{LOUISIANA}

State

Alois J. MAYER, Director, Division of Weights and Measures, Department of Agriculture and Immigration, P. O. Box 4292, Capitol Station, Baton Rouge.

\section{MAINE}

State

City : Portland

State

County :

Anne Arundel

Baltimore

Montgomery
C. P. Osgoon, Chief, Division of Inspection, Department of Agriculture, State House, Augusta.

James A. Borle, Deputy State Sealer of Weights and Measures.

Charles J. Wills, Jr., Sealer of Weights and Measures, City Building.

\section{MARYLAND}

Paul E. Nystrom, Chief, State Department of Markets, Board of Agriculture, University of Maryland, College Park.

JoHn E. MAHoNeY, Superintendent of Weights and Measures.

RICHARD N. S'MITH, Assistant Superintendent of Weights and Measures.

W. S. ARBuckle, Professor, Dairy Manufacturing, Dairy Department.

JACK S. CoNRAD, Inspector, Dairy Department.

Amos R. Meyer, Associate Professor.

Milton H. Norris, County Inspector of Weights and Measures, Mountain Road, Pasadena.

Frank J. VITTER, Chief Inspector of Weights and Measures, 25 Susquehanna Arenue, Towson.

A. Morton Thomas, Director, Department of Inspection and Licenses, Court House, Rockville.

W. E. DAYmoff, Inspector of Weights and Measures.

Wrwin W. Bucklin, Chief, Division of Zoning, Permits, and Licenses, County Building, Rockville. 
City : Baltimore

City :

Arlington

Boston

Brookline

Cambridge

Chelsea

Chicopee

Gardner

Malden

Medford

Newton

Salem

Somerville

State

City :

Dearborn

Detroit

Hamtramck

Highland Park

Kalamazoo

Lansing -

Pontiac
George H. Leithalser, Senior Assistant Superintendent, Division of Weights and Measures, Department of Public Works, 1106 Municipal Building.

EDWARD E. JAFFA, Inspector.

\section{MASSACHUSETTS}

John P. McBride, Director of Standards, Department of Labor and Industries, 194 State House, Boston.

JAMES J. DoLAN, City Sealer of Weights and Measures, Town Hall.

JoHn F. McCarthy, City Sealer of Weights and Measures, Room 105 City Hall Annex.

James E. McMahon, Deputy Sealer of Weights and Measures, Town Hall.

JosepH M. O'NeIL, City Sealer of Weights and Measures, Municipal Building.

Francis J. HannabUry, Deputy Sealer of Weights and Measures, City Hall.

Wrlliay T. Theroux, City Sealer of Weights and Measures, City Hall.

Frank K. Hrons, City Sealer of Weights and Measures, City Hall.

Johy J. Kelley, City Sealer of Weights and Measures, 43 Fairlawn.

Willidam S. Vinci, Deputy Sealer of Weights and Measures, City Hall.

J. Ellis Bowen, City Sealer of Weights and Measures, City Hall, Newton Centre.

Bruce A. Kotulak, City Sealer of Weights and Measures, 174 Bridge Street.

JoHn F. CASEY, City Sealer of Weights and Measures, City Hall.

\section{MICHIGAN}

Miles A. Nelson, Chief, Bureau of Marketing and Enforcement, Department of Agriculture, Lewis Cass Building, Lansing.

ClYDE E. Brown, State Inspector, State Department of Agriculture, 703 Cadillac Square Building, Detroit.

M. O. Nickon, City Sealer of Weights and Measures, Police and Courts Building.

William H. Broomhald, Councilman, City Hall.

HAZEN L. FunK, Commissioner and City Sealer, Bureau of Weights and Measures, Department of Purchases and Supplies, 740 Elmwood Arenue.

George F. Austin, Jr., Deputy Sealer.

Stephen W. PiAsecki, City Sealer of Weights and Measures, 10008 Dequindre Street.

JAMES F. BAKER, City Sealer of Weights and Measures, Highland Park Police Dept.

E. Frank Whittington, City Sealer of Weights and Measures, City Hall.

Walter M. Saxton, City Sealer of Weights and Measures, 333 North Cedar Street.

WALter A. BaERwolf, City Sealer of Weights and Measures, Police Dept. 
State

City : Minneapolis_

State

City : Portsmouth

State

County :

Atlantic

Bergen

Burlington

Cumberland

Essex

Gloucester

Mercer
ErLing Hansen, Supervisor, Department of Weights and Measures, Railroad and Warehouse Commission, South Third Street, Minneapolis.

Russelt S. Ackerman, Superintendent, Department of Licenses, Weights and Measures, Room 3 City Hall.

JoHn G. GUSTAFson, Inspector.

Frank Wolrnski, Inspector.

\section{MISSOURI}

L. C. Carpenter, Commissioner, Department of Agriculture, Jefferson City.

Rollo E. Singleton, Director, Weights and Measures Division.

JosepH A. BERNARD, Commissioner of Weights and Measures, Room 12 City Hall.

MONTANA

Delbert Walrath, Chief Deputy Sealer, Department of Agriculture, State Capitol Post Office, Helena.

\section{NEW HAMPSHIRE}

Clement A. Lyon, Director, Bureau of Weights and Measures, Division of Markets and Standards, Department of Agriculture, State Office Building, Concord.

Alfred H. Dittrich, Chief Inspector.

William A. THomson, City Sealer of Weights and Measures, 56 Ridges Court.

NEW JERSEY

JosePH G. ROGERS, Superintendent, Division of Weights and Measures, Department of Law and Public Safety, 187 West Hanover Street, Trenton.

Archie T. Smith, Assistant Superintendent.

Samuec H. Christie, Jr., Senior Inspector.

James E. Mrens, County Superintendent of Weights and Measures, 350 South Egg Harbor Road, Hammonton.

Michael J. Santimauro, County Superintendent of Weights and Measures, 66 Zabriskie Street, Hackensack.

Ernest Dawson, Assistant County Superintendent of Weights and Measures.

PaUl F. NUnN, County Superintendent of Weights and Measures, Centerton Road, Masonville.

AlFred LIRIo, County Superintendent of Weights and Measures, Box 369, Vineland.

Winfietd K. Thompson, Assistant County Superintendent of Weights and Measures, Court House, Bridgeton.

William H. SchNeidewind, County Superintendent of Weights and Measures, Hall of Records, Newark.

Martin J. Caulfield, County Superintendent of Weights and Measures, Westville Road, Almonesson.

Ralph M. Boden weiser, County Superintendent of Weights and Measures, Court House, Trenton. 
Middlesex

Monmouth

Morris

Passaic

Union

City :

Clifton

Englewood

Hoboken

Jersey City

Passaic

Paterson

Union City
Charles F. Sullivan, County Superintendent of Weights and Measures, Sheriff's Office Building, New Brunswick.

GlenN L. BerRy, County Superintendent of Weights and Measures, 706 Eighth Avenue, Asbury Park.

William I. Thompson, Assistant County Superintendent of Weights and Measures, P. O. Box 76, Allenhurst.

JoHN A. J. Bovie, County Inspector of Weights and Measures, $82 \mathrm{~W}$. Wall S'treet, Neptune City.

DEL G. NeLson, County Superintendent of Weights and Measures, Court House, Morristown.

WILliam Mrller, County Superintendent of Weights and Measures, Administration Building, Paterson.

JAMES M. Dietz, County Superintendent of Weights and Measures, Court House, Elizabeth.

Felix J. SANdRI, Municipal Superintendent of Weights and Measures, City Hall.

Leonard DeRienzo, Municipal Superintendent of Weights and Measures, City Hall.

Anthony Grossi, Municipal Superintendent of Weights and Measures, City Hall.

JoHN S. BUrKe, Municipal Superintendent of Weights and Measures, City Hall.

Paul DeVries, Municipal Superintendent of Weights and Measures, Municipal Building.

JosepH SHAw, Assistant Municipal Superintendent of Weights and Measures.

Joseph P. Leonard, Municipal Superintendent of Weights and Measures, 115 Van Houten Street.

Alfred O. Oslund, Municipal Superintendent of Weights and Measures, Municipal Building.

\section{NEW YORK}

State

E. V. Moore, Assistant Commissioner, Department of Agriculture and Markets, State Office Building, Albany.

Clement A. Baker, Director, Bureau of Weights and Measures.

County :

Genesee

Gienn A. Pullman, County Sealer of Weights and MIeasures, 19 Buffalo Street, Bergen.

Monroe

Earl D. Hubble, County Sealer of Weights and Measures, 1400 South Avenue, Rochester.

Nassau

Robert WILliams, County Sealer of Weights and Measures, Old County Court House Annex, Mineola.

WILLIAM KIRK, JR., Assistant County Sealer of Weights and Measures.

Niagara

H. C. Hulshoff, County Sealer of Weights and Measures, 17 High Street, Lockport.

City :

Binghamton

Harry A. Lason, City Sealer of Weights and Measures, 60 Robinson Street.

Ithaca

E. Paul Nedrow, City Sealer of Weights and Measures, 318 Columbia Street.

Lackawanna

John J. Seres, City Sealer of Weights and Measures, 84 Rosary Avenue.

Long Deach

Irs. Veronica Roche, City Sealer of Weights and Measures, 562 East Market Street, Long Beach, Long Island. 
Rochester

Yonkers

State

County :

Medina

Sandusky

City :

Akron

Cincinnati

Lorain ABOR Tотн, City Sealer of Weights and Measures, 3019 Caroline Arenue.

\section{OKLAHOMA}

State

City : Oklahoma City

T. C. BEck, Assistant Dilector, Marketing Division, State Board of Agriculture, 122 Capitol Building, Oklahonı City.

Charles Edward Clifford, City Chemist, 507 Municipal Building.

\section{OREGON}

State

O. K. Beals, Chief, Division of Foods and Dairies, Weights and Measures, Department of Agriculture, Salem.

Walter B. Steele, Deputy State Sealer of Weights and Measures.

\section{PENNSYLVANIA}

State

Josepr F. Blickley, Director, Bureau of Standard Weights and Measures, Department of Internal Affairs, Capitol Building, Harrisburg.

Spencer H. Seighman, Assistant Director.

JAmes J. Powers, Supervisor, Bureau of IVeights and Measures, 305 City Hall, Philadelphia.

Paul F. WAtson, City Inspector of Weights and Measures, City Hall.

\section{RHODE ISLAND}

State

EDWARD R. Fisher, Sealer of Weights and Measures, Department of Labor, Veterans Memorial Building, 83 Park Street, Providence.

James F. Corrigan, Deputy State Sealer of Weights and Measures. 


\section{SOUTH CAROLINA}

State

J. Roy Jones, Commissioner, Department of Agriculture, Wade Hampton Office Building, P. O. Box 1080, Columbia.

Carl H. Stender, Assistant Commissioner.

\section{TENNESSEE}

State

Wirliam F. Moss, Assistant Commissioner, Department of Agriculture, 411 State Office Building, Nashville.

City :

Memphis

V. D. Rogers, City Inspector of Weights and Measures, 590 Washington Avenue.

Nashville

Tом WebB, Sealer of Weights and Measures, 300 Demonbreun Street.

Maxie Runion, Deputy Sealer of Weights and Measures.

TEXAS

State

L. B. Sherman, State Inspector of Weights and Measures, Department of Agriculture, Austin.

City :

Dallas

F. G. YARBRoUgh, Inspector of Weights and Measures, 311 City Hall.

Fort Worth

R. L. SharP, Inspector of Weights and Measures, Department of Public Health \& Welfare, City Hall.

Houston

M. D. LEACH, Inspector, Weights and Measures Division, Dept. of Public Works, City Hall.

\section{UTAH}

City : Salt Lake City

Edwin C. Westwoon, City Sealer of Weights and Measures, 118 East First Street.

\section{VERMONT}

State

Arden L. LaPlant, Supervisor, Division of Weights and Measures, Department of Agriculture, Agriculture Building, Montpelier.

\section{VIRGINIA}

State

JoHN H. MeEK, Director, Division of Markets, Department of Agriculture, 1200 East Main Street, Richmond.

R. D. Thompson, Supervisor, Weights and Measures Section.

Oscar T. Almarode, State Inspector of Weights and Measures, Box 807, Staunton.

L. R. Gondon, State Inspector of Weights and Measures, Richmond.

J. H. Pierce, State Inspector of Weights and Measures, Woodstock.

Thomas R. Jarvis, Field Supervisor, Weight Station, Department of Highways, Richmond.

C. E. Whitman, Field Supervisor, Scale Maintenance, Department of Highways.

County : Arlington

JAMES I. Francis, Weights and Measures Inspector, 1314 N. Courthouse Road, Arlington.

City :

Danville

CLYPE H. Wrenn, City Sealer of Weights and Measures, City Market Building.

Newport News

JoHn B. LAYTon, City Sealer of W'eights and Measures, City Hall. 
Norfolk
Richmond

W. K. Tripple, Chief, Bureau of Weights and Measures, City Market Building.

J. A. Parron, City Inspector of Weights and Measures.

Corway C. Mundr, Chief, Bureau of Weights and Measures, Laurel and Main Streets.

A. L. BRock WELL, Inspector of Weights and Measures.

M. L. Rice, Inspector of Weights and Measures. James M. Hudgins, City Sealer of Weights and Measures. City Market Building.

\section{WASHINGTON}

City : Seattle

Walter L. Daniels, Director, Licenses and Standards, Office of the Comptroller, 100 County-City Building.

Don MI. Turnbull, Supervisor, Licenses and Standards.

\section{WEST VIRGINIA}

State

Haxser James Harper, State Inspector of Weights and Measures, Moorefield.

C. Hunter Hotт, State Inspector of Weights and Measures, Box 781, Romney.

RoY NEWKIRK, State Inspector of Weights and Measures, Hedgesville.

County: Harrison_._._._... Mrs. Beatrice LanHaM, County Sealer of Weights and Measures, Harrison County Court, Clarksburg.

\section{WISCONSIN}

State

Wirliam Waterman, Supervisor, Weights and Measures Inspection, Department of Agriculture, State Capitol, Madison.

('ity: Wausau__._._._. Alex K. Mrchaelsox, City Sealer of Weights and Measures, Market Square Building.

\section{WYOMING}

State

Elvix IaEmax, Superintendent, Division of Weights and Measures, Capitol Building, Cheyenne.

\section{DELEGATES, GUESTS, AND CONFERENCE STAFF-NATIONAL BUREAU OF STANDARDS}

Director's Office :

A. V. Astin, Director.

A. T. McPherson, Associate Director.

W. S. Busser, Chief, Office of Weights and Measures.

M. W. Jensen, Assistant Chief, Office of Weights and Measures.

R. W. Simith, Consultant, Office of Weights and Measures (Honorary Member).

Mrs. K. M. Schwarz, Attorney-Editor, Office of Weights and Measures.

Mrs. R. E. TAYLor, Secretary, Office of Weights and Measures.

Mrs. F. C. BELL, Clerk-Stenographer, Office of Weights and Measures.

W. R. 'Tilley, Chief, Technical Reports Section, Office of Scientific Publications.

C. L. Bragat, Editor, Technical Reports Section, Office of Scientific Publications.

John Friedman, Technical Reports Section, Office of Scientific Publications.

Mrs. F. T. Achenbach, Office of Scientific Publications.

B. H. Barbour, Publications Section, Office of Scientific Publications. 
Applied Mathematics Division :

Churchill Eisenhart, Chief, Statistical Engineering Lahoratory.

W. S. Connor, JR., Engineer, Statistical Engineering Laboratory.

W. H. Clatworthy, Mathematician, Statistical Engineering Laboratory.

Julius Lieblein, Mathematician, Statistical Engineering Laboratory.

Mary G. NATrella, Statistician, Statistical Engineering Laboratory. Chemistry Division :

E. R. Weaver, Chief, Gas Chemistry Section.

J. H. Eisemann, Gas Chemistry Section.

Management Planning Staff:

T. C. LEFFINGWELL.

Mechanics Division:

H. S. Bean, Chief, Capacity, Density, and Fluid Meters Section.

B. C. Keysar, Capacity, Density, and Fluid Meters Section.

H. H. Allion, Capacity, Density, and Fluid Meters Section.

J. C. Hughes, Capacity, Density, and Fluid Meters Section.

D. R. Tate, Chief, Mass and Scale Section.

L. B. Macurdy, Chief, Mass Unit, Mass and Scale Section.

Miss E. M. Clinton, Physicist, Mass Unit, Mass and Scale Section.

Miss N. J. Tighe, Mass Unit, Mass and Scale Section.

H. H. Russell, Chief, Scale Unit, Mass and Scale Section.

H. L. BAdger, Physicist, S"cale Unit, Mass and Scale Section.

C. H. OAKLEY, Weights and Measures Co-ordinator, Scale Unit, Mass and Scale Section.

Optics and Metrology Division:

I. H. Fuldmer, Chief, Engineering Metrology Section.

L. V. Judson, Chief, Length Section.

R. W. CroucH, JR., Photometry and Colorimetry Section.

W. SOUDER, Retired.

Organic and Fibrous Materials Division:

T. W. LashoF, Paper Section.

Miss J. M. Blandford, Textile Technologist, Textile Section.

\section{GUESTS REPRESENTING UNITED STATES GOVERNMENT}

U. S. Department of Agriculture :

C. L. RICHARD, Supervisor of Scales and Weighing, Livestock Branch, Room 3530 South Building, Washington 25, D. C.

R. J. Neale, Weights and Measures Inspector, Packers and Stockyards Division, Livestock Branch, Production and Marketing Administration, 760 Livestock Exchange Building, Kansas City 2, Mo.

E. A. MURPHY, Federal Meat Inspection, Washington, D. C.

U. S. Department of the Army :

E. R. Melton, Lt. Col., FC, Office Chief of Finance, Washington 25, D. C.

E. H. BaLL, Major, Office Chief of Transportation, Washington 25, D. C.

U. S. Department of Commerce:

Walter Williams, Under Secretary of Commerce, Washington 25, D. C.

W. M. Sawyer, Industry Specialist, Containers and Packing Division, Business and Defense Services Administration, Room 4053 Commerce Building, Washington 25, D. C.

U. S. Department of Health, Education, and Welfare :

S. C. Rowe, Chemist, Food Division, U. S. Food and Drug Administration, Room 4161 South Building, Washington 25, D. C.

U. S. Marine Corps :

T. A. Branch, Captain, Transportation Section, Washington 25, D. C.

C. C. NeLson, Captain, Washington 25, D. C.

U. S. Department of the Navy :

E. T. Moran, Civ. Director, Household Goods, Bureau of Supplies and Accounts, Arlington Annex, Washington 25, D. C.

J. E. MCCormick, Asst. Civ. Director, Household Goods Division, Arlington Annex, Washington 25, D. C.

U. S. Treasury Department:

N. T. Morseld, Chief, Tobacco Branch, Alcohol and Tobacco Tax Division, Internal Revenue Bureau, Washington 25, D. C.

E. W. Teagarden, Engineering Specialist, Bureau of Customs, Washington 25 , D. C. 


\section{GUESTS REPRESENTING MANUFACTURERS OF WEIGHING AND MEASURING DEVICES}

American Meter Company: Wallace T. White, Sales Engineer, 1513 Race Street, Philadelphia, $\mathrm{Pa}$.

American Scale and Vise Companz:

VIRGIL IV. FARRAR, Sales Manager, 6 East 11th Street, Kansas City 6, Mo.

C. V. MARKS, Chief Engineer.

Arers Adhesive Label Corporation: Wilmer P. Webster, District Sales Manager, Commercial Trust Building, Philadelphia 2, Pa.

Badger Meter Manufacturing Company:

J. E. Johxstox, 2357-71 N. 30th Street, Milwaukee 10, Wis.

CHARLES E. KоHL.

Bloomer Brothers Company: RAYNor M. Holmes, Research Engineer, Newark, New York.

BOW SER. INC. :

G. H. GICZEwsKi, Manager Adrance Engineering Section, 1302 E. Creighton, Fort Wayne, Ind.

C. P. GriffitH, Vice President in Charge of Engineering.

W. M. Harks, Vice President and Director of Sales, $33 \mathrm{~N}$. LaSalle Street, Chicago, Ill.

Brodie, Ralph N., Company :

D. W. Kingsley, Eastern Sales Manager, 550 S. Columbus Avenue, Mount Vernon, New, York.

C. J. McCAFfreY, Vice President.

Buffalo Scale Company: T. L. RIcHMond, Jr., President, 46 Letchworth Street, Buffalo, New York.

Chatillon, John \& Sons: George C. Reiney, Vice President, Sales, 85 Cliff Street, New York 38, N. Y.

Cox \& Sterens: James Heatley, Sales Manager, Glen Cove Road, Mineola, N. Y.

Creamery Package Ifg. Company: L. T. Gustafson, General Sales Engineer, $1243 \mathrm{WV}$. Washington Blrd., Chicago 7, Ill.

Dairy Equipment Mfg. Company :

Kenneth S. Hart, President, 1444 E. Washington Avenue, Madison 3, Wis. Don J. Peltier, Winooski, Vermont.

DeLaval Separator Company:

Axel C. Gustafson, General Dairy Representative, Poughkeepsie, N. Y.

QUITo G. RECCHIA, Engineer, Development.

Detecto Scales, Inc. :

MACK RAPP, Vice President, 540 Park Avenue, Brooklyn 5, N. Y.

Mrs. Carrie G. Woodland, Representative, Woodland's Temple Grove, Fellsmere, Fla.

Dixie Cup Companr: Arthur J. Nolan, Vice President, Easton, Pa.

Erie Meter Systems, Inc. :

Paul R. Fishburn, Chief Engineer, P. O. Box 559, Erie, Pa.

William B. JoHNson, JR., Manager of Sales.

Exact Weight Scale Company :

K. B. NefF, President, 944 West 5th Avenue, Columbus 8. Ohio.

W. A. ScheUrer, Vice President.

James F. Sullivan, Chief Engineer.

OlIVER WATSoN, Manager, Chicago Division, 608 S. Dearborn Street, Chicago, Ill.

Ex-Cello-O Corporation: Geve R. Andre, Pure-Pak Division, 1200 Oakman Blvd., Detroit 32, Mich.

Fairbanks, Morse \& Company :

John J. Conneld, Field Engineer, 659 E. 25th Street, Baltimore, Md.

C. G. GeHrINGER, Assistant Manager Scale Division, 600 S. Michigan Avenue, Chicago 5, Ill.

FredErICK C. JoHnson, 80 Broad Street, New York 4, N. Y.

Jerome C. KeNNEY, Field Engineer, 659 E. 25th Street, Baltimore, Md.

G. C. Worthley, Manager, Scale Division, 600 S. Michigan Avenue, Chicago, IIl.

Fisher Governor Company: Walter H. HoAgland, Eastern Manager, 212 East State Street, Westport, Conn. 
Fuller, H. J., Company: H. J. Fuller. President, 1371 W. Third Arenue, Columbus 12, Ohio.

Gap Instrument Corporation: A. S. Goodrich, President, 253 W. Merrick Road, Valley Stream, N. Y.

General Electric Company :

Russell Morgan, 4855 Electric Avenue, Milwaukee, Wis.

Herbert ScHreiber, JR., Industrial Product Engineer.

Gilbert \& Barker Mfg. Co.:

C. A. BEllows, Manager Patents, Weights, and Measures, West Springfield, Mass.

William Keay, Manager, Sales Service.

Girton Manufacturing Company : JACK M. RuckLE, Sales Engineer, Millville, Pa.

Gomolla, Henry, \& Son: Henry W. Gomolla, Owner, 36 Montgomery St., Bloomfield, N. J.

Gould Equipment Company: EARlon W. BARRETt, Representative, Box 1611, Portland, Maine.

Granberg Corporation :

Robert C. ANDERsoN, General Manager, Granco Pumps and Meters, 1308 67 th Street, Oakland, Calif.

Paul B. McCaNn, District Manager, 489 Fifth Avenue, New York, N. Y.

Gurley, W. \& L. E.: Franklin G. Wrlliams, Washington Representative, 5514 Nevada Avenue, N. W., Washington 15, D. C.

Hobart Manufacturing Company :

Murray Craig, Weights and Measures Representative, Dayton Scale Division, Penn Arenue at Simpson Street, Troy, Ohio.

E. A. Reussenzehn, Chief Scale Engineer, Dayton Scale Division, 448 Huffman Avenue, Dayton 3, Ohio.

Hodgson, Alfred E., Scale Distributor, 6932 Market Street, Upper Darby, Pa.

Howe Scale Company :

R. A. Parham, Branch Manager, 1300 Curtain Avenue, Baltimore 18, Md.

Richard F. Straw, Vice President, Sales, 2941 Scale Avenue, Rutland, Vt. Hunter, S. S., Inc. :

JAck W. Polivka, Sales Manager, Box 390, La Grange, Ill.

William M. Shanhouse, General Manager, Syossett, New York.

Lily-Tulip Cup Corporation :

Kеттн B. Mount, Assistant to Vice President, 122 E. 42nd Street, New York $17, N . Y$.

Richard S. WeChSLER, Counsel.

I.incoln Engineering Company : Lutwin C. RotTer, Chief Engineer, 5701 Natural Bridge, St. Louis, Mo.

Marvel Rack Manufacturing Company, Inc.: Charles W. McCarthy, President, 24 N. First Street, Minneapolis, Minn.

McIntyre, John J., Sons :

F. L. McIntyre, 514-16 Knorr Street, Philadelphia 11, Pa. JoHN L. MCINTYRE.

Measuregraph Company : E. A. Powell, Regional Manager, 1710 Edgewood Road, Baltimore, Md.

Mellinger Manufacturing Company :

W. Roger Roop, Engineer, Lancaster, Pa.

Eugene R. Witmer, Sales Manager.

Mojonnier Bros. Co. : J. W. NIsonger, 2301 Tecumseh Street, West Hyattsville, Md. Moulden Supply Company: Haskell V. Johnson, Field Representative, P. O. Box 1247, Jackson, Miss.

Neptune Meter Company:

H. A. Lentz, Jr., Representative, 1803 Finance Building, Philadelphia 2, Pa. Walter H. Sieger, Sales Manager, Petroleum and Industrial Meters, 50 West 50 th Street, New York 20, N. Y.

Eмmетт F. Wenmann, Engineer, 22-12 Jackson Avenue, Long Island City, N. $Y$.

()wens-Illinois Glass Company: J. D. LAIRD, Chief Specification and Service Engineer, Toledo 1, Ohio.

Partee Equipment Company : Paul F. Partee, Spencerville, Indiana.

Penn Scale Mfg. Co., Inc.: Srdney Black, President, 150 W. Berks Street, Philadelphia 22, Pa.

liichardson Scale Company : H. Bandstra, 668 Van Houten Areuue, Clifton, N. J. 
Rockwell Manufacturing Company :

Edward R. Eyler, Sales Engineer, 400 N. Lexington Arenue, Pittsburgh, Pa. Charles B. Johnson, Consulting Engineer.

JAmes H. Judge, Product Manager.

Paul A. Mankin, Chief Engineer.

Charles H. Obrock, Sales Engineer, 7701 Empire State Building, New York, N. Y.

Sanitary Scale Company: J. V. FARwell, III, President, 664 N. Michigan Are., Chicago, Ill.

Sauter, August, N. Y., Inc. :

Gerhart F. Czemba, 230 Park Arenue, New York, N. X.

HAYES G. SHIMP

Seraphin Test Measure Company: T. A. Seraphix, General Manager, 1314 N. 7th Street, Philadelphia 22, Pa.

Smith, A. O., Corporation :

H. D. Leisenring, Sales Manager, Eastern Area, 250 Park Arenue, New York 17, N. Y.

W. G. Moser, Manager, Meter Dirision, 5715 Smithway Street, Los Angeles, Calif.

Stanton Instruments Ltd.: G. R. JoNES, 119 Oxford Street, London W1, England.

Stewart Warner Corporation: Stanley J. Zillinski, 1826 Dirersey Parkway, Chicago, Ill.

Stimpson Computing Scale Company: JoHn J. WAAGE, President, 829-837 Logan Street, Louisville 4, Ky.

Streeter-Amet Company: Verve C. Kexnedr, President, 4101 Rarenswood Arenue, Chicago 13, Ill.

Thatcher Glass Manufacturing Company:

James Arrandale, Director, Quality Control and Serrice Department, 623 W. Water Street, Elmira, N. Y.

ANDrew E. Mauro, Director of Quality Control.

Tokheim Oil Tank and Pump Company :

William Louthan, Manager, Field Serrice, 1602 Wabash Arenue, Fort Wayne 1 , Ind.

KeN SLusHer.

Toledo Scale Company:

ARthur H. Alexander, District Manager, Baltimore, 1720 E. Fayette Street, Baltimore, Md.

Stanley Q. Bennett, Manager of Weights and Measures and Sanitary Standards, 5225 Telegraph Road, Toledo 1, Ohio.

D. J. Boudinot, General Sales Manager.

Brron D. Miller, Manager, Gorernment Dirision, 3329 Eighth Street, N. E., Washington, D. C.

Torsion Balance Company: Fraxk O. Deimel, Manager, Eastern Division, Clifton, N. J.

Triner Scale \& Manufacturing Company: JoHr E. EdGertor, Representatire, 1395 National Press Building, Washington, D. C.

Troemner, Henry: Chardes F. Rosica, Sales Manager, 911 Arch Street, Philadelphia $7, \mathrm{~Pa}$.

U. S. Slicing Machine Compans:

G. D. COAN, 333 Larson Street, La Porte, Indiana.

Matthew D. Ribble, Special Representative, 16660 Normandy, Detroit, Mich. Veeder-Root, Inc. :

J. J. Brannick, Sales Manager, Computer Dirision, 44 Cherryfield Drire, West Hartford 7, Conn.

A. E. McKeever, Sales Manager, Master Meter Duplicator Dirision.

David J. Post, JR., Vice President.

Viking Tool and Machine Company: ArchiE J. Dowd, Manager, Taximeter Division, 2 Main Street, Bellerille, N. J.

Wayne Pump Compans:

Freedon H. AInsworth, Assistant Chief Engineer, Salisbury, Md.

IVILliaM L. CoN NELLY, JR., Sales Engineer.

W. J. Dubsky, Project Engineer.

Winslow Gorernment Standard Scale Works, Inc. : C. E. EHrexHARd, Secretary, 25th and Harthorne Avenue, Terre Haute, Ind.

Wood, John, Company :

L. G. Close, Manager, Baltimore District, Bennett Pump Division, $2127 \mathrm{~N}$. Charles Street, Baltimore 18, Md.

IV. M. HoxIE, Service Manager, Bennett Pump Dirision, Broadway \& Lethen Streets, Muskegon, Mich. 

AND RAILROADS

Agricultural Ammonia Institute: Douglas JoHnston, Chairman, Agricultural Ammonia Institute Committee, John Blue Company, Huntsville, Ala.

American Meat Institute: ARTHUR BroAdwin, 727 National Press Building, Washington 4, D. C.

American Petroleum Institute: Logan L. KenNedy, Chairman, Weights and Measures Committee, (Esso Standard Oil Company), 500 North Broad Street, Elizabeth, N. J.

American Seed Trade Association: William Heckendorn, Executive Secretary, Suite 1107, 30 N. LaSalle Street, Chicago 2, Ill.

American Trucking Associations, Inc. :

Charles P. HofFmann, Jr., Automotive Engineer, 1424 Sixteenth Street, N. W., Washington, D. C.

LEWIS C. KIBBEE.

American Veneer Package Association, Inc. : Don M. JAMEs, Director of Research, 1808 High Street, Camp Hill, Pa.

Association of American Soap \& Glycerine Producers, Inc.: Roy W. PeET, Manager, 295 Madison Avenue, New York 17, N. Y.

Cannon Mills: Herbert Allen Greene, Kannapolis, North Carolina.

Chestnut Farms Dairy: William B. Anderson, Director of Supply, 2535 Pennsylvania Avenue, N. W., Washington 7, D. C.

Chicago Better Business Bureau, Inc.: M. John Madsen, Manager, Fuel Division, 14 E. Jackson Boulevard, Chicago 4, Ill.

Connecticut Milk Producers Association: John S. Seremet, Supervisor, Field Service, 990 Wethersfield Avenue, Hartford, Conn.

Continental Oil Company : R. W. Hird, Assistant Director, Marketing Operations, P. O. Box 2197, Houston 1, Texas.

Dairymen's League Co-op. Association, Inc.: Robert W. Metzger, Assistant Director of Quality Control, 100 Park Arenue, New York, N. Y.

Farm Market Relations, Inc.: Edwin W. Strllwell, President, 975 National Press Building, Washington 4, D. C.

Fruit Dispatch Company:

John N. KeLLey, Manager, Fruit Transportation, Pier 3, North River, New York $6, \mathrm{~N}$. Y.

R. B. Tewksbury, Assistant Manager, Fruit Transportation, Pier 3, North River, New York 6, N. Y.

Gasoline Pump Manufacturers Association : G. Denny Moone, Managing Director, 420 Lexington Avenue, New York 17, N. Y.

General Ice Cream Corporation: G. Emerson Sartain, Producer Relations, Bryant \& Chapman Dairy, 255 Homestead Avenue, P. O. Box 88, Hartford, Conn.

General Mills, Inc.: Oswald A. Oudal, Products Control Manager, Grocery Products Division, 400 Second Avenue, South, Minneapolis, Minn.

Glass Container Manufacturers Institute: C. EARL WAgner, Development Engineer, 8 West 40th Street, New York 18, N. Y.

Gulf Oil Corporation:

E. C. Dickey, Superintendent, Marketing Equipment, Atlanta Sales Division, Gulf Building, Atlanta, Ga.

JoHn O. Habichт, Superintendent, Marketing Equipment, 1515 Locust Street, Philadelphia 2, Pa.

W. K. MсCoy, General Superintendent, Plant Operations and Equipment, Gulf Building, Pittsburgh 30, Pa.

Humble Oil \& Refining Company: J. E. Niland, Chief Engineer, P. O. Box 2180, Houston, Texas.

Industrial Research Syndicate: C. A. LindsAy, Director, 1305 Euclid Street, N. W., Washington 9, D. C.

Illinois Central Railroad: Walter Schlinkert, Superintendent of Scales, 202 North Walnut Street, Centralia, Ill.

Inland Steel Company: R. J. LAvery, Supervisor of Scales, East Chicago, Ind.

International Association of Ice Cream Manufacturers: Donald H .Williams, Assistant to Executive Secretary, 1105 Barr Building, Washington 6, D. C.

LP-Gas Association: Chris F. Neely, Staff Engineer, 11 S. LaSalle Street, Chicago, Ill. 
Siquid Tight Paper Container Association: ArTHur IV. Howe, Jr., Assistant Executive Secretary, 1532 Lincoln-Liberty Building, Philadelphia 7, Pa.

Marvadel Ice Cream Company, Inc.: John C. KrUsen, Manager, 4001 Seven Mile Lane, Baltimore 8, Ma.

Maryland-Virginia Milk Producers Association:

Cecrl F. Cole, Field Representative, $1756 \mathrm{~K}$ street, N. W., Washington, D. C. JA mes B. SMathers, Fieldman.

Millers National Federation: Herman FAkıer, Vice President, 847 National Press Building, Washington, D. C.

National Association of Dairy Equipment Manufacturers: JoHn Marshall, Executive Secretary, 927 Fifteenth Street, N. W., Washington, D. C.

National Association of Scale Manufacturers: Arthur Sanders, Executive Secretary, No. 1 Thomas Circle, Washington 5, D. C.

National Dairy Products Corporation: Walter D. Hunnicutt, Manager, Procurement and Supply Department, 260 Madison Arenue, New York 16, N. Y. National Fisheries Institute:

Cinarles E. Jackson, General Manager, 1614 'Twentieth Street, Washington $9, \mathrm{D} . \mathrm{C}$.

Mat Xavier, Director, West Coast Operations.

National Tank Truck Carriers, Inc.: Lovis REzNek, Director of Safety and Engineering, 1424 Sixteenth Street, N. W., Washington, D. C.

National Tiuck Tank and Trailer Tank Institute: Allan R. Surth, Executive Secretary, 120 S. LaSalle Street, Chicago 3, Ill.

New York, New Haven \& Hartford Railroad Company: Eugene G. Ruot, Scale Supervisor, Work Equipment Department, New Haven, Conn.

Paper Cup and Container Institute:

Dale H. Eckerman, Executive Director, Room 1020 Postum Building, 250 Park Avenue, New York 17, N. Y.

Robert W. Foster, Assistant Executive Director.

Pennsylvania Railroad: BYRon R. Nelson, Supervisior of Scale Inspectors, 30th Street Station, Room 417, Philadelphia 4, Pa.

Phillips Petroleum Company: PAUL IV. Tucker, Technical Representative, Bartlesville, Okla.

Pillsbury Mills, Inc. :

Otis W. Galloway, Claim Agent, 6607 Garden Home Road, S. W., Portland, Oregon.

Charles E. Joyce, Claim Agent, 608 Second Avenue South, Pillsbury Building, Minneapolis 2, Minn.

Pure Oil Company: R. G. Emmetт, Assistant Operating Manager, 35 East Wacker Drive, Chicago, Ill.

Pyrofax Gas Corporation: John P. Russert, Engineering Assistant, 30 E. 42nd Street, New York, N. Y.

Reed, W. P., Weights and Measures Consultant, 3770-B Skyland Drive, Chamblee, Ga.

Republic Steel Corporation: HowARD L. ZUPP, Corporation Weighing Inspector, 333 Delaware Avenue, N. E., Massillon, Ohio.

Safeway Stores, Inc:

Arnold J. Anderson, Retail Operations Manager, 1845 Fourth Street, N. E., Washington, D. C.

Eigar Balshaw, Division Manager.

Luther S. Beale, Employee Relations Manager.

Frank J. Shemhan, Manager, Public Relations, Dexter Services, 726 Jackson Place, N. W., Washington 6, D. C.

Joseph W. Upton, Price Maker, 1845 Fourth Street, N. E., Washington, D. C.

Burton R. Warner, Advertising Manager, 261 Constitution Avenue, N. W., Room 522, Washington, D. C.

Gibson I. Wright, Supply Manager, 1845 Fourth Street, N. E., Washington, D. C.

Saybolt, J. W., Business Counsellor on Weights and Measures Laws, 9209 Carlyle Arenue, Surfside, Miami Beach 41, Fla.

Scale Journal Publishing Company: JARed K. I'ICKelt, Office Manager, 176 W. Arlams Street, Chicago 3, Ill.

Shell Oil Company: Maurice L. Barrett, Senior Engineer, 50 W. 50th Street, New York 20, N. Y.

Sinclair Refining Company : Kenneth W. Brkkin, Manager, Automotive Department, 600 Fifth Arenue, New York, N. Y.

Skelly Oil Company : R. R. Wellington, Kansas City, Mo. 
Socony-Vacuum Oil Company: H. E. Searles, Motor Vehicle Supervisor, New York City Division, 1 Hanson Place, Brooklyn, N. Y.

Suburban Farm Service Company: George N. PEAcock, Operations Manager, 107 Earle Avenue, Easton, Md.

Suburban Propane Gas Corporation: William D. Cook, Assistant to President, P. O. Box 206, Whippany, N. J.

Suburban Rulane Gas Company: Јоно MacIntosh, Chief Engineer, Thrift Road, Charlotte, N. C.

Thread Institute, Inc. :

James B. DUfFY, Chairman, Legislation Committee, 11 West 42nd Street, New York 36, N. Y. (Gardiner Hall Jl. Thread Co., South Willington, Conn.)

Winliam D. SeIdler, Member, Legislation Committee, 11 West 42nd Street, New York 36, N. Y. (Coats \& Clark, Inc., 745 Fifth Ave., New York 22, N. Y.)

David SNYDER, Executive Director, 11 West 42nd Street, New York 36, N. Y. Union Oil Company of California :

HAROLD G. CoOPER, Engineer Facilities, 617 W. Seventh Street, Los Angeles, California.

Visking Corporation:

Elliot Balestier, Jr., Assistant to President, 6733 West 65th Street, Chicago 38 , Ill.

William M. Sawers, Assistant Directol, 711 Bowen Building, 815 Fifteenth Street, N. W., Washington 5, D. C.

Warren Petroleum Corporation: W. H. MILler, Tulsa, Oklahoma.

Western Weighing and Inspection Bureau: E. M. CuRL, Supervisor of Weights, Room 460 Union Station, 917 W. Adams Street, Chicago 6, Ill.

\section{OTHER GUESTS}

M. JАСоB, Director, Service de la Metrologie, Ministere des Affaires Economiques, 229 Rue de la Loi, Bruxelles, Belgium (President, Provisional International Committee on Legal Metrology).

E. Kent Lawrence, 2741 St. Paul Street, Baltimore 18, Md.

Paulo Nelson Pereira, Engineer, Instituto de Pesquisas Tecnologicas, Praca cel Fernando Prestes, 110 Caixa Postal, 7141, Sao Paulo, Brasil.

Frank L. Rogles, 6378 Lansdowne, St. Louis 1, Mo. 
